Estudo clínico randomizado e duplo-cego do Biosilicato sob restaurações de resina composta em dentes afetados por cárie 



\title{
Estudo clínico randomizado e duplo-cego do Biosilicato sob restaurações de resina composta em dentes afetados por cárie
}

\author{
Versão Corrigida
}

Tese apresentada à Faculdade de Odontologia de Ribeirão Preto da Universidade de São Paulo para a obtenção do título de Doutor em Odontologia.

Área de Concentração: Reabilitação Oral.

Orientadora: Profa. Dra. Camila Tirapelli

Ribeirão Preto 
Autorizo a reprodução e divulgação total ou parcial deste trabalho, por qualquer meio convencional ou eletrônico, para fins de estudo e pesquisa, desde que citada a fonte.

\section{FICHA CATALOGRÁFICA}

Elaborada pela Biblioteca Central do Campus USP - Ribeirão Preto

Pintado-Palomino, Karen

Estudo clínico randomizado e duplo-cego do Biosilicato sob restaurações de resina composta em dentes afetados por cárie. Ribeirão Preto, 2017.

139p. : il. ; $30 \mathrm{~cm}$

Tese de Doutorado, apresentada à Faculdade de Odontologia de Ribeirão Preto/USP. Área de concentração: Reabilitação Oral. Versão corrigida da Tese. A versão original se encontra disponível na Unidade que aloja o Programa"

Orientador: Profa. Dra. Camila Tirapelli.

1. Biovidro. 2. Dentina afetada por cárie. 3. Estudo clínico randomizado. Sistemas adesivos. 


\section{FOLHA DE APROVAÇÃO}

Pintado-Palomino, Karen. Estudo clínico randomizado e duplo-cego do Biosilicato sob restaurações de resina composta em dentes afetados por cárie.

Tese apresentada à Faculdade de Odontologia de Ribeirão Preto da Universidade de São Paulo para obtenção do título de Doutor em Odontologia. Área de concentração: Reabilitação Oral.

Aprovado em

\section{Banca Examinadora}

Prof. (a). Dr. (a).:

Instituição:

Julgamento:

Prof. (a). Dr. (a).:

Instituição:

Julgamento:

Prof. (a). Dr. (a).:

Instituição:

Julgamento:

Prof. (a). Dr. (a).:

Instituição:

Julgamento: 

Dedicatária 



\title{
Dedicatória
}

\begin{abstract}
A Deus
Companheiro fiel da minha jornada.

Obrigada por cuidar de mim, guiar meus caminhos e derramar muitas bênçãos.
\end{abstract}

Ao SENHOR dedico este trabalho e a minha vida!

\section{Aos meus pais}

Guillermo Pintado Córdova e Lucrecia Palomino Oquendo, meu melhor exemplo de vida. Vocês são minha referência de esforço, determinação, firmeza, humildade e respeito pelos outros. Obrigada pelo amor infinito, por todo suporte e apoio incondicional em todos os projetos da minha vida. Amo muito vocês!

\section{Aos meus Irmãos}

Tony e Diego, companheiros inseparáveis pela vida inteira, meus melhores amigos. Obrigada pelo grande incentivo e pelo estímulo que me deram suporte para continuar em frente. Obrigada pela proteção de sempre, pelas palavras de conforto e imenso carinho. 

Agradecimentos Especiais 



\section{Agradecimentos Especiais}

À Professora. Dra. Camila Tirapelli, minha orientadora e eterna mestre, que, com sua energia e competência, inspirou-me a seguir a carreira acadêmica. Muito obrigada pela paciência e dedicação de sempre, pela exigência e por compartilhar comigo seus conhecimentos, que abriram meus olhos ao universo da pesquisa; por acreditar e confiar em mim, pelo carinho demonstrado a mim e ao meu trabalho; pelos ensinamentos $e$ aprendizados, por ter plantado em mim a "semente" da docência e da pesquisa. Obrigada querida Profa., por toda nossa vivência, e sobre tudo, por esse sorriso e abraço apertado de sempre! Meu eterno carinho, respeito e gratidão!

À equipe desta pesquisa: Profa. Camila Tirapelli; pela coordenação, suporte constante e orientação do estudo; Pós-graduandos: Cecília Vasconcelos, Raphael Jurca e João Fortes, pelo trabalho ativo, pela competência, pela responsabilidade e pelas horas de dedicação a este estudo; Iniciação científica: Bianka Jurca e Andre Fressatti; pelo apoio, auxílio e pela disposição de sempre. A execução do nosso estudo só foi possível ao trabalho em equipe!

Aos voluntários da pesquisa, pela confiança e compromisso com o estudo. 

Agradecimentas 



\section{Agradecimentos}

À Faculdade de Odontologia de Ribeirão Preto da Universidade de São Paulo (FORP-USP), que me acolheu desde 2009 e se tornou minha casa no Brasil. Obrigada por todas as oportunidades de conhecimento.

Ao Programa de Pós-Graduação em Reabilitação Oral da FORP - USP, representada pelo coordenador Professor Dr. Ricardo Faria Ribeiro, pela valiosa formação acadêmica durante o período de Mestrado e Doutorado.

À Coordenação de Aperfeiçoamento de Pessoal de Nível Superior (CAPES), pelo suporte e Bolsa de Doutorado.

Aos Docentes do Departamento de Materiais Dentários e Prótese da FORP - USP, pelos valiosos conhecimentos compartidos, ensinamentos e contribuição na minha formação profissional e acadêmica.

Aos Professores da Disciplina da Clínica Integrada, Camila Tirapelli, Fátima Jurca, Vinicius Pedrazzi, Rubens de Albuquerque Júnior e Jose Paulo Ribas, que através do Programa PAE, tive a honra de compartilhar cada jornada clínica. Muito obrigada por ter me proporcionado além de seus conhecimentos, o verdadeiro significado de ser Professor!

Ao Prof. Dr. Wilson Matsumoto, pela grande oportunidade de aprender ao seu lado no ambiente clínico. Obrigada por compartilhar comigo sua experiência clínica. A minha admiração pelo seu trabalho!

Aos Professores Drs. Jean-Francois Roulet e Saulo Geraldeli, pela valiosa contribuição e auxílio no desenho metodológico desta pesquisa.

Ao Laboratório de Materiais Vítreos - LaMaV da Universidade Federal de São Carlos, por fornecerem o material (Biosilicato), essencial para o desenvolvimento do estudo.

Aos cirurgiões dentistas e pós-graduandos, Cecilia Vasconcelos, Raphael Jurca, João Fortes e Yan Kawabe, pelo atendimento e realização de tratamentos odontológicos especializados nos voluntários da pesquisa, fundamentais para o retorno dos mesmos. 
Aos Funcionários do Departamento de Materiais Dentários e Prótese, pela inestimável disponibilidade, amabilidade, paciência e colaboração em todo processo do curso de doutorado em Reabilitação Oral.

Aos funcionários das Clínicas da FORP-USP, Fernando, Karina, Gledson, Sr. Jose, Roberta, Verinha, Dani e Silvia, pela competência do trabalho, pelo auxílio na organização dos materiais e de prontuários dos voluntários da pesquisa e, claro, pela simpatia de sempre.

Aos meus amigos, Júlio César de Souza Matta e Jose Carlos Ferreira Junior, técnicos dos laboratórios de apoio clínico e prótese da clínica do DAPE, pelo imenso carinho, paciência e conversas tão amenas durante este período do trabalho.

A Edson Volta, técnico do Laboratório de Núcleo Integrado de Pesquisa em Biocompatibilidade de Materiais (LIPEM), muito obrigada pelo auxílio e disposição em ajudar-me.

Ao Centro de Estudos e Inovação Tecnológica (CEIT) da FORP-USP, que se tornou o meu cantinho de trabalho e onde tive a oportunidade de compartilhar meu dia a dia com excelentes pessoas. Obrigada Denise, Mari, Ceci e Bia pelo ambiente agradável e feliz de trabalho. Obrigada Raony Môlim, pela sua amizade verdadeira, pelo companheirismo e pela alegria contagiante. Com certeza, vou sentir falta de vocês!

Ao Centro de Apoio ao Professor e Estudante Estrangeiro (CAPEE) da Universidade de São Paulo (Campus de Ribeirão Preto), representado por Fernanda dos Reis Almeida, pela assistência e auxílio nas providências necessárias para o estabelecimento no Brasil.

Aos meus colegas de Doutorado, Marcela, Luciana, Maurício, Raniel, Suleima, Francisca, Eduardo e Danilo, aprendi muito com vocês. Obrigada pelas ótimas aulas e valiosas discussões que foram um grande incentivo para minha superação. Muito obrigada pela amizade e convivência agradável.

À Marcela Salles, colega e grande amiga da pós-graduação. Obrigada pela confiança, companheirismo e sutileza nas suas palavras. Foi um prazer ter trabalhado junto! 
À Dona Eva Ferreira Carvalho, minha "mãe brasileira", agradeço infinitamente a Deus por tê-la colocado na minha vida. Muito obrigada por tanto amor e bondade. Obrigada por ter me aberto a porta do seu coração e do seu lar. A Sra. é um anjo na minha vida! Meu imenso carinho e eterna gratidão!

À minha querida amiga Maria Helena Abud, pela receptividade, acolhimento e atenção durante esses anos todos. Obrigada pela preocupação, pelos sábios conselhos e principalmente pelo carinho desde o primeiro dia que nos conhecemos.

Aos meus amigos e colegas de apartamento, Guido, Silvia, Jennifer e Stephie, pelo convívio saudável, pelo apoio em dias difíceis e por poder compartilhar com vocês a saudade de estar longe de casa. Obrigada pela companhia tão agradável e pelo carinho demostrado no dia a dia.

Aos meus amigos peruanos que encontrei em Ribeirão Preto, Gaby, Milli, Diego, Kelly, Juan e em especial a Karlita Carpio, pela ajuda imensurável com teus compatriotas, por sua firmeza e pelo estímulo constante de ser um melhor cidadão. A todos vocês, obrigada pela amizade e carinho de sempre!

A minha grande amiga Carlita Alandia, a irmãzinha que ganhei no Brasil. Obrigada por todas as experiências vividas, pela cumplicidade, pelo apoio incondicional e pela nossa valiosa amizade. Você é um belo exemplo de superação, esforço e nobreza. Obrigada Carlita, porque sei que sempre posso contar com você!

A toda minha familia e amigos que deixei no Peru. Obrigada por sempre torcer por mim, pelas vibrações nas minhas conquistas e palavras de incentivo nas minhas frustações. Vocês são minha maior força e motivação!

Ao Brasil, por me acolher e ter me mostrado a hospitalidade, gentileza, generosidade e a alegria do povo brasileiro. Obrigada Brasil por brindar a oportunidade, a estrangeiros como eu, de realizar os sonhos. Que Deus abençoe esta terra maravilhosa!

A todos que direta ou indiretamente contribuíram para a realização deste trabalho. 

"Não fui eu que ordenei a você? Seja forte e corajoso! Não se apavore nem desanime, pois, o Senhor, o seu Deus, estará com você por onde você andar".

Josué 1:9 

Resuma 

Pintado-Palomino, K. Estudo clínico randomizado e duplo-cego do Biosilicato sob restaurações de resina composta em dentes afetados por cárie [tese]. Ribeirão Preto: Universidade de São Paulo, Faculdade de Odontologia de Ribeirão Preto; 2017.

\section{RESUMO}

O presente estudo teve por objetivo avaliar o efeito de um biomaterial vitrocerâmico $\left(\right.$ Biosilicato ${ }^{\circledR}$ ) no desempenho clínico de restaurações posteriores em resina composta. 92 cavidades Classe I e Classe II com lesão de cárie (no terço meio da dentina) foram selecionadas e distribuídas aleatoriamente em quatro grupos segundo o protocolo adesivo: 1Biosilicato / sistema adesivo convencional de dois passos, 2- Controle / sistema adesivo convencional de dois passos, 3- Biosilicato / sistema adesivo autocondicionante de dois passos e 4- Controle / sistema adesivo autocondicionante de dois passos. Dois operadores realizaram os protocolos adesivos e restauraram as cavidades com uma resina composta nanohíbrida (IPS Empress, Ivoclar) usando a técnica incremental. Os participantes foram remarcados após uma semana, 6, 12 e 18 meses para avaliação clínica realizada por dois examinadores, cegados e calibrados de acordo com os critérios FDI. Os dados foram analisados com o teste não paramétrico de Kruskal-Wallis e o teste de Dunn de comparação múltipla, com nível de significância de 5\%. Os resultados revelaram que não houve diferença estatisticamente significante $(p>0.05)$ entre os grupos experimentais e os respectivos controles em nenhuma avaliação, entretanto, houve diferença estatisticamente significativa ( $\mathrm{p}$ $<0.05)$ entre os grupos controles $(2 \mathrm{x} 4)$ para o critério forma anatômica ( 1 semana) e adaptação marginal (18 meses). $\mathrm{O}$ grupo 2 foi estatisticamente diferente do grupo 3 ( $\mathrm{p}<$ 0.05), para o critério fratura do material/retenção (18 meses) e adaptação marginal (1 semana), onde o grupo 2 apresentou melhor desempenho. $\mathrm{O}$ uso do Biosilicato no protocolo restaurador de dentina afetada por cárie não alterou o desempenho clinico de restaurações em resina composta no período de 18 meses de acompanhamento. A associação entre o sistema adesivo autocondicionante de dois passos e o Biosilicato gerou desempenho clínico inferior, comparado ao sistema adesivo convencional (controle), em termos de adaptação marginal e fratura do material/retenção.

Palavras-chave: Dentina afetada por cárie. Vidros bioativos. Estudo clínico randomizado. Sistemas adesivos. 

Alstract 

Pintado-Palomino, K. Double-blind, randomized clinical trial of Biosilicate under resin composite restorations in caries affected teeth [thesis]. Ribeirão Preto: University of São Paulo, Ribeirão Preto School of Dentistry; 2017.

\begin{abstract}
The aim of this study was to evaluate the effect of a bioactive glass-ceramic (Biosilicate ${ }^{\circledR}$ ) on clinical performance of posterior resin composite restorations. A total of 92 restorations in Class I and Class II cavities with carious lesion (medium third of dentin) were selected and assigned randomly into four groups according to the adhesive protocol used: 1- Biosilicate / Two-step etch and rinse system, 2- Control / Two-step etch and rinse system, 3- Biosilicate / Two-step self-etching system and 4- Control / Two-step self-etching system). Two operators carried out the adhesive protocols and restored the cavities with a nano-hybrid resin composite (IPS Empress, Ivoclar) using the incremental technique. Participants were recalled at one week, 6, 12 and 18 months for clinical evaluation performed by two blinded examiners and calibrated according to FDI criteria. Data were analyzed using Krusall-Wallis nonparametric test and multiple comparison Dunn test with a significance level of 5\%. Results showed no statistical difference $(\mathrm{p}>0.05)$ between the experimental groups and their respective controls; however, there were statistical difference between control groups $(2 \times 4)$ $(\mathrm{p}<0.05)$ for anatomical form (1 week) and marginal adaptation (18 months). Group 2 was statistically different from Group 3 ( $\mathrm{p}<0.05)$, for fracture of material/retention (18 months) and marginal adaptation category (1 week), where Group 2 showed the better performance. The use of Biosilicate, in a restorative protocol for caries-affected dentin, did not alter the clinical performance of posterior resin composite restorations. The association between Biosilicate and two-step self-etching adhesive system showed an inferior clinical performance, compared to the conventional adhesive system (control), in terms of marginal adaptation and fracture of material/retention.
\end{abstract}

Key-words: Caries-affected dentin. Bioactive glasses. Randomized clinical trial. Adhesive systems. 

Lista de Figuras 



\section{LISTA DE FIGURAS}

Figura 1 - Produtos utilizados no estudo: a. Biosilicato ${ }^{\circledR}$ em pó, b. Adesivo convencional (primer e bond em frasco único), c. Adesivo autocondicionante (primer e bond em frascos separados) e d. Resina composta................................................ 62

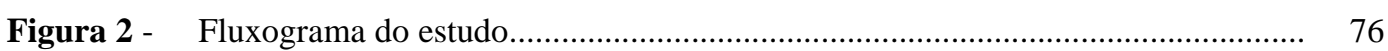

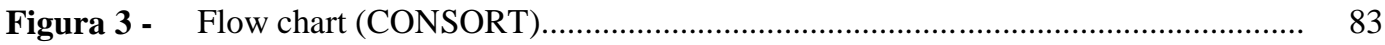

Figura 4 - Avaliação clínica das restaurações após 01 semana, 06, 12 e 18 meses. Restaurações clinicamente aceitáveis (escore 1, 2 ou 3) para as propriedades estéticas (Brilho superficial manchamento marginal, estabilidade de cor e forma anatômica), funcionais (Fratura do material e retenção, adaptação marginal, contorno oclusal e desgaste) e biológicas (Recorrência de cárie e integridade dental)

Figura 5 Critérios FDI (Forma Anatômica, Fratura de Material e Retenção e Adaptação Marginal) que mostraram desempenho clínico diferente durante os períodos de avaliação. * indica diferença estatisticamente significante $(\mathrm{p}<0,05)$. 

Lista de Tabelas 



\section{LISTA DE TABELAS}

Tabela 1- Materiais usados no estudo.......................................................................

Tabela 2- Grupos do estudo e protocolos de tratamento.................................................... 69

Tabela 3- $\quad$ Métodos de avaliação das restaurações para cada categoria................................... 71

Tabela 4- Distribuição de sexo e idade dos participantes que receberam tratamento de

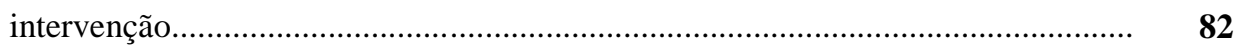

Tabela 5- Distribuição das restaurações que receberam tratamento de intervenção de acordo como o dente e a classe ....................................................................... 82

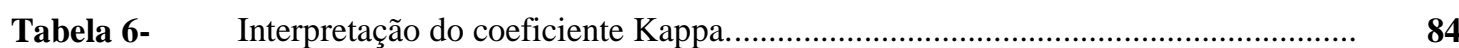

Tabela 7- Coeficiente de Kappa geral para concordância entre os avaliadores para dados agregados $(1,2$ e 3$)$ aceitável e (4 e 5) inaceitável................................................ $\quad 85$

Tabela 8- $\quad$ Estatística descritiva para as propriedades estéticas. Frequência absoluta para cada propriedade e tempo de avaliação.

Tabela 9- $\quad$ Estatística descritiva para as propriedades funcionais. Frequência absoluta para cada propriedade e tempo de avaliação.

Tabela 10- Estatística descritiva para as propriedades biológicas. Frequência absoluta para cada propriedade e tempo de avaliação.

Tabela 11- Restaurações clinicamente inaceitáveis (escore 4 ou 5) de acordo com os critérios FDI

Tabela 12- $\quad$ Teste de Kruskal-Wallis para comparação entre os grupos em cada variável e tempo de avaliação

Tabela 13- Comparações múltiplas (Teste de Dunn) entre grupos para os casos cujos p-valor do teste de Kruskal-Wallis foi significativo. 

Lista de Zuadras 



\section{LISTA DE QUADROS}

Quadro 1 - Critérios de avaliação da FDI 

Sumária 



\section{SUMÁRIO}

1. INTRODUÇÃ

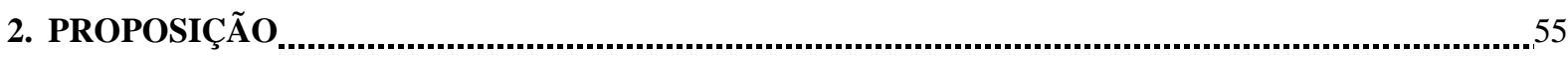

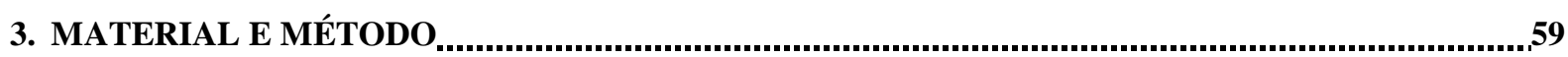

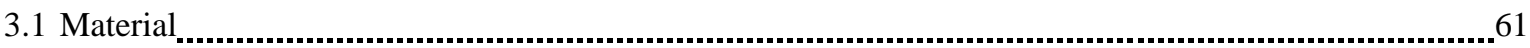

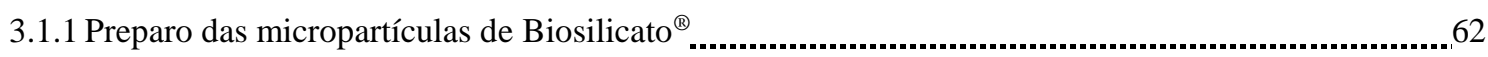

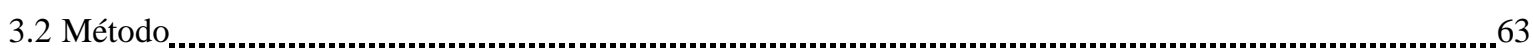

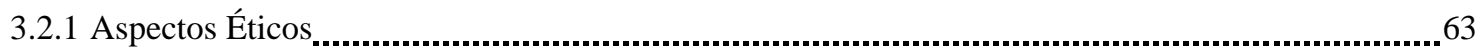

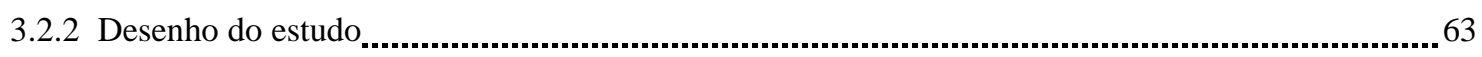

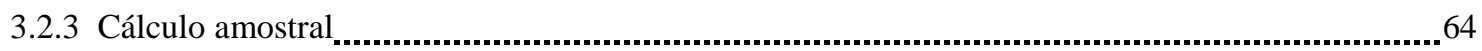

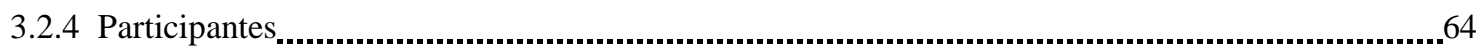

3.2.5 Calibração dos operadores e examinadores.........................................................................6

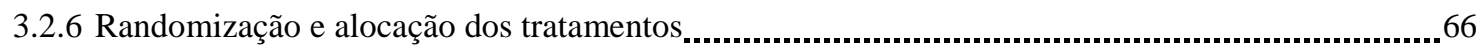

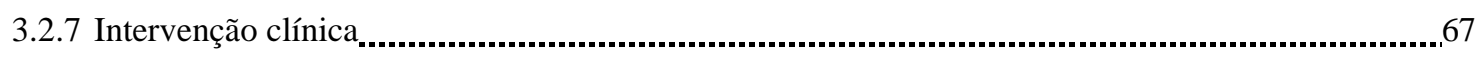

3.2.7.1 Remoção da cárie e preparo das cavidades ..............................................................67

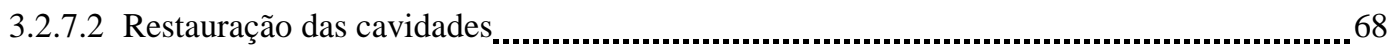

3.2.8 Avaliação das restaurações .................................................................................... 70

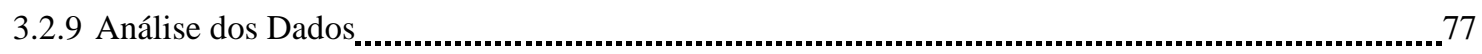

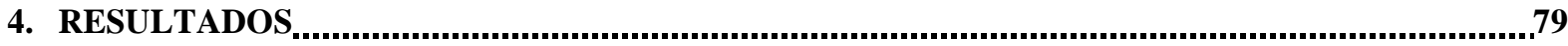

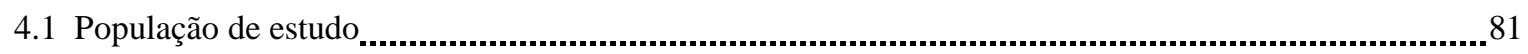

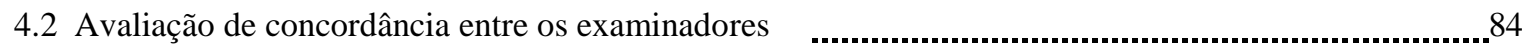

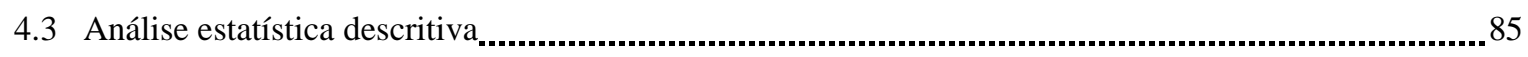

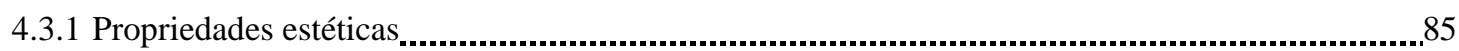

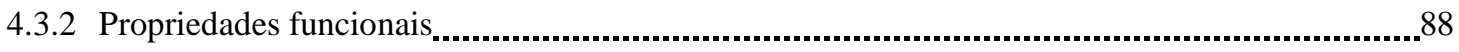

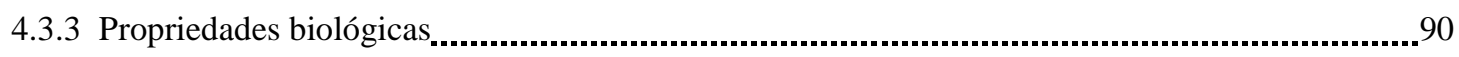

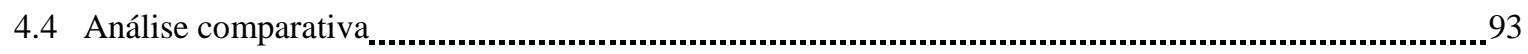

4.4.1 Comparação dos grupos em cada tempo de avaliação.........................................................93

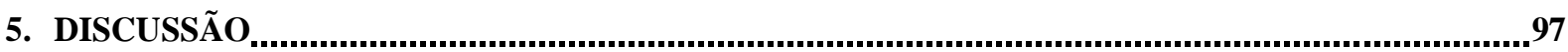

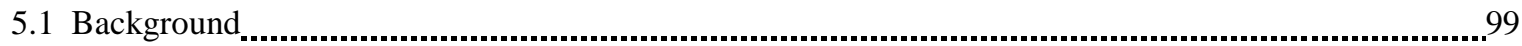

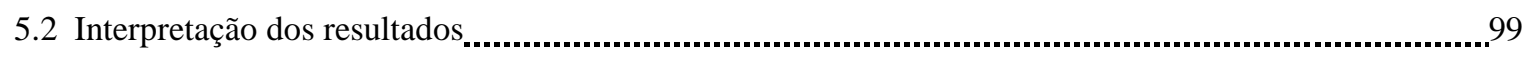

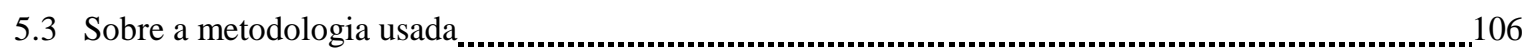

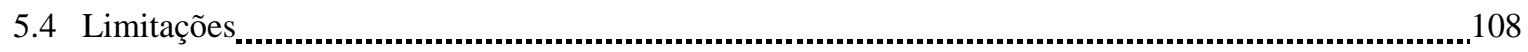

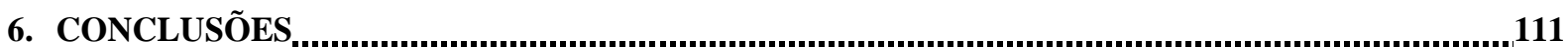

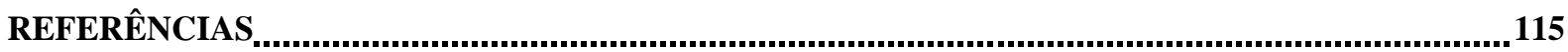

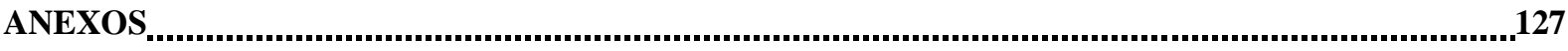

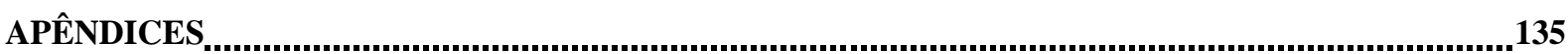



1. Intraduçãa 



\section{INTRODUÇÃO}

A cárie dental é considerada o processo patológico mais comum que altera o substrato da dentina e resulta na necessidade de um tratamento restaurador (1-3). Embora tenha diminuído nos últimos anos, ainda é o principal problema de saúde oral em países desenvolvidos e subdesenvolvidos $(4,5)$.

Neste contexto, atualmente, a resina composta representa a abordagem mais aceita para restaurar lesões cariosas e é considerada como o material de primeira escolha para restaurações diretas em dentes posteriores (6, 7). Segundo Heintz e Rousson (2012) (8), mais de 550 milhões de restaurações diretas são realizadas por ano ao redor do mundo, sendo que cerca de $55 \%$ dos casos correspondem a restaurações em resina composta. No Brasil, as restaurações posteriores em resina composta devido a cárie constituem também a maior parte dos tratamentos realizados na prática clínica diária (9). A sua taxa de sobrevida é satisfatória, uma vez que revisões sistemáticas envolvendo restaurações posteriores em resina composta têm concluído que a taxa anual de falha varia entre $1 \%$ e $3 \%(8,10,11)$.

Apesar do alto índice de sucesso relatado em restaurações classe I e classe II, observase que ainda existem falhas, sendo a cárie secundária (cárie adjacente à restauração) a principal causa $(6,8,10)$. De fato, estudos baseados na prática clínica odontológica, têm reportado que mais do $40 \%$ das restaurações de resina composta em dentes permanentes são substituídas por cárie secundária $(12,13)$. Além da cárie secundária, a fratura do material é motivo de insucesso a curto prazo $(6,10,11,14)$. Ainda outros problemas, dentre as causas de falha, têm sido reportados na literatura, tais como perda de retenção do material, sensibilidade pós-operatória, defeitos na adaptação marginal e descoloração marginal $(15,16)$. O tratamento de restaurações com falha constitui até o $60 \%$ de todos os tratamentos realizados na prática clínica $(17,18)$. Dessa forma, a necessidade de um reparo e/ou substituição da restauração pode gerar um gasto econômico para o paciente ou para o setor de saúde pública (19).

Um dos principais fatores que pode levar a estas deficiências clínicas está associado à ruptura da interface adesiva dentina/resina, decorrente de uma deficiente adesão (20-22). A ruptura desta interface adesiva tem sido atribuída à falha dos adesivos atuais em selar e aderir adequadamente à dentina. Isto ocorre porque a dentina, diferente do esmalte, é um substrato de difícil adesão devido a seu alto conteúdo orgânico (30-50\% em volume e 18\% em peso) e umidade (20\% de água) (23). Durante o processo de cárie, a superfície da dentina é alterada dificultando mais ainda o processo de adesão. 
De acordo com os estudos pioneiros realizados por Fusayama et al. (1972) (24), a dentina cariada consiste em duas camadas: 1) uma camada externa, altamente infectada, com conteúdo necrótico e presença de bactérias (predominantemente proteolíticas), altamente desmineralizada apresentando fibras de colágeno desnaturadas de forma irreversível e não remineralizável e 2) uma camada interna ou dentina afetada, menos contaminada, parcialmente desmineralizada e potencialmente remineralizável.

No conceito atual de odontologia restauradora minimamente invasiva (25), preconizase a remoção seletiva da cárie, na tentativa de conservar a estrutura dental. Com esta abordagem, apenas a dentina infectada é removida e a dentina afetada é preservada para possível remineralização. Consequentemente, durante o preparo da cavidade para uma restauração adesiva após remoção de dentina infectada, grandes áreas das cavidades consistem em dentina afetada e não dentina hígida (1), o que torna este substrato de muita relevância clínica.

Devido aos ciclos de desmineralização e remineralização que resultam do processo da cárie, a dentina afetada é qualitativamente diferente da dentina normal (livre de cárie) (26) em vários aspectos incluindo os morfológicos, físicos, químicos e mecânicos. O progresso da cárie reduz o conteúdo mineral, a cristalinidade da hidroxiapatita (26-29) e proteoglicanos (30) e causa alterações na estrutura secundária do colágeno (26). A dentina afetada contém maior conteúdo de água (14-53\%) devido à substituição do mineral perdido por água (31). Em relação às propriedades mecânicas, estudos laboratoriais têm reportado valores inferiores de microdureza $(3,32-34)$ sendo aproximadamente a metade em relação aos da dentina normal (35). Marshall et al. (2001) (36) reportaram que o módulo de elasticidade (18,2 GPa) e a nanodureza $(0,8 \mathrm{GPa})$ da dentina intertubular é significantemente inferior à dentina intertubular não afetada (20,6 e 1,0 GPa, respectivamente).

Além disso, o smear layer formado na dentina afetada por cárie é diferente na sua morfologia e estrutura química, uma vez que tal substrato se encontra parcialmente desmineralizado. Em condições normais, tanto o smear layer quanto o smear plug (no interior dos túbulos dentinários) são basicamente formados por hidroxiapatita e partículas de detritos de colágeno desnaturado. Já na dentina afetada, esta camada é mais rica em componentes orgânicos e mais espessa que na dentina hígida (37). Ainda, as fibras de colágeno encontramse altamente desorganizadas e o mineral preso na matriz orgânica, podendo dificultar sua remoção por meio de condicionamento ácido e interferir no processo de adesão (38).

Como resultado das alterações químicas, morfológicas e mecânicas, a dentina afetada por cárie responde de maneira diferente ao processo de adesão. Aparentemente, a infiltração 
dos monômeros resinosos é dificultada pela presença de alguns minerais (ex. whitlockita) ao longo dos túbulos dentinários $(26,28,39)$. Além disso, existem evidências que os adesivos são pobremente polimerizados na interface adesiva $(26,28)$. A camada híbrida produzida pelos sistemas adesivos tende a ser mais espessa, porém apresenta uma qualidade inferior (1, 2). Em consequência, a resistência adesiva é afetada neste substrato, tornando-se inferior em 20-50\% (23). Recentemente, duas revisões sistemáticas (2, 40) abordando estudos laboratoriais concluíram que a resistência de união é menor na dentina afetada independente do sistema adesivo usado (adesivo convencional ou adesivo autocondicionante).

Todos os fatores acima mencionados podem favorecer a instabilidade da interface adesiva e mecanismos de degradação hidrolítica da camada híbrida produzida pelos sistemas adesivos (41). Nesta situação, a durabilidade da adesão e o desempenho das restaurações podem ser comprometidos. A este respeito, estudos clínicos reportam uma pobre adaptação marginal, descoloração marginal e perda de retenção da restauração ao longo do tempo, quando a interface adesiva é exposta na cavidade oral (42).

Perante esta situação, na prática clínica, a remineralização da dentina afetada desmineralizada é importante na recuperação da funcionalidade dos tecidos afetados, melhorando a estabilidade adesiva e a durabilidade dos materiais resinosos (43-45). De acordo com Tem Cate et al. (2001) (46), um substrato mais mineralizado ("mais duro") não só se torna mais resistente às forças mecânicas presentes no meio oral, mas também dificulta a acumulação bacteriana prevenindo a presença de cárie primária e secundária.

Sendo assim, com o intuito de superar a limitada durabilidade da interface dentinaresina produzida pelos sistemas adesivos contemporâneos e as deficiências clínicas decorrentes dela, estratégias envolvendo remineralização da dentina tornam-se uma opção terapêutica para este fim. Materiais a base de ionômero de vidro capazes de liberar íons flúor têm sido comumente usados com este propósito, porém estes não são capazes de restaurar as propriedades mecânicas da dentina. Nesse sentido, o uso de sistemas adesivos contendo componentes bioativos capazes de liberar alguns íons (ex. $\mathrm{Ca}^{2+}$ e $\mathrm{CaPO}_{4}{ }^{3-}$ ) e técnicas adesivas baseadas em pré-tratamento superficial da dentina com vidros bioativos parecem ser as abordagens terapêuticas remineralizadoras mais promissoras neste setor (47).

Sauro et al. (2012) (48) estudaram os efeitos terapêuticos de adesivos experimentais contendo vidro bioativo (Bioglass 45S5) na interface resina-dentina. Usando microscopia confocal, os autores mostraram o conteúdo mineral em diferentes regiões da dentina (camada adesiva, a camada híbrida e dentina intertubular). Os resultados indicaram que houve formação mineral após 3 meses e aumento no módulo de elasticidade da camada híbrida, 
reduzindo assim a nanoinfiltração. De forma similar Profeta et al. (2012) (49), avaliaram o efeito de adesivos contendo vidro bioativo na interface adesiva em procedimentos adesivos convencionais (condicionamento ácido prévio). Observou-se a presença de minerais dentro dos túbulos e na camada híbrida. Os autores evidenciaram redução da nanoinfiltração após seis meses de armazenamento em solução tampão sem redução da resistência de união.

Ainda, outros estudos laboratoriais $(50,51)$ têm sustentado que os vidros bioativos usados como pré-tatamento da superfície dentinária podem produzir um smear layer bioativo com propriedades terapêuticas na interface adesiva favorecendo a sua integridade e aumento de resistência de união quando usada com sistemas autocondicionantes ou ionômero de vidro modificado por resina.

Aparentemente, o uso de vidros bioativos parece ser uma estratégia promissora para aumentar a durabilidade das restaurações adesivas, uma vez que os estudos in vitro mencionados mostram sua eficácia e principalmente porque há evidência de que sua aplicação resulta na formação de cristais de apatita na dentina, que é um aspecto importante para a remineralização (52). Contudo, ainda não há evidência clínica de que estas abordagens melhorem o desempenho das restaurações.

De forma geral, os vidros bioativos têm sido amplamente usados em diversos campos da área da saúde devido à sua habilidade de interagir ativamente com os tecidos, induzindo a deposição de hidroxicarbonoapatita (HCA) em presença de fluidos corporais ou saliva (53). O vidro bioativo mais conhecido é o Bioglass ${ }^{\circledR} 45 \mathrm{~S} 5$, vidro do sistema quaternário, desenvolvido por Larry Hench na década de 1960, que tem uma composição de 24,5Na2 $\mathrm{O}-24.5 \mathrm{CaO}$ $45 \mathrm{SiO}_{2}-6 \mathrm{P}_{2} \mathrm{O}_{5}$ (\% em peso) (54). Os vidros bioativos em ambiente aquoso iniciam rapidamente uma reação superficial para formar a camada de HCA.

Hench organizou as reações dos vidros bioativos com os fluidos em 5 estágios principais (55). No estágio I, ocorre uma lixiviação de cátions $\mathrm{Na}^{+}$e substituição dos mesmos na estrutura dos vidros por cátions $\mathrm{H}^{+}$ou $\mathrm{H}_{3} \mathrm{O}^{+}$. Isto causa um aumento do $\mathrm{pH}$ provocando a ruptura das ligações Si-O-Si e o silício é liberado no fluido, na forma de silanol ( $\left.\mathrm{Si}(\mathrm{OH})_{4}\right)$ (estágio II). Se o pH local for menor de 9,5, o grupo silanol é condensado formando uma camada porosa rica em sílica na superfície do vidro (estágio III). A estrutura aberta da sílica gel permite que a troca iônica entre o vidro e o fluído continue ocorrendo; desta maneira, os íons cálcio e fósforo se difundem por essa camada e, somados aos íons cálcio e aos fosfatos presentes na solução, formam a camada amorfa de fosfato de cálcio na superfície do vidro (estágio IV). Há cristalização de uma camada de HCA pela incorporação de ânions $\mathrm{OH}^{-}$e $\mathrm{CO}_{3}{ }^{2-}$ da solução (estágio $\mathrm{V}$ ). 
A busca de novos materiais bioativos que conservassem o elevado índice de bioatividade apresentado pelos vidros bioativos e, ao mesmo tempo, apresentassem propriedades mecânicas superiores levou a um grupo de pesquisadores brasileiros ao desenvolvimento e patente (WO 2004074199 A1) de uma nova vitrocerâmica denominada Biosilicato (56).

O Biosilicato é a designação de uma composição particular de $23,75 \mathrm{Na}_{2} \mathrm{O}-23,75 \mathrm{CaO}$ $48,5 \mathrm{SiO}_{2}-4 \mathrm{P}_{2} \mathrm{O}_{5}$ (\% em peso) com um alto grau de cristalinidade $(\sim 99,5 \%)$ e elevados índices de bioatividade $\left(\mathrm{I}_{\mathrm{B}}>8\right)$. Devido à sua elevada bioatividade $(57,58)$ e propriedades mecânicas, o Biosilicato é comparável com outros vidros bioativos, tais como o gold-standar Bioglass 45S5 $(59,60)$. Os diversos estudos in vitro e in vivo têm demonstrado seu potencial na regeneração óssea $(58,61,62)$ e suas propriedades não citotóxicas (63) e antibacterianas (64). Em consequência, o referido material tem muitas possibilidades de uso na área da saúde, sendo uma opção na regeneração de tecidos (60).

Além da elevada bioatividade, a característica cristalina e partículas com menor potencial de corte do material desenvolvido permitiram vislumbrar seu uso no tratamento da hipersensibilidade dentinária. O estudo in vitro conduzido por Tirapelli et al. (2010) (65),

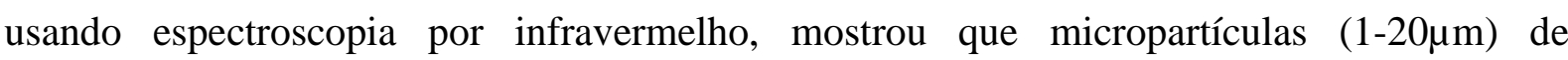
Biosilicato podem levar a deposição de HCA sobre a superfície da dentina, após 30 minutos de reação - evidenciando o bom potencial para oclusão dos túbulos dentinários e remineralização da superfície dental. Os resultados do referido estudo in vitro, levaram a execução de um estudo clínico, com duas formulações experimentais de agentes

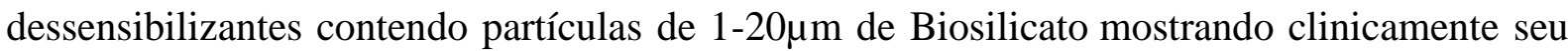
potencial para o tratamento da hipersensibilidade dentinária em casos de dentina exposta (66).

Em decorrência de seu efeito dessensibilizante demonstrado previamente, estudos posteriores foram realizados para avaliar o efeito remineralizador do Biosilicato. Tais estudos verificaram que o uso de micropartículas de Biosilicato pode favorecer a remineralização dos tecidos dentários desmineralizados, proporcionando um aumento de minerais (cálcio e fosforo) e beneficiando a microdureza dos tecidos (67-69).

Devido à sua versatilidade, o Biosilicato vem sendo pesquisado no campo da odontologia restauradora nos últimos anos. Os testes laboratoriais têm indicado um aumento da resistência de união quando as micropartículas de vitrocerâmica são incorporadas a materiais restauradores a base de resina (70) ou quando aplicadas como tratamento de superfície (71) sem interferir na morfologia da interface adesiva (72). Mais recentemente, Morais et al. (2016) (73) avaliaram in vitro a resistência de união da interface adesiva da 
dentina, tratada previamente com Biosilicato (micropartículas de $4 \mu \mathrm{m}$ em suspensão 10\%) produzida por dois sistemas adesivos. Os resultados mostraram que sua aplicação influenciou positivamente na resistência de união dos sistemas adesivos convencionais. Quando usado após acondicionamento ácido, apresentou os maiores valores de resistência de união e a maior quantidade de íons $\mathrm{Ca}$ e $\mathrm{P}$ quando comparado ao grupo controle. Nos sistemas autocondicionantes, a aplicação do Biosilicato não interferiu na adesão à dentina.

Apesar dos resultados in vitro citados sugerirem um potencial benéfico nos procedimentos restauradores adesivos, ainda não há informações sobre estudos clínicos prospectivos corroborando sua efetividade sobre a dentina afetada por cárie em restaurações com resina composta. Assim, a proposta de nosso estudo foi avaliar o efeito do Biosilicato no desempenho clínico de restaurações posteriores em resina composta como tratamento de superfície da dentina afetada por cárie. A hipótese nula $\left(\mathrm{H}_{0}\right)$ testada neste estudo foi que não há diferença no desempenho clínico das restaurações em resina composta, independente do uso do vidro bioativo. 
2. Propasicãa 



\section{PROPOSIÇÃO}

\section{Objetivo geral}

O objetivo de estudo foi avaliar o desempenho clínico do Biosilicato em dentina afetada por cárie, sob restaurações posteriores de resina composta.

\section{Objetivos específicos}

1. Comparar o desempenho clínico dos protocolos restauradores usando Biosilicato associados a dois sistemas adesivos diferentes (grupos experimentais)

2. Observar o desempenho clínico de dois sistemas adesivos no protocolo restaurador de dentina afetada por cárie (grupos controles)

3. Identificar dentre os protocolos, para cada aspecto de desempenho clínico analisado durante 18 meses, a melhor indicação para restauração de dentina cariada. 

3. Material e Método 



\section{MATERIAL E MÉTODO}

\subsection{Material}

Os materiais utilizados no estudo estão descritos na Tabela 1 e ilustrados na Figura 1.

Tabela 1- Materiais usados no estudo.

\begin{tabular}{|c|c|c|c|c|}
\hline Categoria & Material & Composição & Lote & Fabricante \\
\hline $\begin{array}{l}\text { Vitro-cerâmica } \\
\text { bioativa }\end{array}$ & Biosilicato $^{\circledR}$ & $\begin{array}{l}\text { Sistema quaternário } \mathrm{P}_{2} \mathrm{O}_{5}-\mathrm{Na}_{2} \mathrm{O}-\mathrm{CaO}- \\
\mathrm{SiO}_{2} \\
(1 \text { a } 20 \mu \mathrm{m}), 100 \% \text { cristalino }(\mathrm{PI} \\
0300644-1) .\end{array}$ & --------- & $\begin{array}{l}\text { Vitrovita, } \\
\text { São Carlos, } \\
\text { SP, Brasil }\end{array}$ \\
\hline $\begin{array}{l}\text { Adesivo } \\
\text { convencional de } \\
\text { dois passos }\end{array}$ & $\begin{array}{l}\text { Adper }{ }^{\mathrm{TM}} \text { Single } \\
\text { Bond } 2\end{array}$ & $\begin{array}{l}\text { BisGMA, 2-HEMA, dimetacrilatos, } \\
\text { etanol, água, fotoiniciador, copolímero } \\
\text { funcional de metacrilato de ácido } \\
\text { poliacrílico e ácido polialcenóico. }\end{array}$ & $\mathrm{N} 474513$ & $\begin{array}{l}\text { 3M ESPE, } \\
\text { Sumaré, SP, } \\
\text { Brasil }\end{array}$ \\
\hline $\begin{array}{l}\text { Adesivo } \\
\text { autocondicionante } \\
\text { de dois passos }\end{array}$ & AdheSE $^{\circledR}$ & $\begin{array}{l}\text { Primer: dimetacrilato, acrilato de ácido } \\
\text { fosfônico, iniciadores e estabilizadores em } \\
\text { solução aquosa. }\end{array}$ & $\begin{array}{l}\text { S02201 } \\
\text { S07242 }\end{array}$ & $\begin{array}{c}\text { Ivoclar } \\
\text { Vivadent, } \\
\text { Barueri, SP, } \\
\text { Brasil }\end{array}$ \\
\hline & & $\begin{array}{l}\text { Bond: HEMA, dimetacrilato, dióxido de } \\
\text { silício, iniciadores e estabilizadores. }\end{array}$ & & \\
\hline Resina Composta & $\begin{array}{l}\text { IPS Empress }{ }^{\circledR} \\
\text { Direct }\end{array}$ & $\begin{array}{l}\text { Resina nano-híbrida: } \\
\text { Matriz monomérica: dimetacrilato (20- } \\
21,5 \% \text { em peso). Partículas: bário, } \\
\text { trifluoreto de itérbio, dióxido de silício, } \\
\text { copolímeros (77,5-79\% em peso). } \\
\text { Aditivos, catalisadores, estabilizadores e } \\
\text { pigmentos. } \\
\text { O conteúdo total de partículas inorgânicas } \\
\text { é de } 75-79 \% \text { em peso ou } 52-59 \% \text { em } \\
\text { volume. Tamanho médio das partículas de } \\
550 \mathrm{~nm} \text {. }\end{array}$ & $\begin{array}{c}\text { Resina } \\
\text { de } \\
\text { esmalte: } \\
\text { T23755 } \\
\text { Resina } \\
\text { de } \\
\text { dentina: } \\
\text { T07389 }\end{array}$ & $\begin{array}{c}\text { Ivoclar } \\
\text { Vivadent, } \\
\text { Barueri, SP, } \\
\text { Brasil }\end{array}$ \\
\hline
\end{tabular}


Figura 1 - Produtos utilizados no estudo: a. Biosilicato ${ }^{\circledR}$ em pó, b. Adesivo convencional (primer e bond em frasco único), c. Adesivo autocondicionante (primer e bond em frascos separados) e d. Resina composta.
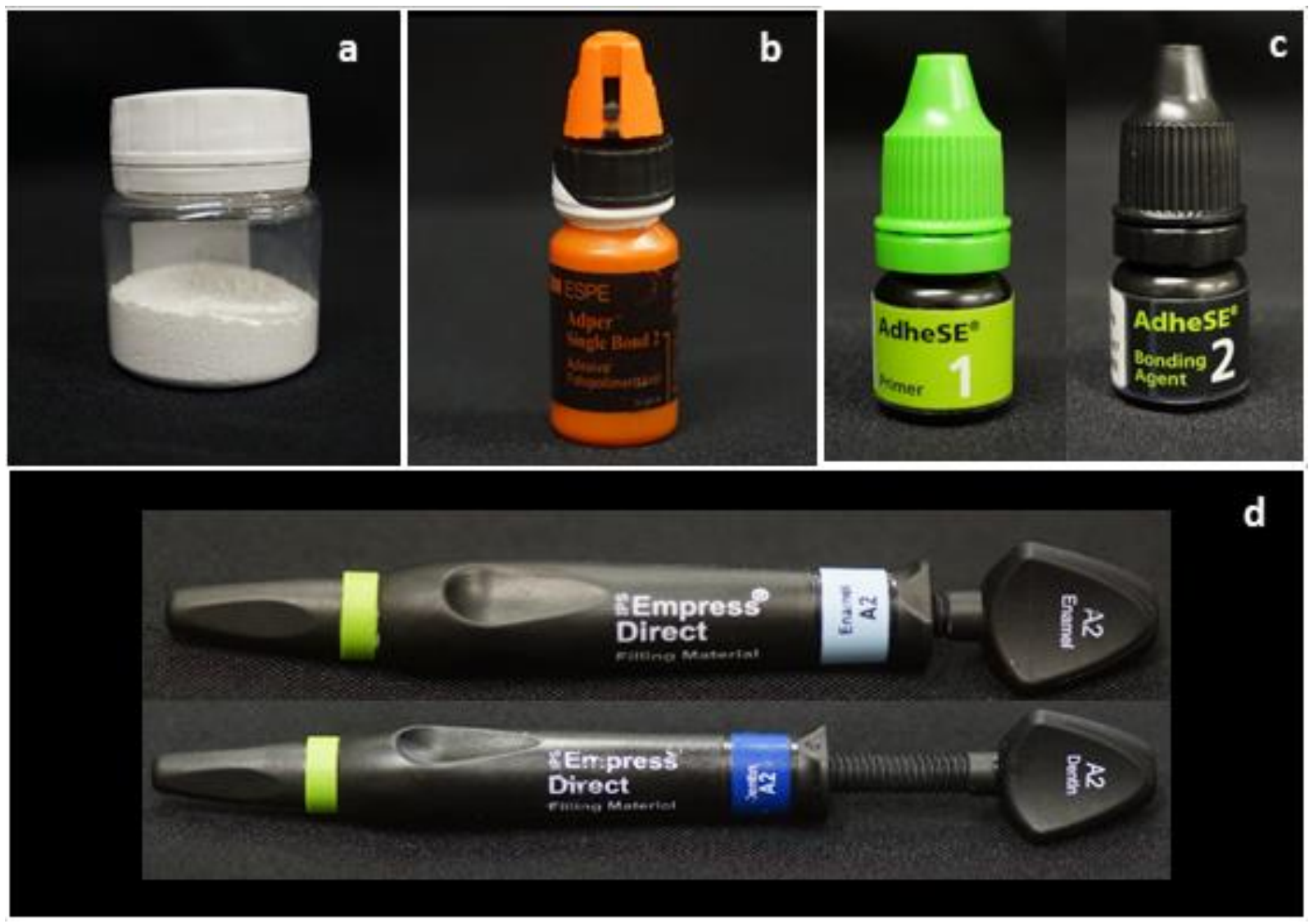

\subsubsection{Preparo das micropartículas de Biosilicato ${ }^{\circledR}$}

A produção das micropartículas bioativas foi realizada pelo Instituto de Inovação em Vitro-cerâmicas (Vitrovita, São Carlos, SP, Brasil) de acordo com o processo de preparação descrito no depósito de patente (56).

Este processo envolveu:

a) Pesagem das matérias-primas em balança analítica de alta precisão.

b) Mistura e homogeneização das matérias-primas em um misturador planetário.

c) Fusão da mistura em um cadinho de platina em forno elétrico.

d) Obtenção de placas vítreas a partir do material fundido.

e) Tratamentos térmicos das placas vítreas em uma mufla para promoção da cristalização e obtenção de um material isento de fase vítrea.

f) Moagem do material cristalino em um moinho planetário utilizando-se jarro e meios de moagem de ágata.

g) Separação do material particulado obtido. 
Para isto foram utilizadas matérias-primas de elevada pureza (pureza analítica), livre de metais pesados e substâncias tóxicas. A produção foi realizada em ambiente limpo, utilizando equipamentos previamente limpos e assépticos. Após a produção o biomaterial foi esterilizado em calor seco a temperatura de $350{ }^{\circ} \mathrm{C}$ por 1 hora e embalado em embalagens assépticas.

\subsection{Método}

\subsubsection{Aspectos Éticos}

O presente estudo foi revisado e aprovado pelo Comitê de Ética em Pesquisa Clínica da Faculdade de Odontologia de Ribeirão Preto, Universidade de São Paulo (Protocolo CAAE: 27790214.1.0000.5419) (Anexo A). O presente estudo foi registrado no United States National Institutes of Health com número de protocolo NCT02389569¹ (Anexo B).

\subsubsection{Desenho do estudo}

O delineamento experimental foi realizado de acordo com as normas para estudos clínicos randomizados (CONSORT) (74). Assim, o presente trabalho é um estudo clínico prospectivo, randomizado, com grupo controle e duplo-cego que avaliou o desempenho clínico do Biosilicato usado com dois tipos de sistemas adesivos em restaurações classe I e classe II de dentes permanentes posteriores afetados por cárie. O cegamento foi realizado tanto paro os participantes do estudo quanto para os examinadores. Os operadores conheciam a alocação dos tratamentos devido aos diferentes protocolos clínicos realizados. A unidade de observação foi a restauração.

Neste estudo, considerou-se como variável dependente: 1) o desempenho clínico do Biosilicato (variável qualitativa categórica ordinal) determinado pelos critérios estabelecidos da Fédération Dentaire Internationale (FDI) e como variáveis independentes ou fatores de variação: 1) o sistema adesivo (sistema adesivo convencional de dois passos e sistema adesivo autocondicionante de passo único), 2) o tratamento da dentina afetada por cárie (tratamento experimental com Biosilicato e tratamento controle sem Biosilicato) e, 3) o fator vinculado tempo (1 semana, 6, 12 e 18 meses). Considerando os fatores de variação, o modelo de fatorial do estudo foi 2 × 2 , com quatro grupos.

\footnotetext{
${ }^{1} \mathrm{O}$ presente estudo encontra-se registrado no site www.clinicaltrials.gov como "Clinical study of Biosilicate under resin composite restorations in caries affected teeth"
} 
Para atingir o objetivo da pesquisa, participaram no estudo quatro pesquisadores qualificados e responsáveis pelas seguintes funções:

- Pesquisador 1 (P1): Operador 1

- Pesquisador $2(\mathrm{P} 2)$ : Operador 2

- Pesquisador 3 (P3): Examinador cego 1

- Pesquisador 4 (P4): Examinador cego 2

\subsubsection{Cálculo amostral}

De acordo com as orientações para delineamento de estudos sobre sucesso clínico de restaurações em resina composta (75), o cálculo do tamanho da amostra (N) foi realizado considerando a necessidade de um teste com poder estatístico $(1-\beta)=0.80$, erro tipo I $(\alpha=0.05)$ e efeito do tratamento esperado em 15\% (10). O cálculo foi feito usando o software $\mathrm{G}^{*}$ Power (76) que indicou um tamanho amostral total de $\mathrm{N}=64$, considerando 4 grupos experimentais e quatro momentos de avaliação, utilizando análise de variância para medidas repetidas, dentro dos fatores (Anexo C). Considerando as recomendações de adicionar um número extra de pacientes para remediar as situações de abandono de tratamento, estabelecemos um acréscimo de $25 \%$, totalizando um $\mathrm{N}=80$ alocados em quatro grupos, como o número mínimo de intervenções.

\subsubsection{Participantes}

O estudo foi realizado nas Clínicas Odontológicas da Faculdade de Odontologia de Ribeirão Preto - Universidade de São Paulo entre dezembro de 2014 e dezembro de 2016. Um total de 230 participantes se apresentaram como voluntários para o estudo, os quais foram examinados por dois cirurgiões dentistas previamente treinados com os critérios de elegibilidade. A avaliação foi realizada por meio de anamnese (Apêndice A), exame clínico intraoral usando um espelho bucal \# 05 (Golgran, SP, Brasil), uma sonda exploradora \# 05 (Golgran, SP, Brasil) e uma sonda periodontal Goldman Fox dupla milimetrada (Golgran, SP, Brasil). O exame radiográfico digital (radiografia periapical ou bitewing) foi realizado usando um equipamento de Raio X (Spectro 70X, Dabi Atlante, Ribeirão Preto, Brasil) e sensor digital (FONA CDR elite, EUA) com um tempo de exposição de 0,32 s fixado em $70 \mathrm{kVp}$. Testes de vitalidade pulpar foram realizados para excluir elementos dentários com danos irreversíveis. 


\section{Critérios de inclusão:}

a) Pacientes de ambos os gêneros, com idade entre 18 e 50 anos

b) Presença de lesões cariosas ativas de profundidade média em dentina, em dentes sem restauração prévia (Classe I ou II) em pelo menos um dente posterior (pré-molar ou molar do arco superior ou inferior)

c) Pacientes com baixo e médio risco de cárie, de acordo com os critérios da American Dental Association (ADA) (77)

d) Pacientes sem histórico de dor dental espontânea

e) Respostas positivas a testes de vitalidade pulpar

f) Nenhuma evidência de radiolucidez periapical

g) Pacientes dispostos a retornar às avaliações durante o período da pesquisa

\section{Critérios de exclusão:}

a) Pacientes com uso constante de medicação

b) Pacientes com doença periodontal

c) Ausência de dentes antagonistas ou adjacentes (todas os dentes a serem restaurados deviam estar em oclusão)

d) Possuir nos dentes antagonistas restaurações em porcelana

e) Pacientes com hábitos parafuncionais

f) Pacientes com tratamento ortodôntico ativo

g) Dentes com presença de trincas ou fraturas

h) Higiene oral deficiente

i) Pacientes grávidas ou em período de lactação

j) Pacientes fumantes

Os participantes, que após examinados se enquadraram no perfil de inclusão foram convidados a participar da pesquisa. O número de dentes selecionados por cada participante limitou-se a quatro. Os participantes foram informados verbalmente e de forma escrita sobre a natureza do estudo e assinaram o Termo de Consentimento Livre e Esclarecido (Apêndice B) antes de iniciar qualquer procedimento restaurador. 


\subsubsection{Calibração dos operadores e examinadores}

Com relação aos operadores (P1 e P2), o processo de calibração consistiu em uma sessão de treinamento, executando uma restauração de cada grupo experimental, a fim de identificar todos os passos envolvidos no protocolo de restauração e padronizar a confecção das restaurações.

Quanto à calibração dos examinadores (P3 e P4), o treinamento foi realizado em três fases para padronizar os critérios de avaliação. Inicialmente, os examinadores realizaram um estudo teórico de forma detalhada dos critérios propostos pela FDI $(78,79)$ para conhecer a descrição dos escores a serem usados. Posteriormente, os examinadores realizaram um treinamento clínico que consistiu na avaliação, de acordo com os critérios, de 10 restaurações posteriores em resina composta onde todas as categorias foram consideradas. Finalmente, a fim de auxiliar o processo de calibração utilizou-se uma ferramenta de calibração eletrônica denominada "e-calib" (www.e-calib.info). Esta ferramenta foi usada para calibração de oito categorias (brilho superficial, manchamento marginal, estabilidade de cor, forma anatômica, fratura e retenção, adaptação marginal, recorrência de cárie e integridade dental) acessando através da plataforma casos clínicos de restaurações posteriores, apresentados em alta qualidade. Apenas examinadores experientes, com treinamento suficiente para cada categoria e após uma calibração adequada em nível $\geq 85 \%$ garantiu um resultado reprodutível (Anexo D).

\subsubsection{Randomização e alocação dos tratamentos}

A randomização foi feita levando em consideração que: (1) a unidade de observação foi a restauração e (2) os dentes selecionados por participante (um a quatro) deveriam ser alocados em grupos diferentes. Dessa forma, a randomização foi realizada para cada participante, onde os dentes selecionados foram alocados por sorteio em um dos grupos. Assim, evitou-se ter mais de uma restauração de um mesmo participante fazendo parte de um mesmo grupo, minimizando os efeitos relacionados a este (ex. idade, hábitos alimentares, hábitos de higiene, etc.). A randomização não atingiu uma relação de alocação balanceada (23: 23: 24: 22) devido a que os participantes não contavam com a mesma quantidade de dentes para receber a intervenção. 


\subsubsection{Intervenção clínica}

Os procedimentos restauradores foram realizados por dois operadores (P1 e P2), cirurgião dentistas, pós-graduandos, previamente treinados e calibrados. Os operadores confeccionaram um número similar de restaurações $(\mathrm{P} 1=49$ e $\mathrm{P} 2=43)$.

\subsubsection{Remoção da cárie e preparo das cavidades}

Após anestesia com mepivacaína a 3\% (Mepisv, Nova DFL, Rio de Janeiro, RJ, Brasil), foi realizada profilaxia do dente com lesão de cárie utilizando uma pasta de pedra pomes e água e taça de borracha para remover a película salivar e placa bacteriana, seguido de lavagem e secagem. A seguir, o campo operatório foi isolado com dique de borracha (Madeitex, São José dos Campos, SP, Brasil) usando grampos \# 200 a 205 (molares) ou \# 206 a 209 (pré-molares) (Duflex, SSWhite, Juiz de Fora, MG, Brasil) dependendo da anatomia e morfologia do dente a ser tratado.

Uma vez realizado o isolamento absoluto, continuou-se com a remoção de cárie. $\mathrm{O}$ acesso à lesão de cárie ou remoção do esmalte cariado (remoção do esmalte cavo superficial) foi realizado (quando necessário) usando pontas diamantadas esféricas \# 1012-1014 (KG Sorensen, Barueri, SP, Brasil), de tamanhão compatível à da cavidade, montadas em turbina de alta rotação (Kavo, Joinville, SC, Brasil) sob irrigação constante de água abundante. Em cavidades classe II, o acesso à face proximal foi estabelecido da forma mais conservadora possível, com sua orientação em direção à lesão proximal, mantendo as paredes da caixa proximal livres de contato com o dente adjacente. Para minimizar as chances de contato acidental com a superfície proximal do dente adjacente, a mesma foi protegida com matriz metálica (Matrix Tofflemire, TDV Dental Ltda., Pomerode, SC, Brasil) estabilizada com uma cunha de madeira (TDV Dental Ltda., Pomerode, SC, Brasil).

A seguir, foi realizada a remoção seletiva da dentina cariada de acordo com os critérios de intervenção minimamente invasiva (25). Isto é, a remoção da camada superficial ou dentina infectada (apenas o tecido mole desorganizado e necrótico, sem capacidade de remineralização) e preservação da camada interna ou dentina afetada (passível de remineralização). Dessa forma, removeu-se a dentina superficial com auxílio de curetas de dentina (Golgran Ind., SP, Brasil) ou brocas esféricas carbide \# 1/2, 1, 2 ou 3 (KG Sorensen, Barueri, SP, Brasil) montadas em turbina de baixa rotação (Kavo, Joinville, SC, Brasil). O tecido da dentina afetada, de consistência dura e textura coriácea foi verificado através de 
exame visual e tátil da cavidade usando sonda exploradora $n^{\circ} 05$ (Golgran Ind., SP, Brasil) e preservado na cavidade.

A forma de contorno de todas as cavidades (Classe I e Classe II) foram orientadas apenas pela presença de tecido cariado, como vem sendo preconizado na literatura (80). A margens cavo superficiais das caixas proximais quanto das superfícies oclusais foram finalizadas sem confecção de bisel. Não foram feitas retenções adicionais.

\subsubsection{Restauração das cavidades}

Após a remoção do tecido cariado, realizou-se a limpeza da cavidade com irrigação de agua destilada e a secagem com papel absorvente estéril. Em cavidades Classe II, inseriu-se uma matriz metálica circunferencial em porta matriz Tofflemeire (Golgran Ltda., São Caetano do Sul, SP, Brasil) e uma cunha de madeira. A área de contato da matriz com o dente adjacente foi cuidadosamente brunida com brunidor \#29 (SSWhite Duflex, Rio de Janeiro, RJ, Brasil). A adaptação da matriz à parede gengival do preparo foi verificada com sonda exploradora.

A seguir, os dentes distribuídos aleatoriamente nos grupos experimentais, tal como definidos na Tabela 2, foram tratados de acordo com o seguinte protocolo:

- Grupo 1 (experimental): A cavidade foi condicionada com ácido fosfórico 35\% (Etchant gel, VITA Zahnfabrik), no esmalte (15 s) e na dentina (15 s), lavada com jato de água abundante e secada com papel absorvente estéril. A umidade da dentina foi conferida pelo aspecto brilhante. Em seguida, o pó de Biosilicato ${ }^{\circledR}$ (Vitrovita, São Carlos, SP, Brasil) $(\sim 0,04 \mathrm{~g})$ foi aplicado com auxílio de um microaplicador (Microbrush, KG Sorensen, Cotia, SP, Brasil) e friccionado na superfície da dentina por aproximadamente $10 \mathrm{~s}$. O sistema adesivo convencional de frasco único Adper Single Bond 2 (3M ESPE, Sumaré, SP, Brasil) foi aplicado em duas camadas com um microaplicador (Microbrush, KG Sorensen, Cotia, SP, Brasil), removendo o excesso de solvente com um leve e constante jato de ar (5 s) até a dentina apresentar um aspecto brilhante e sem cúmulos de adesivo nos ângulos internos. A cavidade foi foto polimerizada por $20 \mathrm{~s}$ com uma fonte de luz LED (Lec Plus, MMO, São Carlos, SP, Brasil) com uma potência de luz de $\geq 700 \mathrm{~mW} / \mathrm{cm}^{2}$.

- Grupo 2 (controle): O mesmo protocolo do Grupo 1 sem aplicação do Biosilicato ${ }^{\circledR}$. 
- Grupo 3 (experimental): AdheSE Primer (Frasco 1, AdheSE, Ivoclar Vivadent, Barueri, SP, Brasil) foi aplicado sobre a superfície do esmalte (15 s) e da dentina (15 s). O excesso do primer foi disperso com um forte jato de ar até que a película superficial de líquido não seja mais visível. Em seguida, o pó de Biosilicato (Vitrovita, São Carlos, SP, Brasil) ( 0,04g) foi aplicado na superfície da dentina com auxílio de um microaplicador (Microbrush, KG Sorensen, Cotia, SP, Brasil) por aproximadamente $10 \mathrm{~s}$. A seguir, AdheSE Bond (Frasco 2, AdheSE, Ivoclar Vivadent, Barueri, SP, Brasil) foi aplicado iniciado pela dentina e continuou no esmalte, conforme as recomendações do fabricante. A cavidade foi foto polimerizada por $20 \mathrm{~s}$ com uma fonte de luz LED (Lec Plus, MMO, São Carlos, SP, Brasil) com uma potência de luz de $\geq 700 \mathrm{~mW} / \mathrm{cm}^{2}$.

- Grupo 4 (controle): o mesmo protocolo do grupo 3 sem aplicação do Biosilicato ${ }^{\circledR}$.

Tabela 2 - Grupos do estudo e protocolos de tratamento.

\begin{tabular}{cl}
\hline Grupos & \multicolumn{1}{c}{ Protocolos de tratamento restaurador } \\
\hline Grupo $1(\mathrm{~N}=23)$ & Condicionamento ácido $\left(\mathrm{H}_{3} \mathrm{PO}_{4} 35 \%\right)+$ Biosilicato + Adper Single Bond 2 + IPS \\
Empress Direct & Condicionamento ácido $\left(\mathrm{H}_{3} \mathrm{PO}_{4} 35 \%\right)+$ Adper Single Bond 2 + IPS Empress Direct \\
Grupo $2(\mathrm{~N}=23)$ & AdheSE primer + Biosilicato + AdheSE bond + IPS Empress Direct \\
Grupo $3(\mathrm{~N}=24)$ & AdheSE primer (primer e bond $)+$ IPS Empress Direct \\
\hline
\end{tabular}

Posteriormente, a resina composta IPS Empress Direct (Ivoclar Vivadent, Barueri, SP, Brasil) foi inserida na cavidade de forma obliqua com incrementos de $2 \mathrm{~mm}$ de espessura. Cada incremento foi fotopolimerizado por $20 \mathrm{~s}$ com uma fonte de luz LED $\geq 700 \mathrm{~mW} / \mathrm{cm}^{2}$ (Lec Plus, MMO, São Carlos, SP, Brasil)

Após finalização da restauração, o dique de borracha foi removido e continuou-se com os registros de contatos oclusais em máxima intercuspidação habitual, lateralidade e protrusão usando papel carbono (Contacto, Angelus, Londrina, PR, Brasil). Os procedimentos de acabamento e polimento das restaurações foram realizados usando pontas diamantadas de granulação fina (KG Sorensen, Cotia, SP, Brasil) sob irrigação de água abundante e borrachas 
de silicone abrasivos (Kit Viking, KG Sorensen, SP, Cotia, Brasil). Tiras de lixa abrasiva (Injecta, Itajai, SC, Brasil) foram usadas para acabamento de restaurações proximais.

\subsubsection{Avaliação das restaurações}

O período de seguimento ou follow-up para coleta de dados aconteceu uma semana após a realização de restaurações e após 06, 12 e 18 meses de acordo com os critérios da FDI (75, 79) (Quadro 1). Cada restauração foi avaliada de forma independente por dois examinadores (P3 e P4) previamente calibrados e não envolvidos nos procedimentos restauradores.

As categorias ou parâmetros clínicos avaliados foram: propriedades estéticas (brilho, manchamento marginal, estabilidade de cor e translucidez e forma anatômica), propriedades funcionais (fratura e retenção, adaptação marginal, contorno oclusal e desgaste, forma anatômica proximal, avaliação radiográfica e opinião do paciente) e propriedades biológicas (hipersensibilidade, recorrência de cárie, integridade dental, resposta periodontal, mucosa adjacente saúde oral e geral).

Os examinadores realizaram as avaliações em ambiente clínico com auxílio de um espelho bucal plano \# 05 (Golgran, SP, Brasil), uma sonda exploradora \# 05 (Golgran, SP, Brasil), uma sonda periodontal milimetrada (Golgran, SP, Brasil) e luz do refletor. A avaliação do parâmetro forma anatômica proximal foi realizada com auxílio de fio dental (Oral-B Pro-Saúde, Procter \& Gamble Ltda., SP, Brasil). O parâmetro hipersensibilidade pósoperatória foi examinada aplicando jato de ar frio durante $5 \mathrm{~s}$, proveniente da seringa tríplice e posicionada a $2 \mathrm{~cm}$ da superfície do dente restaurado. A intensidade da hipersensibilidade foi avaliada a través da escala visual analógica (EVA), onde o paciente relatou a dor numa escala do 0-10 (0 = "ausência de dor" e 10 = "dor intolerável"). Os métodos de avaliação estão descritos na Tabela 3. 
Tabela 3 - Métodos de avaliação das restaurações para cada categoria.

\begin{tabular}{|c|c|}
\hline Categorias & Método de avaliação \\
\hline \multicolumn{2}{|l|}{ Propriedades estéticas } \\
\hline Brilho superficial & Exame visual \\
\hline Manchamento marginal & Exame visual \\
\hline Estabilidade de cor e translucidez & Exame visual \\
\hline Forma anatômica & Exame visual \\
\hline \multicolumn{2}{|l|}{ Propriedades funcionais } \\
\hline Fratura e retenção & Exame visual-tátil \\
\hline Adaptação marginal & Exame visual-tátil \\
\hline Contorno oclusal & Exame visual-tátil \\
\hline Forma anatômica proximal & Exame visual-tátil, fio dental \\
\hline Exame radiográfico ${ }^{a}$ & Raio X \\
\hline Opinião do paciente & $\begin{array}{l}\text { Entrevista com o paciente sobre a satisfação ou insatisfação do } \\
\text { tratamento }\end{array}$ \\
\hline \multicolumn{2}{|l|}{ Propriedades biológicas } \\
\hline Hipersensibilidade pós-operatória & Estímulo com ar frio, Escala Visual Analógica \\
\hline Recorrência de cárie & Exame visual-tátil e radiográfico ${ }^{a}$ \\
\hline Integridade dental & Exame visual-tátil \\
\hline Resposta periodontal & Exame visual-tátil \\
\hline Mucosa adjacente & Exame visual da mucosa oral \\
\hline Saúde oral e geral & $\begin{array}{l}\text { Exame visual da cavidade oral e entrevista sobre o estado } \\
\text { médico }\end{array}$ \\
\hline
\end{tabular}

${ }^{a} \mathrm{O}$ exame radiográfico foi apenas realizado em casos de sintomas clínicos (ex. dor, inchaço) e suspeita de cárie

Para auxiliar a avaliação clínica, as restaurações foram fotografadas em cada retorno com uma câmera digital (Sony Alpha 65, EUA) associada à lente macro (100 mm F/2.8) e flash circular (SIGMA EM-140 DG). A câmera foi configurada no modo manual, ISSO 100, diafragma F-22, velocidade - 1/100, e sua qualidade configurada em "Large".

Cada categoria foi classificada nos seguintes escores:

$1=$ clinicamente excelente

$2=$ clinicamente bom

$3=$ clinicamente suficiente ou satisfatório

4= clinicamente insatisfatório

$5=$ clinicamente deficiente 
Os escores 1, 2 e 3 representam restaurações "clinicamente aceitáveis" enquanto que os escores 4 e 5 representam restaurações "clinicamente inaceitáveis" indicando necessidade de reparo ou substituição, respectivamente; a fim de prevenir algum futuro dano ou reparar algum dano presente. Assim, restaurações com escore 4 e 5 resultaram em falha ou insucesso. As pontuações para cada categoria foram registradas na ficha clínica de avaliação (Apêndice C).

Em cada retorno para a avaliação, o participante foi reavaliado considerando os critérios de inclusão e exclusão. Os participantes foram excluídos do estudo no período de follow-up nas seguintes situações:

- Extração do dente devido a outros motivos diferente ao estudo.

- Retratamento feito por outro dentista não envolvido na pesquisa.

- Enquadramento do paciente em critério de exclusão (ex. gravidez ou início de tratamento ortodôntico).

Os participantes que apresentaram outras necessidades de tratamento constatadas no processo de avaliação clínica, foram encaminhados para as clínicas de graduação da Faculdade de Odontologia para atendimento clínico. 
Quadro 1 - Critérios de avaliação da FDI.

\begin{tabular}{|c|c|c|c|c|}
\hline $\begin{array}{l}\text { A. PROPRIEDADES } \\
\text { ESTÉTICAS }\end{array}$ & 1. Brilho Superficial & $\begin{array}{l}\text { 2.Manchamento } \\
\text { Marginal }\end{array}$ & 3. Estabilidade de cor e translucidez & 4. Forma anatômica \\
\hline $\begin{array}{l}\text { 1. Clinicamente } \\
\text { excelente/muito bom. }\end{array}$ & $\begin{array}{l}\text { 1.1. Brilho semelhante ao } \\
\text { esmalte. }\end{array}$ & $\begin{array}{l}\text { 2.1. Sem manchamento na } \\
\text { margem. }\end{array}$ & $\begin{array}{l}\text { 3.1. Boa estabilidade de cor, sem } \\
\text { alterações no matiz e translucidez. }\end{array}$ & 4.1. Forma ideal. \\
\hline $\begin{array}{l}\text { 2. Clinicamente bom } \\
\text { (após polimento, } \\
\text { provavelmente muito } \\
\text { bom). }\end{array}$ & $\begin{array}{l}\text { 1.2. 1. Levemente opaco, } \\
\text { não perceptível a distância } \\
\text { da fala. } \\
\text { 1.2.2. Alguns poros } \\
\text { isolados. }\end{array}$ & $\begin{array}{l}\text { 2.2. Mínimo manchamento na } \\
\text { margem, facilmente removível } \\
\text { com o polimento }\end{array}$ & $\begin{array}{l}\text { 3.2. Alteração mínima no matiz e } \\
\text { translucidez. }\end{array}$ & $\begin{array}{l}\text { 4.2. Forma levemente } \\
\text { afetada. }\end{array}$ \\
\hline $\begin{array}{l}\text { 3. Clinicamente } \\
\text { suficiente ou } \\
\text { satisfatório (mínimas } \\
\text { deficiências sem } \\
\text { efeitos inaceitáveis, } \\
\text { porém não ajustável } \\
\text { sem danos ao dente). }\end{array}$ & $\begin{array}{l}\text { 1.3.1. Levemente opaco, } \\
\text { mas aceitável se coberto } \\
\text { com filme de saliva. } \\
\text { 1.3.2. Múltiplos poros em } \\
\text { mais de um terço da } \\
\text { superfície. }\end{array}$ & $\begin{array}{l}\text { 2..3. Manchamento moderado } \\
\text { na margem, presente também } \\
\text { em outros dentes. } \\
\text { Esteticamente não } \\
\text { insatisfatória. }\end{array}$ & $\begin{array}{l}\text { 3.3. Desvio evidente, porém, sem afetar } \\
\text { a estética: } \\
\text { 3.3.1 Mais opaco. } \\
\text { 3.3.2 Mais translucido. } \\
\text { 3.3.3 Mais escuro. } \\
\text { 3.3.4 Mais claro. }\end{array}$ & $\begin{array}{l}\text { 4.3. Forma defere, porém } \\
\text { não compromete a } \\
\text { estética. }\end{array}$ \\
\hline $\begin{array}{l}\text { 4. Clinicamente } \\
\text { insatisfatório (mas } \\
\text { reparável). }\end{array}$ & $\begin{array}{l}\text { 1.4.1 Superfície rugosa, o } \\
\text { polimento não é suficiente. } \\
\text { Necessária intervenção } \\
\text { futura. } \\
\text { 1.4.2 Espaços vazios }\end{array}$ & $\begin{array}{l}\text { 2.4. Manchamento marginal } \\
\text { pronunciado; maior } \\
\text { intervenção necessária. }\end{array}$ & $\begin{array}{l}\text { 3.4. Alteração clínica localizada, porém } \\
\text { pode ser corregida por reparo: } \\
\text { 3.4.1. Muito opaco. } \\
\text { 3.4.2. Muito translucido. } \\
\text { 3.4.3. Muito escuro. } \\
\text { 3.4.4. Muito claro. }\end{array}$ & $\begin{array}{l}\text { 4.4. Forma afetada e } \\
\text { esteticamente inaceitável. } \\
\text { Intervenção/correção } \\
\text { necessária. }\end{array}$ \\
\hline $\begin{array}{l}\text { 5. Clinicamente } \\
\text { deficiente (necessita } \\
\text { substituição). }\end{array}$ & $\begin{array}{l}\text { 1.5. Muito rugosa, } \\
\text { Superfície retentiva. } \\
\text { Inaceitável. }\end{array}$ & $\begin{array}{l}2.5 \text { Profundo manchamento } \\
\text { marginal. }\end{array}$ & $\begin{array}{l}\text { 3.5. Inaceitável. } \\
\text { Substituição necessária. }\end{array}$ & $\begin{array}{l}\text { 4.5. Forma } \\
\text { completamente } \\
\text { insatisfatória e/ou } \\
\text { perdida. Reparo não } \\
\text { possível/razoável. } \\
\text { Substituição necessária. }\end{array}$ \\
\hline
\end{tabular}




\begin{tabular}{|c|c|c|c|c|c|c|}
\hline $\begin{array}{l}\text { B. PROPRIEDADES } \\
\text { FUNCIONAIS }\end{array}$ & $\begin{array}{l}\text { 5. Fratura do } \\
\text { material e } \\
\text { retenção }\end{array}$ & 6. Adaptação Marginal & $\begin{array}{l}\text { 7. Contorno Oclusal } \\
\text { e Desgaste } \\
\text { (Qualitativamente) }\end{array}$ & $\begin{array}{l}\text { 8. Forma anatômica } \\
\text { proximal } \\
\text { a. Ponto de contato. } \\
\text { b. Contorno } \\
\end{array}$ & $\begin{array}{c}\text { 9. Avaliação } \\
\text { Radiográfica } \\
\text { (Quando aplicável) }\end{array}$ & $\begin{array}{l}\text { 10. Opinião do } \\
\text { paciente }\end{array}$ \\
\hline $\begin{array}{l}\text { 1. Clinicamente } \\
\text { excelente/muito bom. }\end{array}$ & $\begin{array}{l}\text { 5.1. Sem fraturas } \\
\text { ou trincas. }\end{array}$ & $\begin{array}{l}\text { 6.1 Contorno harmonioso, } \\
\text { sem fendas, sem linhas } \\
\text { brancas ou descoloridas. }\end{array}$ & $\begin{array}{l}\text { 7.1. Desgaste fisiológico } \\
\text { semelhante ao esmalte. }\end{array}$ & $\begin{array}{l}\text { 8.1. Ponto de contato } \\
\text { normal (fio dental ou } \\
\text { matriz de metal de } 25 \mu \mathrm{m} \\
\text { pode passar) }\end{array}$ & $\begin{array}{l}\text { 9.1. Sem patologia, } \\
\text { transição harmoniosa } \\
\text { entre restauração e } \\
\text { dente. }\end{array}$ & $\begin{array}{l}\text { 10.1. Inteiramente } \\
\text { satisfeito com a } \\
\text { função e a estética. }\end{array}$ \\
\hline $\begin{array}{l}\text { 2. Clinicamente bom } \\
\text { (após polimento, } \\
\text { provavelmente muito } \\
\text { bom). }\end{array}$ & $\begin{array}{l}\text { 5.2. Pequena } \\
\text { trinca. }\end{array}$ & $\begin{array}{l}\text { 6.2.1 Fenda marginal } \\
(<150 \mu \mathrm{m}) \text {, linhas brancas. } \\
\text { 6.2.2. Pequena fratura } \\
\text { marginal removível com } \\
\text { polimento. } \\
\text { 6.2.3. Mínimas } \\
\text { irregularidades. }\end{array}$ & $\begin{array}{l}7.2 \text { Desgaste normal, } \\
\text { levemente diferente ao } \\
\text { esmalte. }\end{array}$ & $\begin{array}{l}\text { 8.1 Contato levemente } \\
\text { forte, mas não desvantajoso } \\
\text { (fio dental pode passar só } \\
\text { com pressão) }\end{array}$ & $\begin{array}{l}\text { 9.2.1. Aceitável } \\
\text { excesso de material } \\
\text { presente. } \\
9.2 .2 \text { Degrau } \\
\text { Positivo/negativo } \\
\text { presente na margem } \\
<150 \mu \mathrm{m} .\end{array}$ & $\begin{array}{l}\text { 10.2. Satisfeito } \\
\text { 10.2.1 Estética. } \\
\text { 10.2.2 Função. }\end{array}$ \\
\hline $\begin{array}{l}\text { 3. Clinicamente } \\
\text { suficiente ou } \\
\text { satisfatório (mínimas } \\
\text { deficiências sem efeitos } \\
\text { inaceitáveis, porém } \\
\text { não ajustável sem } \\
\text { danos ao dente). }\end{array}$ & $\begin{array}{l}\text { 5.3. Duas ou } \\
\text { mais ou maiores } \\
\text { trincas e/o fratura } \\
\text { do material que } \\
\text { não afetam a } \\
\text { adaptação } \\
\text { marginal ou o } \\
\text { contato proximal. }\end{array}$ & $\begin{array}{l}\text { 6.3.1 Fenda }<250 \mu \mathrm{m} \text { não } \\
\text { removível. } \\
6.3 .2 \text {. Múltiplas pequenas } \\
\text { fraturas. } \\
\text { 6.3.3. Maiores } \\
\text { irregularidades, } \\
\text { afundamentos ou degraus. }\end{array}$ & $\begin{array}{l}7.3 \text { Desgaste diferente que } \\
\text { o esmalte, mas dentro da } \\
\text { variação biológica. }\end{array}$ & $\begin{array}{l}8.3 \text { Contato fraco sem } \\
\text { danos nos dentes, gengiva } \\
\text { ou estruturas periodontais } \\
\text { (fio passa facilmente com } \\
\text { ligeira pressão). }\end{array}$ & $\begin{array}{l}\text { 9.3.1 Fenda marginal } \\
<250 \mu \mathrm{m} \text {. } \\
\text { 9.3.2. Visíveis } \\
\text { degraus negativos < } \\
250 \mu \mathrm{m} . \\
\text { 9.3.3 Deficiente } \\
\text { radiopacidade do } \\
\text { material restaurador. } \\
\text { Sem efeitos adversos. }\end{array}$ & $\begin{array}{l}\text { 10.3. Mínima } \\
\text { crítica, mas sem } \\
\text { efeitos clínicos } \\
\text { adversos. } \\
\text { 10.3.1Deficiencias } \\
\text { estéticas. } \\
\text { 10.3.2 Falta de } \\
\text { mastigacão } \\
\text { confortável. } \\
\text { 10.3.3 Tratamento } \\
\text { desagradável. }\end{array}$ \\
\hline $\begin{array}{l}\text { 4. Clinicamente } \\
\text { insatisfatório (mas } \\
\text { reparável). }\end{array}$ & $\begin{array}{l}\text { 5.4.1 Lascas que } \\
\text { danificam a } \\
\text { adaptação } \\
\text { marginal ou o } \\
\text { ponto de contato. } \\
5.4 .2 \text { Fratura de } \\
\text { grande volume } \\
\text { com perda parcial } \\
\text { (menos da } \\
\text { metade da } \\
\text { restauração). }\end{array}$ & $\begin{array}{l}\text { 6.4.1Fenda }>250 \mu \mathrm{m} \text { ou } \\
\text { dentina/base exposta. } \\
6.4 .2 \text { Severo afundamento } \\
\text { ou fratura marginal. } \\
\text { 6.4.3. Maiores } \\
\text { irregularidades ou degraus } \\
\text { (necessidade de reparação). }\end{array}$ & $\begin{array}{l}\text { 7.4. Desgaste excede } \\
\text { consideravelmente o } \\
\text { desgaste normal de } \\
\text { esmalte; ou pontos de } \\
\text { contato oclusal perdidos. }\end{array}$ & $\begin{array}{l}\text { 8.4. Contato muito fraco, } \\
\text { devido a dano por impacto } \\
\text { de alimentos (fita de matriz } \\
\text { metálica de } 100 \mu \mathrm{m} \text { pode } \\
\text { passar). } \\
\text { Reparável. }\end{array}$ & $\begin{array}{l}\text { 9.4.1 Fenda marginal } \\
>250 \mu \mathrm{m} . \\
\text { 9.4.2 Excesso de } \\
\text { material, porém não } \\
\text { removível. } \\
\text { 9.4.3 Degrau negativo } \\
>250 \mu \mathrm{m} \text { e reparável. }\end{array}$ & $\begin{array}{l}\text { 10.4 Paciente tem } \\
\text { desejo de melhora. } \\
\text { 10.4.1 Estética. } \\
\text { 10.4.2 Função (ex. } \\
\text { irritação da } \\
\text { língua). Reparável. } \\
\text { Refazer a forma } \\
\text { anatômica ou } \\
\text { remodelação é } \\
\text { possível. }\end{array}$ \\
\hline $\begin{array}{l}\text { 5. Clinicamente } \\
\text { deficiente (necessita } \\
\text { substituição). }\end{array}$ & $\begin{array}{l}5.4 \text { Perda parcial } \\
\text { ou total da } \\
\text { restauração ou } \\
\text { múltiplas } \\
\text { fraturas. }\end{array}$ & $\begin{array}{l}\text { 6.5.1 Restauração completa } \\
\text { ou parcial está solta, porém } \\
\text { in situ. } \\
\text { 6.5.2 Grandes fendas } \\
\text { generalizadas ou } \\
\text { irregularidades. }\end{array}$ & 7.5. Desgaste excessivo. & $\begin{array}{l}\text { 8.5. Contato muito fraco } \\
\text { e/ou evidente dano por } \\
\text { impacto de alimentos e/ou } \\
\text { dor/gengivite. }\end{array}$ & $\begin{array}{l}\text { 9.5.1 Cárie } \\
\text { secundária, grandes } \\
\text { fendas, grande } \\
\text { sobrecontorno. } \\
\text { 9.5.2 Lesão apical } \\
\text { 9.5.3 Fratura/perda da } \\
\text { restauração ou do } \\
\text { dente. }\end{array}$ & $\begin{array}{l}10.5 . \\
\text { Completamente } \\
\text { insatisfeito e/ou } \\
\text { efeitos adversos } \\
\text { inclusive dor. }\end{array}$ \\
\hline
\end{tabular}

Continuação 


\begin{tabular}{|c|c|c|c|c|c|c|}
\hline $\begin{array}{l}\text { C. PROPRIEDADES } \\
\text { BIOLOGICAS }\end{array}$ & $\begin{array}{l}\text { 11. Hipersensibilidade } \\
\text { pós-operatória }\end{array}$ & $\begin{array}{l}\text { 12. Recorrência de } \\
\text { cárie }\end{array}$ & $\begin{array}{l}\text { 13. Integridade dental } \\
\text { (trinca do esmalte, } \\
\text { fraturas dentais) } \\
\end{array}$ & $\begin{array}{l}\text { 14. Resposta periodontal } \\
\text { (sempre comparado a } \\
\text { um dente referencial) }\end{array}$ & $\begin{array}{l}\text { 15. Mucosa } \\
\text { adjacente }\end{array}$ & $\begin{array}{l}\text { 16. Saúde oral e } \\
\text { geral. }\end{array}$ \\
\hline $\begin{array}{l}\text { 1. Clinicamente } \\
\text { excelente/muito bom. }\end{array}$ & $\begin{array}{l}\text { 11.1. Sem } \\
\text { hipersensibilidade }\end{array}$ & $\begin{array}{l}\text { 12.1. Sem cáries } \\
\text { primária ou secundária. }\end{array}$ & $\begin{array}{l}\text { 13.1. Integridade } \\
\text { completa. }\end{array}$ & $\begin{array}{l}\text { 14.1. Sem placa, } \\
\text { inflamação nem bolsas. }\end{array}$ & $\begin{array}{l}\text { 15.1. Mucosa } \\
\text { saudável adjacente } \\
\text { à restauração. }\end{array}$ & $\begin{array}{l}\text { 16.1. Sem } \\
\text { sintomas gerais ou } \\
\text { orais. }\end{array}$ \\
\hline $\begin{array}{l}\text { 2. Clinicamente bom (após } \\
\text { polimento, provavelmente } \\
\text { muito bom). }\end{array}$ & $\begin{array}{l}\text { 11.2. Baixa } \\
\text { hipersensibilidade por } \\
\text { um curto período de } \\
\text { tempo }\end{array}$ & $\begin{array}{l}\text { 12.2. Pequena e } \\
\text { localizada }\end{array}$ & $\begin{array}{l}\text { 13.2.1. Fratura marginal } \\
\text { do esmalte pequena } \\
(<150 \mu \mathrm{m}) \text {. } \\
\text { 13.2.2 Trinca fina em } \\
\text { esmalte }(<150 \mu \mathrm{m}) \text {. }\end{array}$ & $\begin{array}{l}\text { 14.2. Pouca placa, sem } \\
\text { inflamação (gengivite), } \\
\text { sem desenvolvimento de } \\
\text { bolsa. } \\
\text { 14.2.1. Sem } \\
\text { 14.2.2. Com sobre } \\
\text { contorno, fendas ou forma } \\
\text { anatômica inadequada. }\end{array}$ & $\begin{array}{l}\text { 15.2. Mucosa } \\
\text { saudável após } \\
\text { remoção mínima } \\
\text { de irritação } \\
\text { mecânica (placa, } \\
\text { cálculo, bordas } \\
\text { afiadas) }\end{array}$ & $\begin{array}{l}\text { 16.2. Mínimos } \\
\text { sintomas } \\
\text { transitórios e de } \\
\text { curta duração; } \\
\text { localizados e } \\
\text { generalizados. }\end{array}$ \\
\hline $\begin{array}{l}\text { 3. Clinicamente suficiente } \\
\text { ou satisfatório (mínimas } \\
\text { deficiências sem efeitos } \\
\text { inaceitáveis, porém não } \\
\text { ajustável sem danos ao } \\
\text { dente). }\end{array}$ & $\begin{array}{l}11.3 . \\
\text { Hipersensibilidade } \\
\text { leve; sem queixa do } \\
\text { paciente, sem } \\
\text { necessidade de } \\
\text { tratamento. }\end{array}$ & $\begin{array}{l}\text { 12.3. Maiores áreas de: } \\
\text { 1. Desmineralização } \\
\text { 2. Erosão ou } \\
\text { 3. Abrasão/abfração } \\
\text { sem exposição da } \\
\text { dentina. Apenas } \\
\text { medidas preventivas } \\
\text { são necessárias. }\end{array}$ & $\begin{array}{l}\text { 13.3.1. Defeito no } \\
\text { esmalte marginal } \\
(<250 \mu \mathrm{m}) \text {. } \\
\text { 13.3.2 Trincas }(<250 \mu \mathrm{m}) \text {. } \\
\text { 13.2.3 Lasca do esmalte. } \\
\text { 13.2.4 Trincas múltiplas. }\end{array}$ & $\begin{array}{l}\text { 14.3. Diferença de até um } \\
\text { grau de severidade em } \\
\text { relação ao baseline e ao } \\
\text { dente controle. } \\
\text { 14.3.1. Sem } \\
\text { 14.3.2. Com sobre } \\
\text { contorno, fendas ou forma } \\
\text { anatômica inadequada. }\end{array}$ & $\begin{array}{l}\text { 15.3. Alteração da } \\
\text { mucosa, mas sem } \\
\text { suspeita de relação } \\
\text { causal com o } \\
\text { material } \\
\text { restaurador. }\end{array}$ & $\begin{array}{l}\text { 16.3 Sintomas } \\
\text { transitórios locais } \\
\text { e/ou } \\
\text { generalizados. }\end{array}$ \\
\hline $\begin{array}{l}\text { 4. Clinicamente } \\
\text { insatisfatório (mas } \\
\text { reparável). }\end{array}$ & $\begin{array}{l}11.4 .1 \\
\text { Hipersensibilidade } \\
\text { intensa. } \\
\text { Intervenção necessária, } \\
\text { mas sem substituição. }\end{array}$ & $\begin{array}{l}\text { 12.4. Cárie com } \\
\text { cavitação e suspeita de } \\
\text { cárie sob restauração. } \\
\text { Localizado e accessível } \\
\text { podendo ser restaurado. }\end{array}$ & $\begin{array}{l}\text { 13.4.1. Maiores defeitos } \\
\text { do esmalte marginal; } \\
\text { fenda }>250 \mu \mathrm{m} \text { ou dentina } \\
\text { ou base exposta } \\
13.4 .2 \text { grandes trincas } \\
>250 \mu \mathrm{m} \text {, penetração da } \\
\text { sonda exploradora. } \\
\text { 13.4.3. Grande lasca do } \\
\text { esmalte ou fratura de } \\
\text { paredes. }\end{array}$ & $\begin{array}{l}\text { 14.4. Aumento da } \\
\text { profundidade da bolsa > } \\
1 \mathrm{~mm} \text { requerendo } \\
\text { intervenção. } \\
\text { 14.4.1. Sem } \\
\text { 14.4.2. Com sobre } \\
\text { contorno, fendas ou forma } \\
\text { anatômica inadequada. }\end{array}$ & $\begin{array}{l}\text { 15.4. Suspeita de } \\
\text { reação alérgica } \\
\text { leve, liquenoide ou } \\
\text { tóxica. }\end{array}$ & $\begin{array}{l}\text { 16.4. Persistência } \\
\text { de sintomas locais } \\
\text { ou generalizados. } \\
\text { Estomatite oral de } \\
\text { contato ou líquen } \\
\text { plano ou reações } \\
\text { alérgicas. } \\
\text { Intervenção } \\
\text { necessária, mas } \\
\text { sem substituição. }\end{array}$ \\
\hline $\begin{array}{l}\text { 5. Clinicamente deficiente } \\
\text { (necessita substituição). }\end{array}$ & $\begin{array}{l}\text { 11.5. Pulpite aguda } \\
\text { intensa ou dente sem } \\
\text { vitalidade. Tratamento } \\
\text { endodôntico é } \\
\text { necessário e a a } \\
\text { restauração deve ser } \\
\text { substituída. }\end{array}$ & $\begin{array}{l}\text { 12.5. Cárie profunda } \\
\text { ou dentina exposta que } \\
\text { não é accessível para } \\
\text { reparar a restauração. }\end{array}$ & $\begin{array}{l}\text { 13.5. Fratura de cúspide } \\
\text { ou dental. }\end{array}$ & $\begin{array}{l}\text { 14.5. Gengivite ou } \\
\text { periodontite aguda/severa. } \\
\text { 14.5.1 Sem } \\
\text { 14.5.2. Com sobre } \\
\text { contorno, fendas ou forma } \\
\text { anatômica inadequada. }\end{array}$ & $\begin{array}{l}\text { 15.5. Suspeita de } \\
\text { reação alérgica } \\
\text { severa, liquenoide } \\
\text { ou reação tóxica. }\end{array}$ & $\begin{array}{l}\text { 16.5. Sintomas } \\
\text { locais e/ou } \\
\text { generalizados } \\
\text { agudos /severos. }\end{array}$ \\
\hline
\end{tabular}


Figura 2 - Fluxograma do estudo.

\section{Fase 1: Período Run-in}

Seleção de participantes
Randomização e alocação de participantes
Calibração

- Operadores (P1 e P2)

- Examinadores (P3 e P4)

Fase 2: Período Run-out (P1, P2)

\section{Intervenção clínica}

Protocolo adesivo com sistema adesivo convencional -2 passos

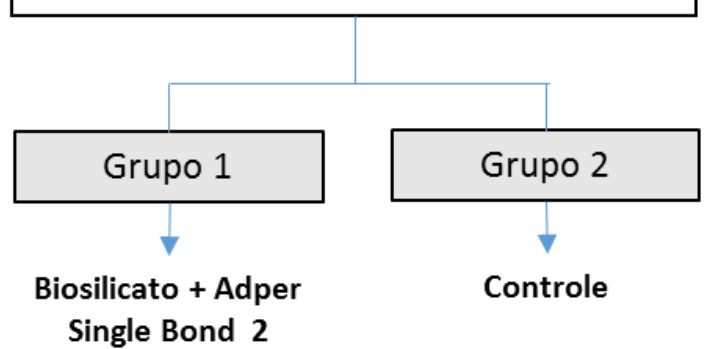

Protocolo adesivo com sistema adesivo autocondicionante -2 passos

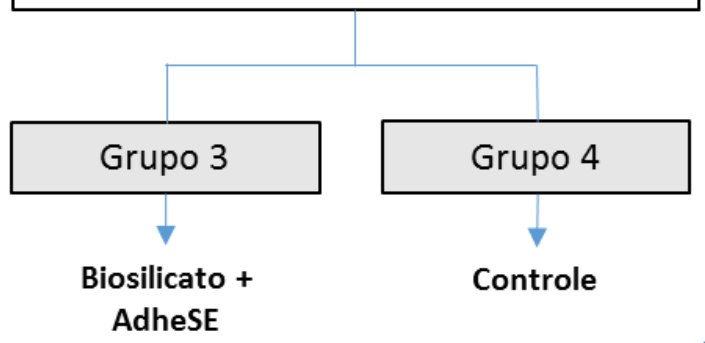

\section{Fase 3: Período Follow-up (P3 e P4)}

\section{Avaliação clínica - Critérios FDI (1 semana, 6, 12, 18 meses)}

\begin{tabular}{|l|}
\hline \multicolumn{1}{|c|}{$\begin{array}{c}\text { Propriedades } \\
\text { Estéticas }\end{array}$} \\
\hline -Brilho superficial \\
-Manchamento \\
marginal \\
- Estabilidade de cor e \\
translucidez \\
- Forma anatômica \\
\\
\end{tabular}

\begin{tabular}{|c|}
\hline \multicolumn{1}{|c|}{$\begin{array}{c}\text { Propriedades } \\
\text { Funcionais }\end{array}$} \\
\hline • Fratura de material e \\
retenção \\
-Adaptação marginal \\
- Contorno oclusale \\
desgaste \\
- Forma anatômica \\
proximal \\
-Avaliação \\
radiográfica \\
•Opinião do paciente \\
\hline
\end{tabular}

\begin{tabular}{|l|}
\hline \multicolumn{1}{|c|}{$\begin{array}{c}\text { Propriedades } \\
\text { Biológicas }\end{array}$} \\
\hline •Hipersensibilidade \\
- Recorrência de cárie \\
- Resposta \\
periodontal \\
-Mucosa adjacente \\
- Saúde oral e geral \\
\\
\end{tabular}




\subsubsection{Análise dos Dados}

A análise estatística foi realizada considerando as variáveis categóricas (escore 1, 2, 3, 4 e 5), ou seja, não representam exatamente quantidades, mas sim categorias. A análise iniciou com os cálculos do coeficiente Cohen de Kappa para a avaliação da concordância entre os examinadores para cada parâmetro clínico. $\mathrm{Na}$ análise de concordância foi considerado as variáveis com valores agrupados sendo os escores 1, 2 e 3 consideradas “aceitáveis" e 4 e 5 como "inaceitáveis".

Foi realizada também uma análise estatística descritiva para descrever as distribuições dos critérios avaliados através de frequências absolutas.

Com a finalidade de responder aos objetivos do estudo foram utilizados testes estatísticos não paramétricos. Os escores obtidos para cada parâmetro clínico nos grupos experimentais e grupos controles foram dispostos em conjunto e ordenados de forma crescente, atribuindo-lhes os postos correspondentes. A soma de ordenações e postos médios foi calculado e analisado pelo teste estatístico Kruskal-Wallis para avaliar a diferença entre os grupos em cada momento de avaliação. O teste de comparações múltiplas de Dunn foi aplicado para detectar quais grupos diferem entre si. Os testes de hipótese consideraram 5\% de significância, ou seja, a hipótese nula foi rejeitada quando p-valor foi menor que 0,05 .

Todas as análises foram realizadas usando o software IBM SPSS Statistics versão 20,0 para Windows (SPSS Inc., Armonk, NY, USA). 

4. Resultados 



\section{RESULTADOS}

\subsection{População de estudo}

Com a finalidade de atingir o tamanho de amostra proposta inicialmente, um total de 230 voluntários foram avaliados de acordo com os critérios de elegibilidade entre dezembro de 2014 e junho de 2015. Após avaliação inicial, 66 voluntários atenderam os critérios de inclusão, os quais foram selecionados para participar no estudo. Vinte e oito $(42,4 \%)$ dos participantes selecionados eram homens e 38 (57,6\%) mulheres com idade entre 18 e 50 anos (média de 32,15 $\pm 7,80$ ) (Tabela 4).

Os participantes receberam um total de 92 restaurações, alocadas aleatoriamente no Grupo $1(\mathrm{~N}=23)$, no Grupo $2(\mathrm{~N}=23)$, no Grupo $3(\mathrm{~N}=24)$ e no Grupo $4(\mathrm{~N}=22)$. Cada participante contribuiu no mínimo com uma restauração e no máximo com quatro restaurações. Aproximadamente $73 \%$ das restaurações foram realizadas em molares e $27 \%$ em pré-molares, sendo que $63 \%$ do total de restaurações foram cavidades Classe I e $37 \%$ Classe II. A distribuição das restaurações de acordo com tipo de dente e classe de restauração está descrita na Tabela 5 .

No período de follow-up ou de avaliação das restaurações, houve uma perda de cinco participantes na avaliação inicial (após uma semana) devido às faltas na consulta de retorno, representando uma perda de sete restaurações (3 no Grupo 1, 3 no Grupo 2 e 1 no Grupo 4).

$\mathrm{Na}$ avaliação de 6 meses, nove participantes não compareceram aos retornos, representando a perda de nove restaurações (2 no Grupo 1, 3 no Grupo 2, 1 no Grupo 3 e três no Grupo 4). Adicionalmente, dois participantes foram excluídos do estudo (devido à substituição da restauração por apresentar hipersensibilidade pós-operatória e exodontia do dente restaurado por finalidade protética) representando a perda de duas restaurações (2 no Grupo 1).

$\mathrm{Na}$ avaliação de 12 meses, dois participantes desistiram de participar no estudo devido à mudança fora da região e por apresentar problemas de saúde de alto risco respectivamente, representando a perda de duas restaurações (1 no Grupo 1 e 1 no Grupo 4).

Por fim, na avaliação de 18 meses, seis participantes não permaneceram no estudo, representando a perda de 11 restaurações (5 no Grupo 1, 4 no Grupo 2 e 2 no Grupo 3). As razões foram o não comparecimento às consultas de quatro participantes, falecimento de um participante por acidente automobilístico e a exclusão do estudo de um participante devido a substituição realizada advinda da perda total da restauração. Assim, um total de 42 
participantes $(63,6 \%)$ e 61 restaurações $(66,3 \%)$ foram acompanhadas para avaliação ao longo de 18 meses. A Figura 3 ilustra o fluxo de participantes durante o estudo.

Tabela 4 - Distribuição de sexo e idade dos participantes que receberam tratamento de intervenção.

\begin{tabular}{ll}
\hline & Número de participantes $(\%)$ \\
\hline Sexo & $28(42,42 \%)$ \\
Masculino & $38(57,58 \%)$ \\
Feminino & $66(100 \%)$ \\
Total & \\
& \\
Idade (anos) & $32(48 \%)$ \\
18-30 & $34(52 \%)$ \\
$30-50$ & 32,15 \\
Média & 7,80 \\
Desvio padrão & 33,50 \\
Mediana & \\
\hline
\end{tabular}

Tabela 5 - Distribuição das restaurações que receberam tratamento de intervenção de acordo como o dente e a classe.

\begin{tabular}{cccccc}
\hline \multirow{2}{*}{ Grupos } & \multicolumn{2}{c}{ Pré-molares } & & \multicolumn{2}{c}{ Molares } \\
\cline { 2 - 3 } \cline { 5 - 6 } & Classe I & Classe II & & Classe I & Classe II \\
\hline Grupo 1 & $1(1,09 \%)$ & $8(8,70 \%)$ & & $9(9,78 \%)$ & $5(5,43 \%)$ \\
Grupo 2 & $4(4,35 \%)$ & $4(4,35 \%)$ & & $9(9,78 \%)$ & $6(6,52 \%)$ \\
Grupo 3 & $0(0 \%)$ & $2(2,17 \%)$ & & $20(21,74 \%)$ & $2(2,17 \%)$ \\
\hline Trupo 4 & $1(1,09 \%)$ & $5(5,43 \%)$ & & $14(15,22 \%)$ & $2(2,17 \%)$ \\
\hline Total & $6(6,52 \%)$ & $19(20,65 \%)$ & & $52(56,52 \%)$ & $15(16,30 \%)$ \\
\hline
\end{tabular}


Figura 3 - Flow chart (CONSORT).

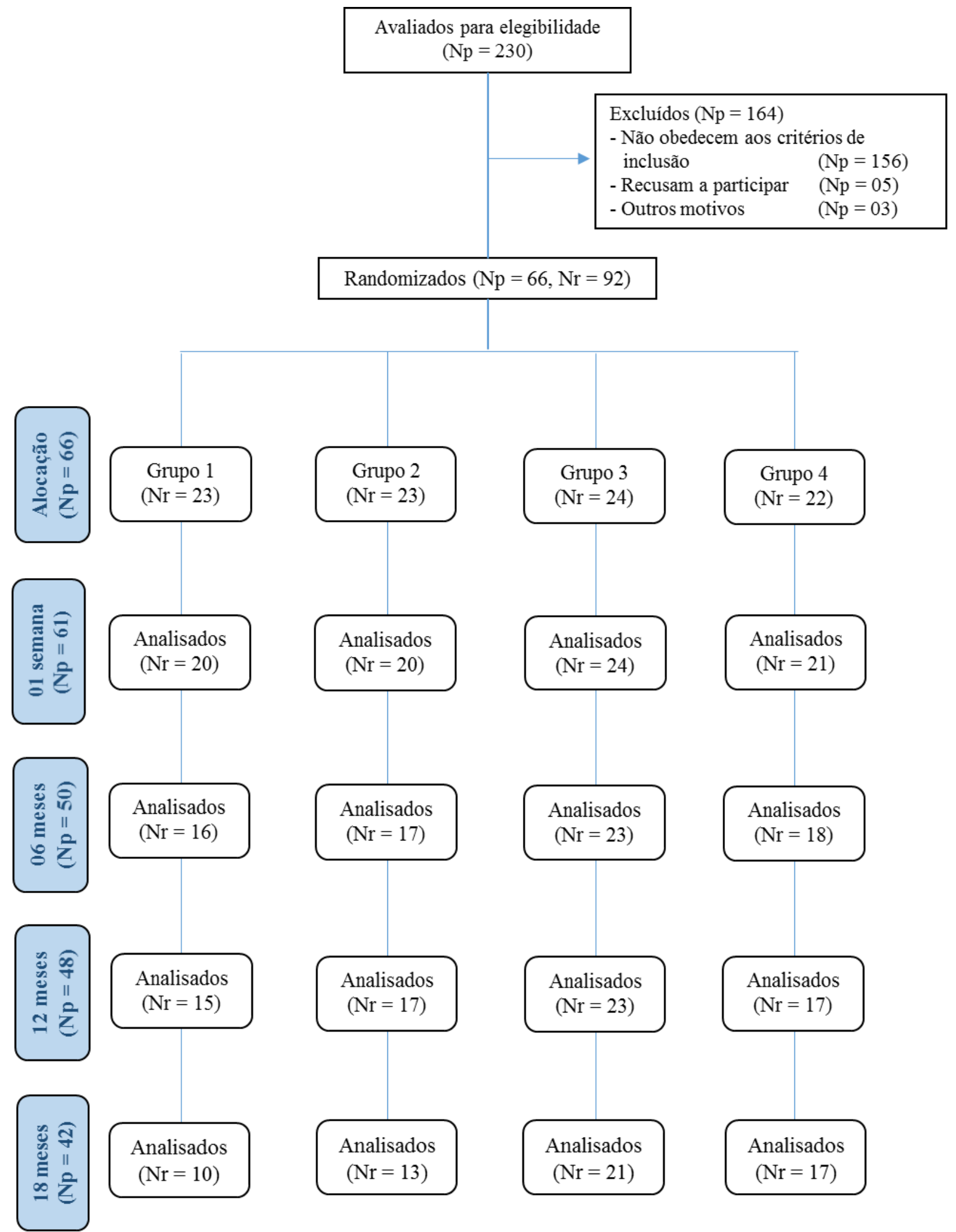

$\mathrm{Np}=$ número de participantes; $\mathrm{Nr}=$ número de restaurações 


\subsection{Avaliação de concordância entre os examinadores}

A análise iniciou com os cálculos do coeficiente Cohen de Kappa para a avaliação da concordância entre os examinadores. A Tabela 6 apresenta os valores do coeficiente Kappa e respectivas interpretações.

Tabela 6 - Interpretação do coeficiente Kappa.

\begin{tabular}{cl}
\hline Kappa & Concordância \\
\hline$<0.00$ & Nenhuma \\
$0.00-0.20$ & Leve \\
$0.21-0.40$ & Justa \\
$0.41-0.60$ & Moderada \\
$0.61-0.80$ & Boa \\
$0.81-0.99$ & Ótima \\
1 & Perfeita \\
\hline
\end{tabular}

Adaptado de Landis e Koch (1977)(81)

Na Tabela 7 temos os valores de Kappa para a amostra geral. Observamos valores interpretados como concordância Perfeita (Coeficiente Kappa $=1,00)$ para todas as variáveis das propriedades estéticas e biológicas bem como as variáveis contorno oclusal e desgaste e forma anatômica proximal. Observou-se ainda valores altos para adaptação marginal (Coeficiente Kappa = 0,80) indicando boa concordância e valores de ótima concordância para a opinião do paciente (Coeficiente Kappa $=0,91)$ e fratura do material e retenção $(0,81)$. 
Tabela 7 - Coeficiente de Kappa geral para concordância entre os avaliadores para dados agregados $(1,2$ e 3 ) aceitável e (4 e 5) inaceitável.

\begin{tabular}{|c|c|c|c|}
\hline Variável & \multicolumn{2}{|c|}{ IC $95 \%$} & Kappa \\
\hline \multicolumn{4}{|l|}{ Propriedades estéticas } \\
\hline Brilho superficial & 1,00 & 1,00 & 1,00 \\
\hline Manchamento marginal & 1,00 & 1,00 & 1,00 \\
\hline Estabilidade de cor e translucidez & 1,00 & 1,00 & 1,00 \\
\hline Forma anatômica & 1,00 & 1,00 & 1,00 \\
\hline \multicolumn{4}{|l|}{ Propriedades funcionais } \\
\hline Fratura do material e retenção & 0,67 & 0,96 & 0,81 \\
\hline Adaptação marginal & 0,52 & 1,00 & 0,80 \\
\hline Contorno oclusal e desgaste & 1,00 & 1,00 & 1,00 \\
\hline Forma anatômica proximal & 1,00 & 1,00 & 1,00 \\
\hline Avaliação radiográfica & - & - & - \\
\hline Opinião do paciente & 0,73 & 1,00 & 0,91 \\
\hline \multicolumn{4}{|l|}{ Propriedades biológicas } \\
\hline Hipersensibilidade & 1,00 & 1,00 & 1,00 \\
\hline Recorrência de cárie & 1,00 & 1,00 & 1,00 \\
\hline Integridade dental & 1,00 & 1,00 & 1,00 \\
\hline Resposta periodontal & 1,00 & 1,00 & 1,00 \\
\hline Mucosa adjacente & 1,00 & 1,00 & 1,00 \\
\hline Saúde oral e geral & 1,00 & 1,00 & 1,00 \\
\hline
\end{tabular}

IC: intervalo de confiança

\subsection{Análise estatística descritiva}

As tabelas 8-10 mostram o número de restaurações avaliadas com valores de escores 1 (clinicamente muito bom) a 5 (clinicamente insatisfatório com indicação de substituição) para cada uma das propriedades de acordo com os critérios FDI ao longo de 18 meses. A figura 4 ilustra de forma representativa as restaurações clinicamente aceitáveis (escore 1, 2 ou 3).

\subsubsection{Propriedades estéticas}

De forma geral, as restaurações de todos os grupos avaliadas ao longo de 18 meses, obtiveram escore 1, 2 ou 3 (consideradas clinicamente aceitáveis) em todos os critérios estéticos a exceção de duas restaurações do grupo 3 (8\%) que receberam escore 5 (uma aos 12 meses e outras aos 18 meses) (Tabela 8). 
De forma específica, para cada critério, observou-se:

- Brilho Superficial: inicialmente (uma semana) houve maior frequência do escore 1 para o grupo 1 e 2 e do escore 2 para o grupo 3 e 4 . Nas avaliações seguintes, houve uma tendência do grupo 1 e 2 a uma diminuição do escore 1 e aumento do escore 2.

- Manchamento Marginal: inicialmente (uma semana) houve maior frequência do escore 1 para todos os grupos. Nas próximas avaliações, observou-se uma tendência a uma diminuição do escore 1 e um aumento da frequência do escore 2.

- Estabilidade de Cor: em todas as avaliações houve maior frequência do escore 1 para o grupo 2 e do escore 2 para os grupos 1,3 e 4 .

- Forma Anatômica: em todas as avaliações e para todos os grupos houve maior frequência do escore 2. Adicionalmente, verificou-se na avaliação de uma semana a ocorrência do escore 3 em 6 restaurações do grupo 3 e em 8 restaurações do grupo 4. 
Tabela 8 - Estatística descritiva para as propriedades estéticas. Frequência absoluta para cada propriedade e tempo de avaliação.

\begin{tabular}{|c|c|c|c|c|c|c|c|c|c|c|c|c|c|c|c|c|c|c|c|c|c|}
\hline \multirow{3}{*}{$\begin{array}{c}\text { Propriedades } \\
\text { estéticas }\end{array}$} & \multirow{3}{*}{$\begin{array}{l}\text { Tempo de } \\
\text { avaliação }\end{array}$} & \multicolumn{20}{|c|}{ Grupo } \\
\hline & & \multicolumn{5}{|c|}{1} & \multicolumn{5}{|c|}{2} & \multicolumn{5}{|c|}{3} & \multicolumn{5}{|c|}{4} \\
\hline & & 1 & 2 & 3 & 4 & 5 & 1 & 2 & 3 & 4 & 5 & 1 & 2 & 3 & 4 & 5 & 1 & 2 & 3 & 4 & 5 \\
\hline \multirow[t]{4}{*}{ Brilho Superficial } & 1 semana & 11 & 7 & 2 & 0 & 0 & 11 & 9 & 0 & 0 & 0 & 9 & 13 & 2 & 0 & 0 & 5 & 11 & 5 & 0 & 0 \\
\hline & 06 meses & 8 & 7 & 1 & 0 & 0 & 7 & 8 & 2 & 0 & 0 & 12 & 10 & 1 & 0 & 0 & 5 & 12 & 1 & 0 & 0 \\
\hline & 12 meses & 6 & 9 & 0 & 0 & 0 & 10 & 7 & 0 & 0 & 0 & 9 & 11 & 2 & 0 & 1 & 5 & 9 & 3 & 0 & 0 \\
\hline & 18 meses & 4 & 5 & 1 & 0 & 0 & 5 & 8 & 0 & 0 & 0 & 7 & 12 & 1 & 0 & 1 & 7 & 9 & 1 & 0 & 0 \\
\hline Manchamento & 1 semana & 11 & 9 & 0 & 0 & 0 & 11 & 8 & 1 & 0 & 0 & 14 & 10 & 0 & 0 & 0 & 12 & 8 & 1 & 0 & 0 \\
\hline \multirow[t]{3}{*}{ Marginal } & 06 meses & 9 & 7 & 0 & 0 & 0 & 6 & 11 & 0 & 0 & 0 & 9 & 13 & 1 & 0 & 0 & 11 & 7 & 0 & 0 & 0 \\
\hline & 12 meses & 6 & 7 & 2 & 0 & 0 & 5 & 11 & 1 & 0 & 0 & 4 & 17 & 1 & 0 & 1 & 5 & 12 & 0 & 0 & 0 \\
\hline & 18 meses & 1 & 8 & 1 & 0 & 0 & 3 & 9 & 1 & 0 & 0 & 3 & 16 & 1 & 0 & 1 & 4 & 12 & 1 & 0 & 0 \\
\hline \multirow[t]{3}{*}{ Translucidez } & 06 meses & 6 & 10 & 0 & 0 & 0 & 8 & 9 & 0 & 0 & 0 & 10 & 13 & 0 & 0 & 0 & 7 & 10 & 1 & 0 & 0 \\
\hline & 12 meses & 6 & 9 & 0 & 0 & 0 & 9 & 8 & 0 & 0 & 0 & 7 & 15 & 0 & 0 & 1 & 5 & 12 & 0 & 0 & 0 \\
\hline & 18 meses & 7 & 2 & 1 & 0 & 0 & 9 & 4 & 0 & 0 & 0 & 7 & 12 & 1 & 0 & 1 & 7 & 9 & 1 & 0 & 0 \\
\hline \multirow[t]{4}{*}{ Forma Anatômica } & 1 semana & 3 & 14 & 3 & 0 & 0 & 7 & 10 & 3 & 0 & 0 & 5 & 13 & 6 & 0 & 0 & 0 & 13 & 8 & 0 & 0 \\
\hline & 06 meses & 1 & 14 & 1 & 0 & 0 & 2 & 14 & 1 & 0 & 0 & 1 & 20 & 2 & 0 & 0 & 1 & 15 & 2 & 0 & 0 \\
\hline & 12 meses & 1 & 12 & 2 & 0 & 0 & 1 & 15 & 1 & 0 & 0 & 0 & 20 & 2 & 0 & 1 & 1 & 14 & 2 & 0 & 0 \\
\hline & 18 meses & 0 & 9 & 1 & 0 & 0 & 0 & 13 & 0 & 0 & 0 & 1 & 16 & 3 & 0 & 1 & 2 & 14 & 1 & 0 & 0 \\
\hline
\end{tabular}




\subsubsection{Propriedades funcionais}

De forma geral, todos os grupos ao longo dos 18 meses mostraram maior frequência do escore 1 para os critérios Fratura do Material e Retenção, Contorno Oclusal e Desgaste, Forma Anatômica Proximal e Opinião do Paciente e do escore 2 para o critério Adaptação Marginal. Embora com menor frequência, houve também restaurações com escore 4 ou 5 (Tabela 9).

De forma específica, para cada critério, observou-se:

- Fratura do Material e Retenção: em todas as avaliações e para todos os grupos houve maior frequência do escore 1 , seguido do escore 2 e do escore 3 . Porém, observou-se restaurações com escore 4 ou 5 (clinicamente inaceitável) ao longo dos 18 meses: na avaliação de 01 semana, no grupo 4 (10\%); na avaliação de 06 meses, no grupo 2 (10\%), grupo 3 (8\%) e grupo 4 (5\%); na avaliação de 12 meses, no grupo $1(1 \%)$, grupo $3(8 \%)$ e grupo $4(5 \%)$ e na avaliação de 18 meses, no grupo $3(21 \%)$ e grupo $4(5 \%)$.

- Adaptação Marginal: em todas as avaliações e para todos os grupos houve maior frequência do escore 2. Além disso, todas as restaurações receberam escore 1, 2 ou 3, a exceção do grupo 3, que apresentou escore 4 ou 5 em 2 restaurações ( $8 \%$ ) aos 12 meses e em 2 restaurações (8\%) aos 18 meses.

- Contorno Oclusal e Desgaste: em todas as avaliações e para todos os grupos houve maior frequência do escore 1 , seguida do escore 2 e escore 3 . Assim, todas as restaurações obtiveram escore 1,2 ou 3 , a exceção do grupo 3 , onde verificouse o escore 5 em uma restauração aos 12 meses (4\%) e 18 meses (4\%).

- Forma Anatômica Proximal: em todas as avaliações e para todos os grupos, as restaurações classe II, obtiveram escore 1, 2 ou 3, a exceção do grupo 3 que apresentou uma restauração (4\%) com escore 5 aos 12 meses.

- Avaliação Radiográfica: houve apenas a necessidade de avaliação radiográfica de uma restauração do grupo 1 (5\%), uma do grupo 3 (4\%) após uma semana e uma do grupo 4 (5\%) após 12 meses, resultando em escore 3 para todos os casos.

- Opinião do Paciente: em todas as avaliações e para todos os grupos houve maior frequência do escore 1. Verificou-se, na avaliação de uma semana, escore $4 \mathrm{em}$ duas restaurações do grupo 1 (10\%), em uma restauração do grupo 3 (4\%) e em três restaurações do grupo 4 (15\%). 
Tabela 9 - Estatística descritiva para as propriedades funcionais. Frequência absoluta para cada propriedade e tempo de avaliação.

\begin{tabular}{|c|c|c|c|c|c|c|c|c|c|c|c|c|c|c|c|c|c|c|c|c|c|}
\hline \multirow{3}{*}{$\begin{array}{l}\text { Propriedades } \\
\text { funcionais }\end{array}$} & \multirow{3}{*}{$\begin{array}{l}\text { Tempo de } \\
\text { avaliação }\end{array}$} & \multicolumn{20}{|c|}{ Grupo } \\
\hline & & \multicolumn{5}{|c|}{1} & \multicolumn{5}{|c|}{2} & \multicolumn{5}{|c|}{3} & \multicolumn{5}{|c|}{4} \\
\hline & & 1 & 2 & 3 & 4 & 5 & 1 & 2 & 3 & 4 & 5 & 1 & 2 & 3 & 4 & 5 & 1 & 2 & 3 & 4 & 5 \\
\hline \multirow{4}{*}{$\begin{array}{l}\text { Fratura do material } \\
\text { e Retenção }\end{array}$} & 1 semana & 18 & 1 & 1 & 0 & 0 & 20 & 0 & 0 & 0 & 0 & 20 & 3 & 1 & 0 & 0 & 17 & 2 & 0 & 2 & 0 \\
\hline & 06 meses & 14 & 0 & 2 & 0 & 0 & 14 & 1 & 0 & 2 & 0 & 16 & 3 & 2 & 2 & 0 & 17 & 0 & 0 & 1 & 0 \\
\hline & 12 meses & 14 & 0 & 0 & 1 & 0 & 15 & 1 & 1 & 0 & 0 & 16 & 2 & 3 & 1 & 1 & 11 & 5 & 0 & 1 & 0 \\
\hline & 18 meses & 7 & 1 & 2 & 0 & 0 & 13 & 0 & 0 & 0 & 0 & 12 & 2 & 2 & 4 & 1 & 14 & 2 & 0 & 1 & 0 \\
\hline \multirow{4}{*}{$\begin{array}{l}\text { Adaptação } \\
\text { Marginal }\end{array}$} & 1 semana & 3 & 16 & 1 & 0 & 0 & 8 & 11 & 1 & 0 & 0 & 1 & 20 & 3 & 0 & 0 & 1 & 17 & 3 & 0 & 0 \\
\hline & 06 meses & 1 & 14 & 1 & 0 & 0 & 2 & 12 & 3 & 0 & 0 & 0 & 22 & 1 & 0 & 0 & 0 & 15 & 3 & 0 & 0 \\
\hline & 12 meses & 0 & 13 & 1 & 1 & 0 & 1 & 15 & 1 & 0 & 0 & 1 & 16 & 4 & 1 & 1 & 0 & 11 & 6 & 0 & 0 \\
\hline & 18 meses & 2 & 6 & 2 & 0 & 0 & 2 & 11 & 0 & 0 & 0 & 0 & 15 & 4 & 1 & 1 & 0 & 10 & 7 & 0 & 0 \\
\hline \multirow{4}{*}{$\begin{array}{l}\text { Contorno Oclusal e } \\
\text { Desgaste }\end{array}$} & 1 semana & 19 & 0 & 0 & 0 & 0 & 20 & 0 & 0 & 0 & 0 & 23 & 1 & 0 & 0 & 0 & 21 & 0 & 0 & 0 & 0 \\
\hline & 06 meses & 15 & 0 & 0 & 0 & 0 & 17 & 0 & 0 & 0 & 0 & 23 & 0 & 0 & 0 & 0 & 18 & 0 & 0 & 0 & 0 \\
\hline & 12 meses & 13 & 1 & 0 & 0 & 0 & 13 & 4 & 0 & 0 & 0 & 19 & 3 & 0 & 0 & 1 & 15 & 2 & 0 & 0 & 0 \\
\hline & 18 meses & 8 & 2 & 0 & 0 & 0 & 13 & 0 & 0 & 0 & 0 & 15 & 4 & 1 & 0 & 1 & 15 & 2 & 0 & 0 & 0 \\
\hline \multirow{4}{*}{$\begin{array}{l}\text { Forma Anatômica } \\
\text { Proximal }\end{array}$} & 1 semana & 8 & 1 & 3 & 0 & 0 & 5 & 2 & 1 & 0 & 0 & 2 & 0 & 1 & 0 & 0 & 7 & 0 & 0 & 0 & 0 \\
\hline & 06 meses & 7 & 2 & 2 & 0 & 0 & 6 & 0 & 0 & 0 & 0 & 2 & 0 & 1 & 0 & 0 & 3 & 2 & 0 & 0 & 0 \\
\hline & 12 meses & 8 & 0 & 2 & 0 & 0 & 4 & 0 & 2 & 0 & 0 & 1 & 0 & 1 & 0 & 1 & 5 & 0 & 0 & 0 & 0 \\
\hline & 18 meses & 6 & 1 & 0 & 0 & 0 & 5 & 0 & 0 & 0 & 0 & 1 & 0 & 1 & 0 & 0 & 3 & 2 & 0 & 0 & 0 \\
\hline \multirow{4}{*}{$\begin{array}{l}\text { Avaliação } \\
\text { Radiográfica }\end{array}$} & 1 semana & - & - & 1 & - & - & - & - & - & - & - & - & - & 1 & - & - & - & - & - & - & - \\
\hline & 06 meses & - & - & - & - & - & - & - & - & - & - & - & - & - & - & - & - & - & - & - & - \\
\hline & 12 meses & - & - & - & - & - & - & - & - & - & - & - & - & - & - & - & - & - & 1 & - & - \\
\hline & 18 meses & - & - & - & - & - & - & - & - & - & - & - & - & - & - & - & - & - & - & - & - \\
\hline \multirow{4}{*}{$\begin{array}{l}\text { Opinião do } \\
\text { Paciente }\end{array}$} & 1 semana & 18 & 0 & 0 & 2 & 0 & 20 & 0 & 0 & 0 & 0 & 20 & 1 & 2 & 1 & 0 & 16 & 1 & 1 & 3 & 0 \\
\hline & 06 meses & 16 & 0 & 0 & 0 & 0 & 17 & 0 & 0 & 0 & 0 & 23 & 0 & 0 & 0 & 0 & 18 & 0 & 0 & 0 & 0 \\
\hline & 12 meses & 15 & 0 & 0 & 0 & 0 & 17 & 0 & 0 & 0 & 0 & 22 & 1 & 0 & 0 & 0 & 17 & 0 & 0 & 0 & 0 \\
\hline & 18 meses & 10 & 0 & 0 & 0 & 0 & 13 & 0 & 0 & 0 & 0 & 21 & 0 & 0 & 0 & 0 & 17 & 0 & 0 & 0 & 0 \\
\hline
\end{tabular}




\subsubsection{Propriedades biológicas}

A Tabela 10 mostra a frequência absoluta para as propriedades biológicas.

- Hipersensibilidade Pós-operatória: em todas as avaliações e para todos os grupos houve maior frequência do escore 1. Identificou-se escore 4 apenas em uma restauração (5\%) do grupo 1.

- Recorrência de Cárie: em todas as avaliações e para todos os grupos houve maior frequência do escore 1 , ou seja, sem cárie primária ou secundária. Restaurações com escore 2 ou 3 foram menos frequentes, onde medidas preventivas foram necessárias. Reportou-se, na avaliação de 06 meses, escore 4 em uma restauração (5\%) do grupo 4 com cárie com cavitação e suspeita de cárie sob restauração.

- Integridade Dental: em todas as avaliações e para todos os grupos houve maior frequência do escore 1 , seguida do escore 2 e escore 3 . Observou-se o escore 4 apenas em uma restauração (4\%) do grupo 4 na avaliação de uma semana.

- Resposta Periodontal, Mucosa Adjacente e Saúde Oral e Geral: em todas as avaliações e para todos os grupos reportaram-se escore 1, 2 ou 3 para esses critérios, não havendo situações de insucesso. 
Tabela 10 - Estatística descritiva para as propriedades biológicas. Frequência absoluta para cada propriedade e tempo de avaliação.

\begin{tabular}{|c|c|c|c|c|c|c|c|c|c|c|c|c|c|c|c|c|c|c|c|c|c|}
\hline \multirow[b]{3}{*}{ Propriedades biológicas } & \multirow{3}{*}{$\begin{array}{l}\text { Tempo de } \\
\text { avaliação }\end{array}$} & \multicolumn{20}{|c|}{ Grupo } \\
\hline & & \multicolumn{5}{|c|}{1} & \multicolumn{5}{|c|}{2} & \multicolumn{5}{|c|}{3} & \multicolumn{5}{|c|}{4} \\
\hline & & 1 & 2 & 3 & 4 & 5 & 1 & 2 & 3 & 4 & 5 & 1 & 2 & 3 & 4 & 5 & 1 & 2 & 3 & 4 & 5 \\
\hline \multirow[t]{4}{*}{ Hipersensibilidade } & 1 semana & 17 & 2 & 0 & 1 & 0 & 18 & 2 & 0 & 0 & 0 & 20 & 3 & 0 & 0 & 0 & 19 & 1 & 1 & 0 & 0 \\
\hline & 06 meses & 15 & 0 & 1 & 0 & 0 & 16 & 1 & 0 & 0 & 0 & 23 & 0 & 0 & 0 & 0 & 18 & 0 & 0 & 0 & 0 \\
\hline & 12 meses & 15 & 0 & 0 & 0 & 0 & 16 & 1 & 0 & 0 & 0 & 23 & 0 & 0 & 0 & 0 & 17 & 0 & 0 & 0 & 0 \\
\hline & 18 meses & 10 & 0 & 0 & 0 & 0 & 13 & 0 & 0 & 0 & 0 & 19 & 1 & 1 & 0 & 0 & 17 & 0 & 0 & 0 & 0 \\
\hline \multirow[t]{4}{*}{ Recorrência de Cárie } & 1 semana & 18 & 2 & 0 & 0 & 0 & 18 & 2 & 0 & 0 & 0 & 23 & 1 & 0 & 0 & 0 & 21 & 0 & 0 & 0 & 0 \\
\hline & 06 meses & 16 & 0 & 0 & 0 & 0 & 16 & 1 & 0 & 0 & 0 & 23 & 0 & 0 & 0 & 0 & 16 & 1 & 0 & 1 & 0 \\
\hline & 12 meses & 15 & 0 & 0 & 0 & 0 & 17 & 0 & 0 & 0 & 0 & 22 & 1 & 0 & 0 & 0 & 16 & 0 & 1 & 0 & 0 \\
\hline & 18 meses & 9 & 1 & 0 & 0 & 0 & 13 & 0 & 0 & 0 & 0 & 20 & 0 & 1 & 0 & 0 & 17 & 0 & 0 & 0 & 0 \\
\hline \multirow[t]{4}{*}{ Integridade Dental } & 1 semana & 17 & 2 & 1 & 0 & 0 & 17 & 2 & 1 & 0 & 0 & 22 & 2 & 0 & 0 & 0 & 17 & 2 & 1 & 1 & 0 \\
\hline & 06 meses & 15 & 1 & 0 & 0 & 0 & 15 & 2 & 0 & 0 & 0 & 23 & 0 & 0 & 0 & 0 & 18 & 0 & 0 & 0 & 0 \\
\hline & 12 meses & 14 & 0 & 1 & 0 & 0 & 17 & 0 & 0 & 0 & 0 & 22 & 0 & 1 & 0 & 0 & 16 & 0 & 1 & 0 & 0 \\
\hline & 18 meses & 9 & 1 & 0 & 0 & 0 & 13 & 0 & 0 & 0 & 0 & 21 & 0 & 0 & 0 & 0 & 16 & 0 & 1 & 0 & 0 \\
\hline \multirow[t]{4}{*}{ Resposta Periodontal } & 1 semana & 6 & 11 & 3 & 0 & 0 & 4 & 9 & 7 & 0 & 0 & 2 & 16 & 6 & 0 & 0 & 2 & 13 & 6 & 0 & 0 \\
\hline & 06 meses & 5 & 9 & 2 & 0 & 0 & 1 & 14 & 2 & 0 & 0 & 2 & 17 & 4 & 0 & 0 & 4 & 11 & 3 & 0 & 0 \\
\hline & 12 meses & 0 & 14 & 1 & 0 & 0 & 2 & 12 & 3 & 0 & 0 & 1 & 18 & 4 & 0 & 0 & 2 & 12 & 3 & 0 & 0 \\
\hline & 18 meses & 1 & 7 & 2 & 0 & 0 & 1 & 9 & 3 & 0 & 0 & 2 & 15 & 4 & 0 & 0 & 1 & 14 & 2 & 0 & 0 \\
\hline \multirow[t]{4}{*}{ Mucosa Adjacente } & 1 semana & 19 & 0 & 1 & 0 & 0 & 20 & 0 & 0 & 0 & 0 & 23 & 0 & 1 & 0 & 0 & 20 & 0 & 1 & 0 & 0 \\
\hline & 06 meses & 15 & 0 & 1 & 0 & 0 & 17 & 0 & 0 & 0 & 0 & 22 & 0 & 1 & 0 & 0 & 18 & 0 & 0 & 0 & 0 \\
\hline & 12 meses & 14 & 0 & 1 & 0 & 0 & 17 & 0 & 0 & 0 & 0 & 22 & 1 & 0 & 0 & 0 & 17 & 0 & 0 & 0 & 0 \\
\hline & 18 meses & 9 & 0 & 1 & 0 & 0 & 13 & 0 & 0 & 0 & 0 & 21 & 0 & 0 & 0 & 0 & 17 & 0 & 0 & 0 & 0 \\
\hline \multirow[t]{4}{*}{ Saúde Oral e Geral } & 1 semana & 9 & 8 & 3 & 0 & 0 & 11 & 7 & 2 & 0 & 0 & 12 & 9 & 3 & 0 & 0 & 11 & 8 & 2 & 0 & 0 \\
\hline & 06 meses & 8 & 7 & 1 & 0 & 0 & 7 & 9 & 1 & 0 & 0 & 9 & 12 & 2 & 0 & 0 & 10 & 6 & 2 & 0 & 0 \\
\hline & 12 meses & 5 & 10 & 0 & 0 & 0 & 6 & 11 & 0 & 0 & 0 & 6 & 17 & 0 & 0 & 0 & 9 & 8 & 0 & 0 & 0 \\
\hline & 18 meses & 4 & 6 & 0 & 0 & 0 & 5 & 8 & 0 & 0 & 0 & 7 & 13 & 1 & 0 & 0 & 6 & 10 & 1 & 0 & 0 \\
\hline
\end{tabular}


Figura 4 - Avaliação clínica das restaurações após 01 semana, 06, 12 e 18 meses. Restaurações clinicamente aceitáveis (escore 1, 2 ou 3) para as propriedades estéticas (Brilho superficial manchamento marginal, estabilidade de cor e forma anatômica), funcionais (Fratura do material e retenção, adaptação marginal, contorno oclusal e desgaste) e biológicas (Recorrência de cárie e integridade dental).

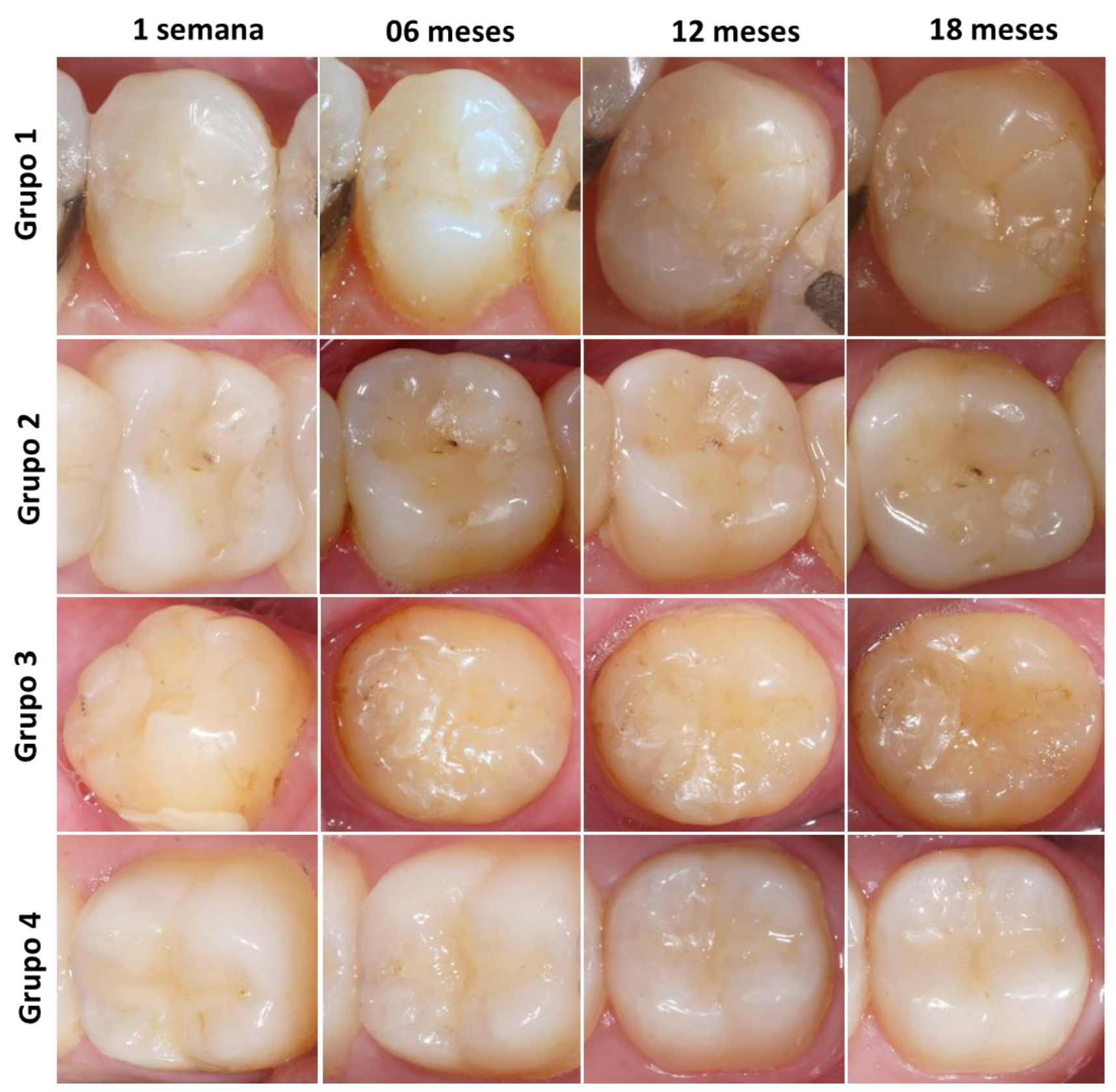


Por fim, a Tabela 11 mostra os casos de restaurações clinicamente inaceitáveis durante o estudo.

Tabela 11 - Restaurações clinicamente inaceitáveis (escore 4 ou 5) de acordo com os critérios FDI.

\begin{tabular}{|c|c|c|c|c|}
\hline Tempo & Critério & Escore & Grupo & Dente/Classe \\
\hline \multicolumn{5}{|c|}{1 semana } \\
\hline & Fratura e retenção e Opinião do paciente & 4 & 4 & $36 / \mathrm{II}$ \\
\hline & Fratura e retenção e Opinião do paciente & 4 & 4 & $37 / \mathrm{I}$ \\
\hline & Hipersensibilidade e Opinião do paciente & 4 & 1 & 27/II \\
\hline & Integridade dental & 4 & 4 & 28/I \\
\hline & Opinião do paciente & 4 & 1 & 27/I \\
\hline & Opinião do paciente & 4 & 4 & $48 / \mathrm{I}$ \\
\hline \multicolumn{5}{|c|}{06 meses } \\
\hline & Fratura e retenção & 4 & 2 & $27 / \mathrm{I}$ \\
\hline & Fratura e retenção & 4 & 4 & $37 / \mathrm{I}$ \\
\hline & Fratura e retenção & 4 & 3 & 34/II \\
\hline & Fratura e retenção & 4 & 2 & $38 / I^{\Omega}$ \\
\hline & Fratura e retenção & 4 & 3 & $47 / I^{\Omega}$ \\
\hline & Recorrência de cárie & 4 & 4 & 28/I \\
\hline \multicolumn{5}{|c|}{12 meses } \\
\hline & Fratura e retenção & 4 & 4 & 25/II \\
\hline & Fratura e retenção e Adaptação marginal & 4 & 1 & $14 / \mathrm{II}$ \\
\hline & Fratura e retenção e Adaptação marginal & 4 & 3 & $17 / \mathrm{II}$ \\
\hline & Fratura e retenção & 5 & 3 & $17 / \mathrm{II} *$ \\
\hline \multicolumn{5}{|c|}{18 meses } \\
\hline & Fratura e retenção & 4 & 4 & $48 / \mathrm{I}^{\delta}$ \\
\hline & Fratura e retenção & 4 & 3 & $28 / \mathrm{I}^{\delta}$ \\
\hline & Fratura e retenção & 4 & 3 & $37 / \mathrm{I}$ \\
\hline & Fratura e retenção & 4 & 3 & $48 / \mathrm{I}$ \\
\hline & Fratura e retenção & 5 & 3 & $27 / I *$ \\
\hline & Fratura e retenção & 4 & 3 & $48 / \mathrm{I}$ \\
\hline
\end{tabular}

$\Omega, \delta$ : restaurações de um mesmo participante

*: restaurações que receberam escore 5 para todos os critérios funcionais (a exceção dos itens Avaliação

Radiográfica e Opinião do paciente) e estéticos. 


\subsection{Análise comparativa}

\subsubsection{Comparação dos grupos em cada tempo de avaliação}

Para avaliar a diferença entre os grupos em cada momento foi aplicado o teste de Kruskal-Wallis. Observamos na Tabela 12 que houve diferença estatisticamente significativa apenas para as variáveis: Forma Anatômica na avaliação de 1 semana (p-valor 0,036); Fratura do Material e Retenção na avaliação de 18 meses (p-valor 0,026) e Adaptação Marginal na avaliação de uma semana (p-valor 0,010) e 18 meses (p-valor 0,021).

Tabela 12 - Teste de Kruskal-Wallis para comparação entre os grupos em cada variável e tempo de avaliação.

\begin{tabular}{|c|c|c|c|c|}
\hline \multirow{3}{*}{ Variáveis } & \multicolumn{4}{|c|}{ p-valor } \\
\hline & \multicolumn{4}{|c|}{ Tempo de avaliação } \\
\hline & 1 semana & 06 meses & 12 meses & 18 meses \\
\hline \multicolumn{5}{|l|}{ Propriedades estéticas } \\
\hline Brilho superficial & 0,052 & 0,480 & 0,200 & 0,918 \\
\hline Manchamento marginal & 0.998 & 0,300 & 0,604 & 0,752 \\
\hline Estabilidade de cor & 0,099 & 0,902 & 0,396 & 0,113 \\
\hline Forma anatômica & $0,036 *$ & 0,812 & 0,759 & 0,382 \\
\hline \multicolumn{5}{|l|}{ Propriedades funcionais } \\
\hline Fratura do material e retenção & 0,233 & 0,259 & 0,161 & $0,026 *$ \\
\hline Adaptação marginal & $0,010 *$ & 0,613 & 0,162 & $0,021 *$ \\
\hline Contorno oclusal e desgaste & 0,475 & 1,000 & 0,616 & 0,150 \\
\hline Forma anatômica proximal & 0,370 & 0,410 & 0,153 & 0,283 \\
\hline Opinião do paciente & 0,143 & 1,000 & 0,546 & 1,000 \\
\hline \multicolumn{5}{|l|}{ Propriedades biológicas } \\
\hline Hipersensibilidade & 0,859 & 0,470 & 0,357 & 0,276 \\
\hline Recorrência de cárie & 0,452 & 0,253 & 0,632 & 0,477 \\
\hline Integridade dental & 0,735 & 0,215 & 0,781 & 0,415 \\
\hline Resposta periodontal & 0,304 & 0,444 & 0,954 & 0,962 \\
\hline Mucosa adjacente & 0,809 & 0,583 & 0,569 & 0,165 \\
\hline Saúde oral e geral & 0,911 & 0,824 & 0,376 & 0,942 \\
\hline
\end{tabular}

*p-valor estatisticamente significante $(\mathrm{p}<0,05)$

Para avaliar quais grupos diferiam entre si, foi aplicado o teste de comparações múltiplas. Observamos na Tabela 13 e Figura 4 que houve diferença entre: grupos 2 e 4 (pvalor 0,036) na Forma Anatômica na avaliação de 1 semana, sendo que o grupo 4 apresentou maior pontuação do que o grupo 2; grupos 2 e 3 (p-valor 0,044) em Fratura do Material e Retenção na avaliação de 18 meses, sendo que o grupo 3 apresentou maior pontuação do que 
o grupo 2; grupos 2 e 3 (p-valor 0,038) em Adaptação Marginal na avaliação de 1 semana, sendo que o grupo 3 apresentou maior pontuação do que o grupo 2; grupos 2 e 4 (p-valor 0,023) em Adaptação Marginal na avaliação de 18 meses, sendo que o grupo 4 apresentou maior pontuação do que o grupo 2 .

Tabela 13 - Comparações múltiplas (Teste de Dunn) entre grupos para os casos cujos pvalor do teste de Kruskal-Wallis foi significativo.

\begin{tabular}{|c|c|c|c|c|}
\hline \multirow{2}{*}{$\begin{array}{l}\text { Variáveis } \\
\text { Forma anatômica }\end{array}$} & \multirow{2}{*}{$\begin{array}{l}\begin{array}{l}\text { Tempo de } \\
\text { avaliação }\end{array} \\
1 \text { semana }\end{array}$} & \multicolumn{2}{|c|}{$\begin{array}{c}\text { Comparação entre grupos } \\
\text { (médias) }\end{array}$} & \multirow{2}{*}{$\begin{array}{c}\text { p-valor } \\
0,875\end{array}$} \\
\hline & & $1(2,0)$ & $2(1,8)$ & \\
\hline & & $1(2,0)$ & $3(2,0)$ & 1,000 \\
\hline & & $1(2,0)$ & $4(2,5)$ & 0,184 \\
\hline & & $2(1,8)$ & $3(2,0)$ & 0,821 \\
\hline & & $2(1,8)$ & $4(2,5)$ & $0,036 *$ \\
\hline & & $3(2,0)$ & $4(2,5)$ & 0,435 \\
\hline \multirow{6}{*}{$\begin{array}{l}\text { Fratura do material e } \\
\text { retenção }\end{array}$} & 18 meses & $1(0,8)$ & $2(0,7)$ & 0,211 \\
\hline & & $1(0,8)$ & $3(1,9)$ & 0,893 \\
\hline & & $1(0,8)$ & $4(1,1)$ & 0,972 \\
\hline & & $2(0,7)$ & $3(1,9)$ & $0,044 *$ \\
\hline & & $2(0,7)$ & $4(1,1)$ & 0,526 \\
\hline & & $3(1,9)$ & $4(1,1)$ & 0,336 \\
\hline \multirow[t]{12}{*}{ Adaptação marginal } & 1 semana & $1(1,9)$ & $2(1,7)$ & 0,526 \\
\hline & & $1(1,9)$ & $3(2,1)$ & 0,650 \\
\hline & & $1(1,9)$ & $4(2,2)$ & 0,655 \\
\hline & & $2(1,7)$ & $3(2,1)$ & $0,038 *$ \\
\hline & & $2(1,7)$ & $4(2,2)$ & 0,053 \\
\hline & & $3(2,1)$ & $4(2,2)$ & 1,000 \\
\hline & 18 meses & $1(1,0)$ & $2(1,2)$ & 0,988 \\
\hline & & $1(1,0)$ & $3(2,2)$ & 0,668 \\
\hline & & $1(1,0)$ & $4(2,1)$ & 0,489 \\
\hline & & $2(1,2)$ & $3(2,2)$ & 0,059 \\
\hline & & $2(1,2)$ & $4(2,1)$ & $0,023 *$ \\
\hline & & $3(2,2)$ & $4(2,1)$ & 0,099 \\
\hline
\end{tabular}

*p-valor estatisticamente significante $(\mathrm{p}<0,05)$ 
Figura 5 - Critérios FDI (Forma Anatômica, Fratura de Material e Retenção e Adaptação Marginal) que mostraram desempenho clínico diferente durante os períodos de avaliação. * indica diferença estatisticamente significante $(\mathrm{p}<0,05)$.

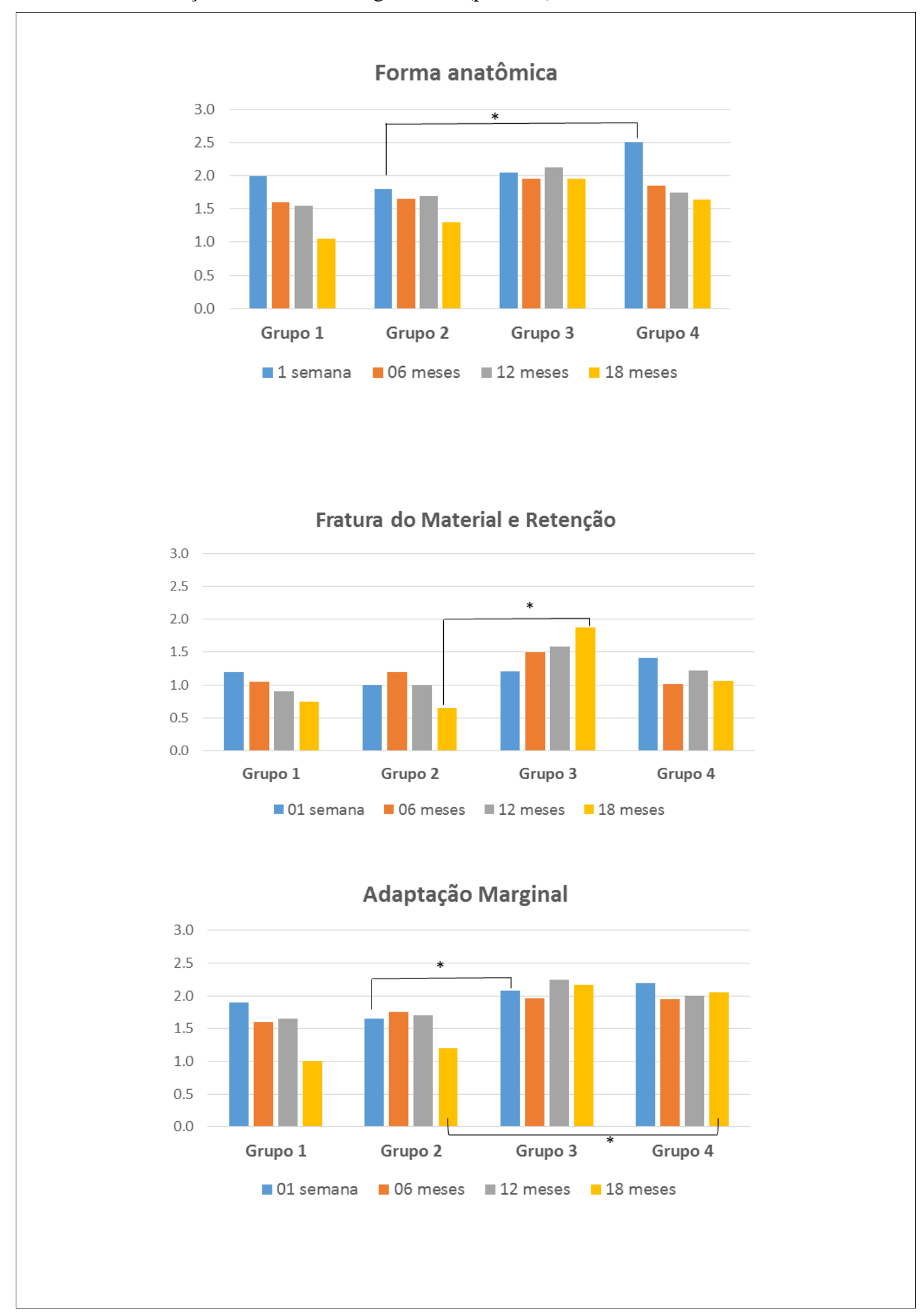


5. Discussãa 



\section{DISCUSSÃO}

\subsection{Background}

O pobre desempenho mecânico da dentina afetada por cárie no processo de adesão $(32,34,82-85)$, associado à degradação da interface adesiva, observado exaustivamente nos testes laboratoriais $(41,86-88)$, têm levado ao desenvolvimento de novas estratégias que envolvem remineralização da dentina afetada, na tentativa de estabilizar a interface adesiva, reparar a dentina desmineralizada e recuperar as propriedades biomecânicas $(47,89,90)$. Diversos estudos in vitro e alguns poucos in vivo, avaliando estas novas abordagens, têm mostrado resultados bastante promissores (49, 51, 91-94).

De forma similar, a vitrocerâmica usada experimentalmente (Biosilicato ${ }^{\circledR}$ ), dada sua alta bioatividade, propriedades remineralizante, antibacteriana $(59,60)$ e mecânica $(68,70$, $73,95)$, foi testada in vitro demonstrando influenciar positivamente na resistência de união da interface adesiva da dentina afetada por cárie (96). Embora estes resultados sugerissem um potencial benéfico nos procedimentos restauradores, não havia na literatura, informações sobre estudos clínicos prospectivos corroborando sua efetividade sobre a dentina afetada por cárie em restaurações com resina composta.

Assim, o presente estudo avaliou o desempenho clínico de restaurações posteriores em resina composta após aplicação da vitrocerâmica bioativa (Biosilicato ${ }^{\circledR}$ ), como tratamento de superfície da dentina afetada por cárie, quando associado a dois sistemas adesivos. Os resultados demostraram que não houve diferença estatisticamente significativa ( $p>0.05$ ) entre os grupos experimentais e os respectivos controles em nenhum tempo de avaliação, aceitando assim, a nossa hipótese nula $\left(\mathrm{H}_{0}\right)$ de que não haveria diferença no desempenho clínico das restaurações em resina composta, independente do uso da vitrocerâmica bioativa.

Entretanto, os resultados deste estudo indicaram que houve diferença estatisticamente significativa $(\mathrm{p}<0.05)$ entre as restaurações que usaram sistemas adesivos diferentes, ou seja, entre os controles (variável Forma Anatômica e Adaptação Marginal). Ainda, diferenças estatisticamente significativas $(\mathrm{p}<0.05)$ foram detectadas entre o grupo controle do sistema convencional e o grupo experimental do sistema autocondicionante (variável Fratura do Material/Retenção e Adaptação Marginal).

\subsection{Interpretação dos resultados}

Revisões sistemáticas e de literatura abrangendo estudos in vitro (1, 2, 40) concordam que o uso do sistema adesivo convencional é questionável na dentina afetada por 
cárie. Acredita-se que a camada híbrida criada pelo sistema convencional degrada de forma mais rápida do que a criada pelo adesivo autocondicionante. Isso está relacionado com o uso do condicionamento com ácido fosfórico (32-37\%), que desmineraliza a dentina de uma forma mais profunda e completa. $\mathrm{O}$ pH do ácido $(0,1-0,4)$ causa uma completa desmineralização das fibras de colágeno, ativando algumas proteases endógenas e tornando o substrato mais suscetível a degradação hidrolítica. Além disso, a sensibilidade na técnica tem sido um fator desfavorável no sucesso da durabilidade destes sistemas (97).

Neste presente estudo clínico, as restaurações realizadas seguindo o protocolo controle do sistema adesivo convencional de dois passos (Adper Single Bond 2, 3MEspe), mostraram de forma geral, um desempenho clinicamente aceitável para todos os parâmetros avaliados e em todos os tempos de avaliação, não havendo diferenças estatisticamente significativas quando comparadas às restaurações tratadas com o protocolo experimental (tratamento com micropartículas de Biosilicato) $(\mathrm{p}>0,05)$. Estudos clínicos randomizados $(42,98-100)$ corroboram o comportamento clinicamente satisfatório do sistema convencional observado neste estudo, contrastando com o consenso estabelecido in vitro. Entretanto, o resultado deste estudo pode ser atribuído ao tempo de avaliação (18 meses), uma vez que, clinicamente, deficiências ou falhas de restaurações posteriores em resina composta são mais comumente observadas após 2-3 anos $(10,11)$.

No que diz respeito ao uso de micropartículas de Biosilicato associado ao sistema convencional, apesar de não ter sido observado um desempenho superior, verificou-se um desempenho clínico aceitável e semelhante ao do grupo controle para todos os parâmetros avaliados (estéticos, funcionais e biológicos). De fato, há evidência laboratorial de que sua aplicação, após condicionamento com ácido fosfórico, influencia positivamente a resistência de união e promove maior formação de íons cálcio e fósforo, tanto na dentina hígida quanto na dentina afetada por cárie $(73,96)$. Tem se argumentado que a maior formação mineral seria, provavelmente, receptor químico para os monômeros funcionais (copolímero funcional de metacrilato de ácidos poliacrílico e polialcenóico) do adesivo convencional (73), contribuindo para um desempenho clínico adequado.

Ainda, os resultados do presente estudo podem corroborar achados de pesquisas laboratoriais com propostas similares. Sauro et al. (2012) (48) concluíram que o uso de adesivos convencionais contendo vidros bioativos, como o Bioglass (45S5), resultava em uma maior resistência de união após três meses. Observou-se que os adesivos experimentais promoviam maior formação mineral, refletida pela reduzida permeabilidade da camada hibrida e aumento significativo do módulo de elasticidade e microdureza da interface adesiva. 
Profeta et al. (2012) (49) apontaram que o uso de vidros bioativos após condicionamento ácido, resulta numa camada hibrida mais estável e de reduzida nanoinfiltração, devido à natureza química da precipitação mineral que ocorre na interface adesiva criada. Embora os achados laboratoriais sugiram um resultado clínico aceitável, como confirmado neste estudo, este deve ser visto com cautela, uma vez que a degradação de uma camada parcialmente infiltrada de monômeros resinosos nos sistemas convencionais acontece em um período de 6 meses a 3-5 anos (97).

No que concerne ao sistema adesivo autocondicionante, a recente revisão sistemática de Pinna et al. (2015) (2) aponta que seu uso, particularmente dos classificados como leves $(\mathrm{pH}>2)$, parece ser o método mais confiável para estabelecer uma adesão na dentina afetada por cárie. Isso é justificado pelo fato de que a desmineralização e a infiltração dos monômeros resinosos ocorrem simultaneamente, assegurando a completa penetração do adesivo. $\mathrm{O}$ pH do primer, contendo os monômeros funcionais, não expõe totalmente as fibras de colágeno, deixando cristais de hidroxiapatita remanescentes na matriz dentinária e o smear plug, ao interior dos túbulos, reduzindo o risco de permeabilidade dentinária durante a infiltração resinosa (101).

Os resultados do nosso estudo, demonstraram que o desempenho clínico das restaurações que seguiram o protocolo adesivo autocondicionante de dois passos (AdheSE, Ivoclar) foi, principalmente, aceitável para todos os parâmetros e tempos de avaliação, não havendo diferença estatisticamente significativa entre o grupo controle e o experimental $(\mathrm{p}>$ 0,05). Entretanto, ao contrário do esperado, foi observado para a variável fratura do material e retenção, um desempenho clinicamente inaceitável em $25 \%$ das restaurações do grupo controle e em $37 \%$ do grupo experimental, não havendo diferença significativa entre eles (p > $0,05)$

A este respeito, outros estudos clínicos randomizados de curto período (1-2 anos) têm indicado, de forma similar, um desempenho satisfatório para adesivos autocondicionantes, porém sem nenhuma ocorrência de insucessos $(98,99)$. Estes estudos clínicos, no entanto, incluíram na amostra dentes posteriores indicados para restauração por diversas situações clínicas (ex. lesão de cárie primária, secundária, fraturas, motivos estéticos, etc.) e não exclusivamente, devido a lesão de cárie ativa primária. Além disso, informações como o substrato restaurado (esmalte ou dentina) e a profundidade (superficial, media ou profunda) não foram detalhadas.

Particularmente, no que diz respeito ao parâmetro fratura do material e retenção, o uso da vitrocerâmica bioativa (Biosilicato) não contribuiu para um melhor comportamento 
clínico quando associado ao sistema autocondicionante. Apesar de não terem sido encontrados estudos clínicos com proposta similares para comparação, os estudos laboratoriais podem ser úteis para este fim já que existe evidência de correlação entre testes de resistência de união e retenção clínica da restauração (102). Assim, nossos achados clínicos podem estar relacionados com os resultados obtidos in vitro por Morais et al. (2016) (73), os quais verificaram que aplicação de micropartículas de Biosilicato na superfície da dentina não aumentou os valores de resistência de união quando associado a adesivos autocondicionantes de dois passos. Contrariamente, nossos resultados foram diferentes dos encontrados no estudo laboratorial realizado por Pires-de-Souza et al. (2007) (95), onde o uso do Biosilicato produz os maiores valores de resistência de união. Porém, ambos estudos laboratoriais, aplicaram protocolos de tratamento experimentais diferentes e foram realizados em dentina hígida, o que pode influenciar nos resultados (40).

Ainda, no presente estudo verificou-se que após 18 meses, o desempenho das restaurações realizadas seguindo o protocolo experimental do sistema autocondicionante (Grupo 3) foi clinicamente inferior quando comparado às restaurações que seguiram o protocolo controle do sistema adesivo convencional (Grupo 2), para o parâmetro fratura do material/retenção $(\mathrm{p}<0,05)$. Esta diferença deve-se ao fato de que todas as restaurações do Grupo 2 avaliadas aos 18 meses receberam escore 1, enquanto que as restaurações do Grupo 3 receberam diferentes escores (1-5). Uma possível explicação para justificar o desempenho clínico do Grupo 3 em termos deste parâmetro funcional, pode estar baseada no processo de adesão e o protocolo experimental definida neste estudo.

No protocolo experimental, usando um sistema autocondicionante de dois passos, as micropartículas do Biosilicato foram aplicadas posteriormente à aplicação do primer, cujos monômeros funcionais apresentam menor acidez do que o dos sistemas convencionais (101). A interação entre o Biosilicato e o primer pode ter modificado o $\mathrm{pH}$ do meio, uma vez que a cristalização total da vitro-cerâmica bioativa torna o meio mais alcalino devido às reações químicas dos biovidros em meio aquoso descritos por Hench (55). Um estudo in vitro prévio (96) tem especulado que a desmineralização do substrato dentinário, nesta situação, poderia ser ainda menos efetiva, uma vez que o $\mathrm{pH}$ ácido do primer acaba sendo neutralizado. Em consequência, pode ser que o processo de adesão ocorreu de forma menos efetiva levando a uma retenção menos eficiente.

Além disso, nos sistemas autocondicionantes, deve-se considerar que adesão química entre os monômeros funcionais e o cálcio da hidroxiapatita tem um papel importante no mecanismo de adesão $(41,101,103)$. Em particular, tem sido relatado que a adesão química 
produzida entre o monômero funcional 10-MDP e os substratos dentais resultam numa interface adesiva mais estável hidroliticamente em relação a outros monômeros funcionais $(47,104,105)$ promovendo resultados clinicamente satisfatórios a curto $(106,107)$ e longo prazo (108). Isto poderia explicar, em parte, os resultados inferiores obtidos com o adesivo autocondicionante usado neste estudo (AdheSE, Ivoclar), uma vez que sua formulação é diferente.

Outro ponto a ser discutido é sobre as diferenças encontradas no parâmetro adaptação marginal $(\mathrm{p}<0,05)$. As restaurações realizadas com o protocolo controle do sistema adesivo convencional (Grupo 2) tiveram um melhor desempenho clínico, quando comparado aos protocolos adesivos do sistema adesivo autocondicionante, do grupo experimental (Grupo 3) após uma semana e do controle (Grupo 4) após 18 meses. No entanto, as diferenças encontradas no período do estudo, foram dentro dos escores clinicamente aceitáveis.

De forma geral, alterações na adaptação marginal estão associadas usualmente ao estresse térmico ou mecânico das restaurações bem como às propriedades viscoelásticas do material restaurador $(109,110)$. Além disso, algumas alterações na integridade marginal podem ocorrer durante a polimerização de resinas, devido a uma contração volumétrica que depende da composição da resina composta utilizada. No presente estudo, uma única resina foi usada em todos os grupos. A resina IPS Empress Direct (Ivoclar) é um compósito nanohíbrido com um conteúdo de carga de 75-79\% em peso e com reduzida contração volumétrica (111). Assim, é provável que a contração volumétrica da resina usada não seja responsável das alterações na adaptação marginal, observadas neste estudo.

Além desses fatores, a influência do tipo de sistema adesivo na adaptação marginal das restaurações diretas tem sido relatada clinicamente, mostrando resultados divergentes. Uma revisão sistemática realizada em 2010 (112), abordando os efeitos do tipo de sistema adesivo no sucesso clínico das restaurações comparou as porcentagens de restaurações classificadas como clinicamente satisfatórias e apontou que os sistemas convencionais eram superiores aos sistemas autocondicionantes em termos de adaptação marginal. Mais tarde, estudos clínicos relataram algumas deficiências clínicas (em termos de adaptação marginal) nos primeiros meses após restauração com sistemas autocondicionantes de um passo (113) e uma significativa deterioração na adaptação marginal após 4 anos, quando usado um sistema autocondicionante de dois passos (42).

De forma contrária, outros estudos clínicos randomizados indicaram que não há diferença no desempenho clínico de restaurações realizadas com diferentes tipos de sistemas adesivos, inclusive para o parâmetro adaptação marginal $(98,100,114)$. No nosso estudo, as 
diferenças em termos de adaptação marginal, entre os diversos protocolos adesivos, foram observadas dentro dos parâmetros clinicamente aceitáveis; não obstante, irregularidades na adaptação marginal da restauração com o passar do tempo podem levar ao insucesso clínico, o que exigiria substituição parcial ou total da restauração.

Ainda, o presente estudo mostrou diferenças para o critério forma anatômica na avaliação de uma semana $(\mathrm{p}<0.05)$ entre os grupos controles. Neste ponto, o parâmetro forma anatômica das restaurações diretas é avaliado principalmente quanto ao seu efeito sobre a aparência estética geral. Porém, em algumas situações clínicas, deficiências anatômicas podem prejudicar a função, por exemplo, contato proximal deficiente e o efeito sobre os tecidos periodontais. Neste estudo, as diferenças detectadas entre os grupos controles foram dentro dos parâmetros clinicamente aceitáveis. Uma vez que a diferença foi detectada apenas na primeira semana de avaliação, é possível especular que o resultado esteja mais relacionado à habilidade do operador, não sendo um fator crítico no desempenho do material (79).

Em relação aos motivos de insucesso de restaurações posteriores em resina composta, períodos de estudo de até cinco anos têm relatado que as falhas são principalmente associadas a fratura (115). Mais recentemente estudos de revisão têm mostrado que estas deficiências clínicas continuam sendo uma constante falha e aparecem normalmente no segundo ano (10, 116). Um resultado similar foi observado neste estudo, onde a maioria das falhas ocorreu devido a fratura do material ou perda de retenção seguido de adaptação marginal inadequada.

Após 18 meses de acompanhamento, as fraturas ou perda de retenção ocorreram principalmente no grupo do sistema autocondicionante, 9 restaurações no grupo experimental (Grupo 3) e 5 no controle (Grupo 4). Estudos clínicos de períodos de avaliação curta tem relacionado esta deficiência a restaurações com extensão "MOD” (117). Neste estudo, no entanto, as fraturas ou perda de retenção ocorreram independente da extensão das cavidades. Uma vez que estas deficiências clínicas foram observadas continuamente no protocolo adesivo com sistema autocondicionante, ao longo do estudo e antes do tempo normalmente relatado na literatura $(10,11,116)$, poderia se pensar que o sistema adesivo foi um fator coadjuvante. Conforme já comentado anteriormente, no caso particular do grupo experimental, a interação entre o sistema autocondicionante e o Biosilicato, pode não ter ocorrido de forma efetiva e consequentemente em algumas deficiências mecânicas e perda de retenção.

Uma outra falha biológica comumente relatada em restaurações posteriores em resina composta é a cárie secundária (cárie adjacente à restauração) $(10,115,118,119)$. Porém, seu desenvolvimento pode levar anos até a manifestação clínica, sendo um motivo de falha de 
médio e longo prazo (> 24 meses). Confirmando esses achados, um estudo de metanálise (10) revelou que a ocorrência de cárie secundária é observada após o segundo ano. De forma similar, a recente revisão sistemática realizada por Ástvaldsdóttir et al. (2015) (11) relatou que mais de $75 \%$ dos casos de cárie secundária ocorrem após os três anos.

No presente estudo, houve uma única ocorrência de cárie secundária, observada no grupo controle do sistema autocondicionante (Grupo 4) após 6 meses. A lesão de cárie encontrava-se levemente cavitada na superfície oclusal de um molar superior e com suspeita de cárie sob restauração obtendo um escore 4 (clinicamente deficiente), de acordo com os critérios da FDI. Ao respeito, as lesões de cárie secundária parecem ser mais frequentes nas margens gengivo-proximais que nas margens oclusais e depender mais de uma adequação do ambiente bucal que do material restaurador e o sistema adesivo usado (8).

Nos grupos experimentais, não houve ocorrência de cárie secundária durante o período do estudo. Para ambos os grupos, a incorporação do Biosilicato no protocolo restaurador pode ter inibido o desenvolvimento bacteriano na interface dente-resina devido ao seu efeito antibacteriano (64). Além disso, a baixa incidência de cárie secundária reportada neste estudo (1\%) coincide com estudos prévios de curto prazo $(0.78-1 \%)(117,120)$. Entretanto, a incidência pode aumentar em restaurações com períodos de observações maiores e em pacientes com alto risco de cárie $(6,8,10)$.

No que diz respeito a hipersensibilidade dentinária (HD) pós-operatória, neste estudo, houve maior frequência do escore 1 em todas as avaliações e em todos os grupos. Apenas uma restauração recebeu escore 4, indicado como clinicamente insatisfatório e com necessidade de reparo, após uma semana de ter realizado o procedimento restaurador do Grupo 1 (grupo experimental do sistema convencional). Nas próximas avaliações não houve reporte de HD, que indiquem substituição ou perda da restauração.

Além disso, não se observaram diferenças estatísticas entre os grupos controles e os respectivos grupos experimentais. A aplicação do Biosilicato nos grupos experimentais pode ter colaborado para ausência da HD, uma vez que existem relatos clínicos de sua eficiência no controle da HD $(66,121)$. Adicionalmente, não houve diferença entre grupos controles (com diferentes tipos de sistema adesivos). Tais resultados coincidem com uma recente revisão sistemática (122) que concluiu que o tipo de estratégia adesiva não influenciava o risco nem a intensidade da HD pós-operatória em restaurações posteriores. Dessa forma, a percepção de que os sistemas autocondicionantes causam menos HD pós-operatória que os sistemas convencionais, devido à remoção parcial e incorporação do smear layer na camada híbrida, 
trata-se segundo Perdigão e Swift (2013) (123) apenas de uma "evidência anedótica", uma vez que diversos ensaios clínicos não apoiam esta percepção.

A baixa incidência de HD observada neste estudo, pode também estar relacionada aos critérios usados para a seleção dos dentes (ex. cavidades com profundidade média) bem como aos procedimentos restauradores padronizados e executados por operadores treinados, os quais realizaram as restaurações em condições mais próximas das ideais. Por outro lado, neste estudo, a HD pós-operatória foi avaliada usando um estímulo de ar frio sobre a superfície da restauração e também pelo questionamento ao paciente se sentia algum desconforto relacionado à restauração ou não (item Opinião do paciente). Estudos que avaliaram a HD pós-operatória, de origem espontânea ou estimuladas por fontes diferentes revelaram uma incidência maior $(98,124)$.

\subsection{Sobre a metodologia usada}

\section{- Critérios usados (FDI)}

O uso de critérios clínicos para avaliação de restaurações diretas e indiretas, onde novos materiais restauradores e/ou novas técnicas são empregadas, é altamente recomendado (78, 125). O critério modificado USPHS / Ryge tem sido amplamente utilizado para a avaliação clínica de restaurações posteriores (11). Embora esses critérios não considerem algumas questões biológicas como resposta periodontal, mucosa adjacente e saúde oral e geral, são considerados critérios válidos para fins de comparação entre os estudos em diferentes períodos de observação.

O presente estudo usou os critérios da Federação Dental Internacional (FDI) $(78,79)$ para avaliação clínica. O critério FDI foi proposto e aprovado em 2007, na tentativa de detectar falhas precoces e diferenças entre restaurações que não eram facilmente detectadas pelo tradicional critério USPHS em pesquisas clinicas de curto prazo. O critério está categorizado em três grupos: propriedades estéticas (quatro categorias), propriedades funcionais (seis categorias) e propriedades biológicas (seis categorias). Cada categoria ou parâmetro pode ser expressado em 5 escores diferentes: 1, 2 e 3 para "clinicamente aceitável" e 4 e 5 para "clinicamente inaceitável" (4 para reparável e 5 para substituição da restauração). Embora o critério FDI seja relativamente recente, alguns estudos clínicos têm mostrado que é mais rigoroso e mais sensível quando comparado ao critério USPHS (106, 107), particularmente em avaliações a curto prazo. 
A seleção de quais critérios devem ser incluídos depende do objetivo do estudo. Os critérios fratura, retenção, integridade marginal e descoloração marginal (micro infiltração clínica) são usualmente considerados como parâmetros chave para avaliar a eficácia clínica das técnicas adesivas (112). Porém, uma desvantagem de considerar apenas alguns critérios é a falta de precisão sobre o número de restaurações com insucesso devido a critérios não abordados (78). Levando isto em consideração, o presente estudo considerou todos critérios propostos pela FDI (estéticos, funcionais e biológicos).

\section{- Processo de calibração}

A etapa de calibração dos examinadores é um dos requisitos que garante a fidedignidade e a redução da variabilidade dos achados (126). Para obter uma padronização no uso dos critérios FDI, foi fundamental que os examinadores envolvidos no presente estudo participem de um treinamento antes do início do mesmo.

No processo de calibração com a ferramenta eletrônica "e-calib”, observou-se uma diferença de interpretação entre os critérios estabelecidos e os dos examinadores, particularmente nas propriedades estéticas. Os critérios da FDI representam uma importante contribuição para a Odontologia, porém uma equipe multidisciplinar dos Estados Unidos e da Alemanha desenvolveram o referido processo de calibração, baseado no entendimento de sucesso ou fracasso definida por essa equipe. Contudo, os examinadores deste estudo foram calibrados de acordo com o e-calib, podendo ter alguns conflitos quando os critérios foram aplicados. Durante os próximos períodos de avaliação, continuou-se com a recalibração apenas em ambiente clínico, o que poderia representar um viés na precisão e reprodutibilidade. Contudo, um alto índice de concordância entre os examinadores foi obtido durante o estudo (Coeficiente Kappa $\geq 0.80$ ).

\section{- Controle de vieses e validade}

Com o intuito de minimizar vieses durante a etapa de avaliação, os operadores e examinadores foram diferentes indivíduos. Ainda, os participantes e os examinadores permaneceram cegos aos tratamentos aplicados. Além disso, em vista que alguns fatores relacionados ao paciente tais como risco alto de cárie, higiene oral, hábitos alimentares, fatores oclusais, etc. podem influenciar no desempenho dos protocolos em restaurações diretas $(6,10,127)$, tais fatores foram controlados pelos critérios de inclusão e exclusão definidos neste estudo. Dessa forma, voluntários com alto risco à cárie, higiene oral deficiente e com presença de hábitos parafuncionais não foram incluídos no estudo. Ainda, os 
participantes incluídos no estudo receberam um kit de higiene oral e profilaxia em cada sessão de avaliação a fim de manter uma adequada higiene oral ao longo do estudo.

Por outa parte, fatores como sexo, idade, tipo e localização do dente a ser restaurado parece não ter influência no desempenho e longevidade das restaurações $(127,128)$ e podem não ser considerados como fatores de confusão importantes. Entretanto, o fator idade parece estar associado a maior risco à cárie e alterações da saúde oral e geral, principalmente em indivíduos mais jovens (< 18 anos) ou mais adultos (> 65 anos). Levando isto em consideração, determinou-se, neste estudo, uma faixa etária de 18 a 50 anos. Assim, os participantes tiveram uma idade média de 32 anos, sendo que a distribuição das restaurações entre as faixas de 18-30 (48\%) e 30-50 (52\%) anos foi homogênea.

Outro aspecto a ser considerado é que todos os procedimentos de intervenção foram realizados por dois operadores treinados e padronizados com os protocolos determinados. Por sua vez, os participantes do estudo foram selecionados de acordo com uma série de critérios de elegibilidade estabelecidos. Os operadores e participantes, portanto, não são representativos de suas populações específicas, limitando assim, a validade externa do estudo.

\subsection{Limitações}

Merece atenção mencionar que ao longo deste estudo houveram algumas limitações:

a) houve uma perda de 24 participantes, sendo que a taxa de retorno para avaliação após 18 meses foi de 63,6\%. Ao respeito, estudos clínicos de curto prazo reportados na literatura $(99,120,129,130)$ mostram taxas de retorno maiores (80-100\%), porém com uma amostra relativamente menor. No presente estudo, nossos pacientes tinham as lesões de cárie como queixa principal, e uma vez solucionado o problema, o paciente descomprometia-se com as consultas de retorno para avaliação, mesmo com os incentivos estabelecidos pelos pesquisadores, como tratamentos concomitantes necessários. Ainda sobre esta questão, é importante comentar que a remuneração do paciente para participação é vedada e o seu direito de abandonar o tratamento a qualquer momento é garantido e reforçado pelo TCLE;

b) o desempenho clínico das restaurações foi avaliado em um período 18 meses, o que pode superestimar a eficácia clínica ou apresentar resultados diferentes ao longo prazo. A duração do acompanhamento das restaurações ou período de follow-up é de grande importância, uma vez que deficiências ou falhas das restaurações são mais comumente observadas após 3 anos $(10,11)$. 
Dessa forma, o próximo passo deste estudo será dar continuidade a avaliações com períodos de seguimento maiores.

Por fim, sugere-se a realização de novos estudos clínicos, idealmente com desenho split mouth, que permita comparar a eficácia de novas estratégias restauradoras envolvendo vidros bioativos. Por outro lado, a execução de pesquisas ex-vivo seria uma alternativa interessante para revelar características importantes da interface adesiva exposta no meio oral. Neste aspecto, a confirmação da formação de apatita e a quantificação do conteúdo mineral formado na interface adesiva através de métodos adequados ajudaria a elucidar quais aspectos determinantes no processo adesivo que envolve vidros bioativos (52). 

6. Conclusães 



\section{CONCLUSÕES}

De acordo com a metodologia usada e os resultados obtidos no estudo, pode-se concluir que no tratamento da dentina afetada por cárie:

1. O uso do Biosilicato no protocolo restaurador não afetou o desempenho clinico (estético, funcional e biológico) de restaurações em resina composta no período de 18 meses de acompanhamento.

2. Houve um desempenho clínico semelhante entre os protocolos experimentais que usaram sistema adesivo convencional e sistema autocondicionante

3. Os sistemas convencionais tiveram um desempenho clínico melhor do que os sistemas autocondicionantes em termos de adaptação marginal.

4. A associação entre o sistema adesivo autocondicionante de dois passos e o Biosilicato teve um desempenho clínico inferior, comparado ao sistema adesivo convencional (controle), em termos de adaptação marginal e fratura do material/retenção. 

Referencias 



\section{REFERÊNCIAS ${ }^{2}$}

1. Nakajima M, Kunawarote S, Prasansuttiporn T, Tagami J. Bonding to caries-affected dentin. Jpn Dent Sci Rev. 2011;47(2):102-14.

2. Pinna R, Maioli M, Eramo S, Mura I, Milia E. Carious affected dentine: its behaviour in adhesive bonding. Aust Dent J. 2015;60(3):276-93.

3. Pugach MK, Strother J, Darling CL, Fried D, Gansky SA, Marshall SJ, et al. Dentin caries zones: mineral, structure, and properties. J Dent Res. 2009;88(1):71-6.

4. Sheiham A. Oral health, general health and quality of life. Bull World Health Organ. 2005;83(9):644.

5. Rajendra Santosh AB, Ogle OE, Williams D, Woodbine EF. Epidemiology of Oral and Maxillofacial Infections. Dent Clin North Am. 2017;61(2):217-33.

6. Demarco FF, Corrêa MB, Cenci MS, Moraes RR, Opdam NJ. Longevity of posterior composite restorations: not only a matter of materials. Dent Mater. 2012;28(1):87-101.

7. Lynch CD, Opdam NJ, Hickel R, Brunton PA, Gurgan S, Kakaboura A, et al. Guidance on posterior resin composites: Academy of Operative Dentistry - European Section. J Dent. 2014;42(4):377-83.

8. Heintze SD, Rousson V. Clinical effectiveness of direct class II restorations - a metaanalysis. J Adhes Dent. 2012;14(5):407-31.

9. Traebert J, Marcenes W, Kreutz JV, Oliveira R, Piazza CH, Peres MA. Brazilian dentists' restorative treatment decisions. Oral Health Prev Dent. 2005;3(1):53-60.

10. Opdam NJ, van de Sande FH, Bronkhorst E, Cenci MS, Bottenberg P, Pallesen U, et al. Longevity of posterior composite restorations: a systematic review and meta-analysis. $\mathrm{J}$ Dent Res. 2014;93(10):943-9.

11. Ástvaldsdóttir Á, Dagerhamn J, van Dijken JW, Naimi-Akbar A, Sandborgh-Englund G, Tranæus S, et al. Longevity of posterior resin composite restorations in adults - A systematic review. J Dent. 2015;43(8):934-54.

12. Asghar S, Ali A, Rashid S, Hussain T. Replacement of resin-based composite restorations in permanent teeth. J Coll Physicians Surg Pak. 2010;20(10):639-43.

13. Gordan VV, Riley JL, 3rd, Geraldeli S, Rindal DB, Qvist V, Fellows JL, et al. Repair or replacement of defective restorations by dentists in The Dental Practice-Based Research Network. J Am Dent Assoc. 2012;143(6):593-601.

14. Palotie U, Vehkalahti MM. Reasons for replacement of restorations: dentists' perceptions. Acta Odontol Scand. 2012;70(6):485-90.

\footnotetext{
${ }^{2}$ De acordo com o estilo Vancouver.
} 
15. Perdigão J, Dutra-Corrêa M, Anauate-Netto C, Castilhos N, Carmo AR, Lewgoy HR, et al. Two-year clinical evaluation of self-etching adhesives in posterior restorations. $\mathbf{J}$ Adhes Dent. 2009;11(2):149-59.

16. Kopperud SE, Tveit AB, Gaarden T, Sandvik L, Espelid I. Longevity of posterior dental restorations and reasons for failure. Eur J Oral Sci. 2012;120(6):539-48.

17. Braga SR, Vasconcelos BT, Macedo MR, Martins VR, Sobral MA. Reasons for placement and replacement of direct restorative materials in Brazil. Quintessence Int. 2007;38(4):e189-94.

18. Chrysanthakopoulos NA. Placement, replacement and longevity of composite resinbased restorations in permanent teeth in Greece. Int Dent J. 2012;62(3):161-6.

19. Kanzow P, Wiegand A, Schwendicke F. Cost-effectiveness of repairing versus replacing composite or amalgam restorations. J Dent. 2016;54:41-7.

20. Carvalho RM, Manso AP, Geraldeli S, Tay FR, Pashley DH. Durability of bonds and clinical success of adhesive restorations. Dent Mater. 2012;28(1):72-86.

21. Spencer P, Jonggu Park QY, Misra A, Bohaty BS, Singh V, Parthasarathy R, et al. Durable bonds at the adhesive/dentin interface: an impossible mission or simply a moving target? Braz Dent Sci. 2012;15(1):4-18.

22. Perdigão J. Dentin bonding-variables related to the clinical situation and the substrate treatment. Dent Mater. 2010;26(2):e24-37.

23. Carvalho RM, Tjäderhane L, Manso AP, Carrilho MR, Carvalho CAR. Dentin as a bonding substrate. Endodontic Topics. 2012;21(1):62-88.

24. Fusayama T, Terachima S. Differentiation of two layers of carious dentin by staining. J Dent Res. 1972;51(3):866.

25. Tyas MJ, Anusavice KJ, Frencken JE, Mount GJ. Minimal intervention dentistry--a review. FDI Commission Project 1-97. Int Dent J. 2000;50(1):1-12.

26. Wang Y, Spencer P, Walker MP. Chemical profile of adhesive/caries-affected dentin interfaces using Raman microspectroscopy. J Biomed Mater Res A. 2007;81(2):279-86.

27. Arnold WH, Konopka S, Kriwalsky MS, Gaengler P. Morphological analysis and chemical content of natural dentin carious lesion zones. Ann Anat. 2003;185(5):419-24.

28. Spencer P, Wang Y, Katz JL, Misra A. Physicochemical interactions at the dentin/adhesive interface using FTIR chemical imaging. $J$ Biomed Opt. 2005;10(3):031104.

29. Nakajima M, Kitasako Y, Okuda M, Foxton RM, Tagami J. Elemental distributions and microtensile bond strength of the adhesive interface to normal and caries-affected dentin. J Biomed Mater Res B Appl Biomater. 2005;72(2):268-75. 
30. Suppa P, Ruggeri A, Tay FR, Prati C, Biasotto M, Falconi M, et al. Reduced antigenicity of type I collagen and proteoglycans in sclerotic dentin. J Dent Res. 2006;85(2):133-7.

31. Ito S, Saito T, Tay FR, Carvalho RM, Yoshiyama M, Pashley DH. Water content and apparent stiffness of non-caries versus caries-affected human dentin. J Biomed Mater Res B Appl Biomater. 2005;72(1):109-16.

32. Wei S, Sadr A, Shimada Y, Tagami J. Effect of caries-affected dentin hardness on the shear bond strength of current adhesives. J Adhes Dent. 2008;10(6):431-40.

33. Erhardt MC, Toledano M, Osorio R, Pimenta LA. Histomorphologic characterization and bond strength evaluation of caries-affected dentin/resin interfaces: effects of longterm water exposure. Dent Mater. 2008;24(6):786-98.

34. Shibata S, Vieira LC, Baratieri LN, Fu J, Hoshika S, Matsuda Y, et al. Evaluation of microtensile bond strength of self-etching adhesives on normal and caries-affected dentin. Dent Mater J. 2016;35(2):166-73.

35. Joves GJ, Inoue G, Sadr A, Nikaido T, Tagami J. Nanoindentation hardness of intertubular dentin in sound, demineralized and natural caries-affected dentin. J Mech Behav Biomed Mater. 2014;32:39-45.

36. Marshall GW, Habelitz S, Gallagher R, Balooch M, Balooch G, Marshall SJ. Nanomechanical properties of hydrated carious human dentin. J Dent Res. 2001;80(8):1768-71.

37. Taniguchi G, Nakajima M, Hosaka K, Iwamoto N, Ikeda M, Foxton RM, et al. Improving the effect of $\mathrm{NaOCl}$ pretreatment on bonding to caries-affected dentin using self-etch adhesives. J Dent. 2009;37(10):769-75.

38. Spencer P, Wang Y, Walker MP, Swafford JR. Molecular structure of acid-etched dentin smear layers--in situ study. J Dent Res. 2001;80(9):1802-7.

39. Say EC, Nakajima M, Senawongse P, Soyman M, Ozer F, Tagami J. Bonding to sound vs caries-affected dentin using photo- and dual-cure adhesives. Oper Dent. 2005;30(1):90-8.

40. Ekambaram M, Yiu CKY, Matinlinna JP. Bonding of resin adhesives to caries-affected dentin - A systematic review. Int J Adhes Adhes. 2015;61:23-34.

41. Perdigão J, Reis A, Loguercio AD. Dentin adhesion and MMPs: a comprehensive review. J Esthet Restor Dent. 2013;25(4):219-41.

42. Boeckler A, Boeckler L, Eppendorf K, Schaller HG, Gernhardt CR. A prospective, randomized clinical trial of a two-step self-etching vs two-step etch-and-rinse adhesive and SEM margin analysis: four-year results. J Adhes Dent. 2012;14(6):585-92.

43. Bertassoni LE, Habelitz S, Kinney JH, Marshall SJ, Marshall GW. Biomechanical perspective on the remineralization of dentin. Caries Res. 2009;43(1):70-7. 
44. Niu LN, Zhang W, Pashley DH, Breschi L, Mao J, Chen JH, et al. Biomimetic remineralization of dentin. Dent Mater. 2014;30(1):77-96.

45. Zhong B, Peng C, Wang G, Tian L, Cai Q, Cui F. Contemporary research findings on dentine remineralization. J Tissue Eng Regen Med. 2015;9(9):1004-16.

46. ten Cate JM. Remineralization of caries lesions extending into dentin. J Dent Res. 2001;80(5):1407-11.

47. Sauro S, Pashley DH. Strategies to stabilise dentine-bonded interfaces through remineralising operative approaches - State of The Art. Int J Adhes Adhes. 2016;69:3957.

48. Sauro S, Osorio R, Watson TF, Toledano M. Therapeutic effects of novel resin bonding systems containing bioactive glasses on mineral-depleted areas within the bondeddentine interface. J Mater Sci Mater Med. 2012;23(6):1521-32.

49. Profeta AC, Mannocci F, Foxton RM, Thompson I, Watson TF, Sauro S. Bioactive effects of a calcium/sodium phosphosilicate on the resin-dentine interface: a microtensile bond strength, scanning electron microscopy, and confocal microscopy study. Eur J Oral Sci. 2012;120(4):353-62.

50. Sauro S, Watson TF, Thompson I, Banerjee A. One-bottle self-etching adhesives applied to dentine air-abraded using bioactive glasses containing polyacrylic acid: an in vitro microtensile bond strength and confocal microscopy study. J Dent. 2012;40(11):896-905.

51. Sauro S, Watson TF, Thompson I, Toledano M, Nucci C, Banerjee A. Influence of airabrasion executed with polyacrylic acid-Bioglass $45 \mathrm{~S} 5$ on the bonding performance of a resin-modified glass ionomer cement. Eur J Oral Sci. 2012;120(2):168-77.

52. Fernando D, Attik N, Pradelle-Plasse N, Jackson P, Grosgogeat B, Colon P. Bioactive glass for dentin remineralization: A systematic review. Mater Sci Eng C.

53. Hench LL. Bioceramics: from concept to clinic. J Am Ceram Soc. 1991;74(7):1487510.

54. Hench LL. The story of Bioglass. J Mater Sci Mater Med. 2006;17(11):967-78.

55. Hench LL. An introduction to bioceramics: World Scientific Publishing Co Inc; 2013.

56. Zanotto E, Ravagnani C, Peitl O, Panzeri H, Lara E. Process and compositions for preparing particulate, bioactive or resorbable biosilicates for use in the treatment of oral ailments, WO2004/074199, Fundaçao Universidade Federal de Sao Carlos, Universidade de Sao Paulo, 20 February, Int. C C03C10/00. 2004.

57. Moura J, Teixeira LN, Ravagnani C, Peitl O, Zanotto ED, Beloti MM, et al. In vitro osteogenesis on a highly bioactive glass-ceramic (Biosilicate). J Biomed Mater Res A. 2007;82(3):545-57. 
58. Roriz VM, Rosa AL, Peitl O, Zanotto ED, Panzeri H, de Oliveira PT. Efficacy of a bioactive glass-ceramic (Biosilicate) in the maintenance of alveolar ridges and in osseointegration of titanium implants. Clin Oral Implants Res. 2010;21(2):148-55.

59. Renno AC, Bossini PS, Crovace MC, Rodrigues AC, Zanotto ED, Parizotto NA. Characterization and in vivo biological performance of biosilicate. Biomed Res Int. 2013;2013:141427.

60. Crovace MC, Souza MT, Chinaglia CR, Peitl O, Zanotto ED. Biosilicate ${ }^{\circledR}$ - A multipurpose, highly bioactive glass-ceramic. In vitro, in vivo and clinical trials. J NonCryst Solids. 2016;432, Part A:90-110.

61. Granito RN, Ribeiro DA, Rennó AC, Ravagnani C, Bossini PS, Peitl-Filho O, et al. Effects of biosilicate and bioglass $45 \mathrm{~S} 5$ on tibial bone consolidation on rats: a biomechanical and a histological study. J Mater Sci Mater Med. 2009;20(12):2521-6.

62. Massuda ET, Maldonado LL, Lima Júnior JT, Peitl O, Hyppolito MA, Oliveira JA. Biosilicate ototoxicity and vestibulotoxicity evaluation in guinea-pigs. Braz $\mathrm{J}$ Otorhinolaryngol. 2009;75(5):665-8.

63. Kido HW, Oliveira P, Parizotto NA, Crovace MC, Zanotto ED, Peitl-Filho O, et al. Histopathological, cytotoxicity and genotoxicity evaluation of Biosilicate ${ }^{\circledR}$ glassceramic scaffolds. J Biomed Mater Res A. 2013;101(3):667-73.

64. Martins CH, Carvalho TC, Souza MG, Ravagnani C, Peitl O, Zanotto ED, et al. Assessment of antimicrobial effect of Biosilicate ${ }^{\circledR}$ against anaerobic, microaerophilic and facultative anaerobic microorganisms. J Mater Sci Mater Med. 2011;22(6):1439-46.

65. Tirapelli C, Panzeri H, Soares RG, Peitl O, Zanotto ED. A novel bioactive glassceramic for treating dentin hypersensitivity. Braz Oral Res. 2010;24(4):381-7.

66. Tirapelli C, Panzeri H, Lara EH, Soares RG, Peitl O, Zanotto ED. The effect of a novel crystallised bioactive glass-ceramic powder on dentine hypersensitivity: a long-term clinical study. J Oral Rehabil. 2011;38(4):253-62.

67. Pinheiro H, Lopes B, Klautau E, Cardoso J, Silva B, Cardoso P. Influence of bioactive materials used on the dentin surface whitened with carbamide peroxide $16 \%$. Mat Res. 2010; 13(2):273-8.

68. Pintado-Palomino K, Tirapelli C. The effect of home-use and in-office bleaching treatments combined with experimental desensitizing agents on enamel and dentin. Eur J Dent. 2015;9(1):66-73.

69. Rastelli A, Nicolodelli G, Romano R, Milori D, Perazzoli I, Ferreira E, et al. After bleaching enamel remineralization using a bioactive glass-ceramic (BioSilicate $\AA$ ). Biomedical glasses. 2016;2(1):1-9.

70. Osorio E, Fagundes T, Navarro MF, Zanotto ED, Peitl O, Osorio R, et al. A novel bioactive agent improves adhesion of resin-modified glass-ionomer to dentin. $\mathrm{J}$ Adhes Sci Technol. 2015;29(15):1543-52. 
71. Pires-de-Souza Fde C, de Marco FF, Casemiro LA, Panzeri H. Desensitizing bioactive agents improves bond strength of indirect resin-cemented restorations: preliminary results. J Appl Oral Sci. 2007;15(2):120-6.

72. Panzeri Pires-de-Souza FeC, Silveira RE, Abuna G, Chinelatti MA, Alandia-Román CC, Sinhoreti MA. Morphology of sealant/enamel interface after surface treatment with bioactive glass. Microsc Res Tech. 2015;78(12):1062-8.

73. de Morais RC, Silveira RE, Chinelatti MA, Pires-de-Souza FdCP. Biosilicate as a dentin pretreatment for total-etch and self-etch adhesives: In vitro study. Int J Adhes Adhes. 2016;70:271-6.

74. Moher D, Hopewell S, Schulz KF, Montori V, Gotzsche PC, Devereaux PJ, et al. CONSORT 2010 explanation and elaboration: updated guidelines for reporting parallel group randomised trials. Int J Surg. 2012;10(1):28-55.

75. Hickel R, Roulet JF, Bayne S, Heintze SD, Mjör IA, Peters M, et al. Recommendations for conducting controlled clinical studies of dental restorative materials. Int Dent J. 2007;57(5):300-2.

76. Faul F, Erdfelder E, Lang AG, Buchner A. G*Power 3: a flexible statistical power analysis program for the social, behavioral, and biomedical sciences. Behav Res Methods. 2007;39(2):175-91.

77. Association AD. ADA Caries Risk Assessment Form Completion Instructions. Available at: public health oregon gov/Prevention Wellness/oralhealth/FirstTooth/Documents/ADA-CAMBRA pdf Accessed July. 2014;9.

78. Hickel R, Roulet JF, Bayne S, Heintze SD, Mjör IA, Peters M, et al. Recommendations for conducting controlled clinical studies of dental restorative materials. Science Committee Project 2/98--FDI World Dental Federation study design (Part I) and criteria for evaluation (Part II) of direct and indirect restorations including onlays and partial crowns. J Adhes Dent. 2007;9 Suppl 1:121-47.

79. Hickel R, Peschke A, Tyas M, Mjör I, Bayne S, Peters M, et al. FDI World Dental Federation: clinical criteria for the evaluation of direct and indirect restorations-update and clinical examples. Clin Oral Investig. 2010;14(4):349-66.

80. Sabbagh J, McConnell RJ, McConnell MC. Posterior composites: Update on cavities and filling techniques. J Dent. 2017;57:86-90.

81. Landis JR, Koch GG. The measurement of observer agreement for categorical data. Biometrics. 1977:159-74.

82. Hosoya Y, Tay FR, Miyazaki M, Inoue T. Hardness and elasticity of sound and cariesaffected primary dentin bonded with one-step self-etch adhesive. Dent Mater J. 2007;26(4):493-500. 
83. Hosoya Y, Tay FR. Hardness, elasticity, and ultrastructure of bonded sound and cariesaffected primary tooth dentin. J Biomed Mater Res B Appl Biomater. 2007;81(1):13541.

84. Xuan W, Hou BX, Lu YL. Bond strength of different adhesives to normal and cariesaffected dentins. Chin Med J (Engl). 2010;123(3):332-6.

85. Haj-Ali R, Walker M, Williams K, Wang Y, Spencer P. Histomorphologic characterization of noncarious and caries-affected dentin/adhesive interfaces. $\mathrm{J}$ Prosthodont. 2006;15(2):82-8.

86. Liu Y, Tjäderhane L, Breschi L, Mazzoni A, Li N, Mao J, et al. Limitations in bonding to dentin and experimental strategies to prevent bond degradation. J Dent Res. 2011;90(8):953-68.

87. Deng DL, Yang HY, Guo JM, Huang C, Gan J, Song FF. Effects of exogenous enzymes on the degradation of adhesive-dentin interfaces. Zhonghua Kou Qiang Yi Xue Za Zhi. 2016;51(4):230-4.

88. Breschi L, Mazzoni A, Ruggeri A, Cadenaro M, Di Lenarda R, De Stefano Dorigo E. Dental adhesion review: aging and stability of the bonded interface. Dent Mater. 2008;24(1):90-101.

89. Reis A, Carrilho M, Breschi L, Loguercio AD. Overview of clinical alternatives to minimize the degradation of the resin-dentin bonds. Oper Dent. 2013;38(4):E1-e25.

90. Hernández M, Cobb D, Swift EJ. Current strategies in dentin remineralization. J Esthet Restor Dent. 2014;26(2):139-45.

91. Tay FR, Pashley DH. Biomimetic remineralization of resin-bonded acid-etched dentin. J Dent Res. 2009;88(8):719-24.

92. Peters MC, Bresciani E, Barata TJ, Fagundes TC, Navarro RL, Navarro MF, et al. In vivo dentin remineralization by calcium-phosphate cement. J Dent Res. 2010;89(3):28691.

93. Bresciani E, Wagner WC, Navarro MF, Dickens SH, Peters MC. In vivo dentin microhardness beneath a calcium-phosphate cement. J Dent Res. 2010;89(8):836-41.

94. Toledano M, Osorio E, Aguilera FS, Sauro S, Cabello I, Osorio R. In vitro mechanical stimulation promoted remineralization at the resin/dentin interface. J Mech Behav Biomed Mater. 2014;30:61-74.

95. Pires-de-Souza FeC, de Marco FF, Casemiro LA, Panzeri H. Desensitizing bioactive agents improves bond strength of indirect resin-cemented restorations: preliminary results. J Appl Oral Sci. 2007;15(2):120-6. 
96. de Morais RC. Estudo in vitro do uso de vitrocerâmica bioativa em dentina afetada por cárie natural e artificial: análise da resistência de união de compósitos [dissertação]. Ribeirão Preto: Universidade de São Paulo, Faculade de Odontologia de Ribeirão Preto; 2014.

97. Pashley DH, Tay FR, Breschi L, Tjäderhane L, Carvalho RM, Carrilho M, et al. State of the art etch-and-rinse adhesives. Dent Mater. 2011;27(1):1-16.

98. Sundfeld RH, Scatolin RS, Oliveira FG, Machado LS, Alexandre RS, Sundefeld ML. One-year clinical evaluation of composite restorations in posterior teeth: effect of adhesive systems. Oper Dent. 2012;37(6):E1-8.

99. Boeckler A, Schaller HG, Gernhardt CR. A prospective, double-blind, randomized clinical trial of a one-step, self-etch adhesive with and without an intermediary layer of a flowable composite: a 2-year evaluation. Quintessence Int. 2012;43(4):279-86.

100. Sundfeld RH, Machado LS, Pita DS, Franco LM, Sundfeld D, Sundefeld ML, et al. Three-Year Clinical Evaluation of Class I Restorations in Posterior Teeth. Effects of Two Adhesive Systems. Compend Contin Educ Dent. 2016;37(9):e1-e4.

101. Van Meerbeek B, Yoshihara K, Yoshida Y, Mine A, De Munck J, Van Landuyt KL. State of the art of self-etch adhesives. Dent Mater. 2011;27(1):17-28.

102. Heintze SD. Clinical relevance of tests on bond strength, microleakage and marginal adaptation. Dent Mater. 2013;29(1):59-84.

103. Giannini M, Makishi P, Ayres AP, Vermelho PM, Fronza BM, Nikaido T, et al. Selfetch adhesive systems: a literature review. Braz Dent J. 2015;26(1):3-10.

104. Yoshida Y, Nagakane K, Fukuda R, Nakayama Y, Okazaki M, Shintani H, et al. Comparative study on adhesive performance of functional monomers. J Dent Res. 2004;83(6):454-8.

105. Yoshida Y, Yoshihara K, Nagaoka N, Hayakawa S, Torii Y, Ogawa T, et al. Selfassembled Nano-layering at the Adhesive interface. J Dent Res. 2012;91(4):376-81.

106. Mena-Serrano A, Kose C, De Paula EA, Tay LY, Reis A, Loguercio AD, et al. A new universal simplified adhesive: 6-month clinical evaluation. J Esthet Restor Dent. 2013;25(1):55-69.

107. Perdigao J, Kose C, Mena-Serrano AP, De Paula EA, Tay LY, Reis A, et al. A new universal simplified adhesive: 18-month clinical evaluation. Oper Dent. 2014;39(2):113-27.

108. Peumans M, De Munck J, Van Landuyt KL, Poitevin A, Lambrechts P, Van Meerbeek B. Eight-year clinical evaluation of a 2-step self-etch adhesive with and without selective enamel etching. Dent Mater. 2010;26(12):1176-84. 
109. Wattanawongpitak N, Yoshikawa T, Burrow MF, Tagami J. The effect of bonding system and composite type on adaptation of different $\mathrm{C}$-factor restorations. Dent Mater J. 2006;25(1):45-50.

110. Wattanawongpitak N, Yoshikawa T, Burrow MF, Tagami J. The effect of thermal stress on bonding durability of resin composite adaptation to the cavity wall. Dent Mater J. 2007;26(3):445-50.

111. Sideridou ID, Karabela MM, Vouvoudi E. Physical properties of current dental nanohybrid and nanofill light-cured resin composites. Dent Mater. 2011;27(6):598-607.

112. Krithikadatta J. Clinical effectiveness of contemporary dentin bonding agents. J Conserv Dent. 2010;13(4):173-83.

113. Manchorova-Veleva NA, Vladimirov SB, Keskinova Dcapital A C. Clinical Effect of Dental Adhesive on Marginal Integrity in Class I And Class II Resin-Composite Restorations. Folia Med (Plovdiv). 2015;57(3-4):250-6.

114. Boushell LW, Heymann HO, Ritter AV, Sturdevant JR, Swift EJ, Jr., Wilder AD, Jr., et al. Six-year clinical performance of etch-and-rinse and self-etch adhesives. Dent Mater. 2016;32(9):1065-72.

115. Brunthaler A, König F, Lucas T, Sperr W, Schedle A. Longevity of direct resin composite restorations in posterior teeth. Clin Oral Investig. 2003;7(2):63-70.

116. da Veiga AM, Cunha AC, Ferreira DM, da Silva Fidalgo TK, Chianca TK, Reis KR, et al. Longevity of direct and indirect resin composite restorations in permanent posterior teeth: A systematic review and meta-analysis. J Dent. 2016;54:1-12.

117. Beck F, Dumitrescu N, Konig F, Graf A, Bauer P, Sperr W, et al. One-year evaluation of two hybrid composites placed in a randomized-controlled clinical trial. Dent Mater. 2014;30(8):824-38.

118. van Dijken JWV, Pallesen U. A six-year prospective randomized study of a nano-hybrid and a conventional hybrid resin composite in Class II restorations. Dent Mater. 2013;29(2):191-8.

119. Pallesen U, van Dijken JWV. A randomized controlled 27 years follow up of three resin composites in Class II restorations. J Dent. 2015;43(12):1547-58.

120. Baracco B, Perdigão J, Cabrera E, Giráldez I, Ceballos L. Clinical evaluation of a lowshrinkage composite in posterior restorations: one-year results. Oper Dent. 2012;37(2):117-29.

121. Pintado-Palomino K, Peitl Filho O, Zanotto ED, Tirapelli C. A clinical, randomized, controlled study on the use of desensitizing agents during tooth bleaching. J Dent. 2015;43(9):1099-105. 
122. Reis A, Dourado Loguercio A, Schroeder M, Luque-Martinez I, Masterson D, Cople Maia L. Does the adhesive strategy influence the post-operative sensitivity in adult patients with posterior resin composite restorations?: A systematic review and metaanalysis. Dent Mater. 2015;31(9):1052-67.

123. Perdigao J, Swift EJ, Jr. Critical appraisal: post-op sensitivity with direct composite restorations. J Esthet Restor Dent. 2013;25(4):284-8.

124. Costa T, Rezende M, Sakamoto A, Bittencourt B, Dalzochio P, Loguercio AD, et al. Influence of Adhesive Type and Placement Technique on Postoperative Sensitivity in Posterior Composite Restorations. Oper Dent. 2017;42(2):143-54.

125. Hickel R, Roulet JF, Bayne S, Heintze SD, Mjör IA, Peters M, et al. Recommendations for conducting controlled clinical studies of dental restorative materials. Clin Oral Investig. 2007;11(1):5-33.

126. Peres MA, Traebert J, Marcenes W. Calibration of examiners for dental caries epidemiologic studies. Cad Saude Publica. 2001;17(1):153-9.

127. Kubo S, Kawasaki A, Hayashi Y. Factors associated with the longevity of resin composite restorations. Dent Mater J. 2011;30(3):374-83.

128. Aoyama T, Aida J, Takehara J, Morita M. Factors associated with the longevity of restorations in posterior teeth. J Dent Hlth (Tokyo). 2008;58(1):16.

129. Moncada G, Fernández E, Martín J, Arancibia C, Mjör IA, Gordan VV. Increasing the longevity of restorations by minimal intervention: a two-year clinical trial. Oper Dent. 2008;33(3):258-64.

130. Baracco B, Perdigão J, Cabrera E, Ceballos L. Two-year clinical performance of a lowshrinkage composite in posterior restorations. Oper Dent. 2013;38(6):591-600. 
Anexas 



\section{FACULDADE DE ODONTOLOGIA DE RIBEIRÃO PRETO/FORP/ USP}

\section{PARECER CONSUBSTANCIADO DO CEP}

\section{DADOS DO PROJETO DE PESQUISA}

Título da Pesquisa: ESTUDO PROSPECTIVO, DUPLO-CEGO, RANDOMIZADO, COM GRUPO CONTROLESOBRE O USO DE BIOSILICATO SOB RESTAURAÇÕES EM RESINA COMPOSTA EMDENTES AFETADOS POR CARIE

Pesquisador: Karen Pintado Palomino

Área Temática:

Versão: 4

CAAE: 27790214.1.0000.5419

Instituição Proponente: Universidade de Sao Paulo

Patrocinador Principal: Financiamento Próprio

\section{DADOS DO PARECER}

Número do Parecer: 694.920

Data da Relatoria: $23 / 06 / 2014$

\section{Apresentação do Projeto:}

O objetivo deste estudo é avaliar o desempenho clínico de restaurações Classe I e II em resina composta associados ao Biosilicato®. Material e método: 40 pacientes com lesões cariosas serão incluídos no estudo, os quais serão alocados aleatoriamente em quatro grupos experimentais: G1 (Biosilicato®, Adesivo Adper Single Bond $2 \AA$ e Resina Tetric Evoceram $\AA$ ), G2 (Adesivo Adper Single Bond $2 \AA$ e Resina Tetric Evoceram $\AA$ ), G3 (Biosilicato $\AA$, Adesivo Adhese $\AA$ e Resina Tetric Evoceram $\AA$ ) e G4 (Adesivo Adhese $\AA$ e Resina Tetric Evoceram $®)(n=10)$. Dois examinadores calibrados avaliarão as restaurações após uma semana (baseline), 03 e 06 meses utilizando critérios da FDI (World Dental Federation). Os parâmetros analisados serão: manchamento marginal, retenção, adaptação marginal, sensibilidade pós-operatória e recorrência de cárie. Os dados colhidos serão analisados estatisticamente.

\section{Objetivo da Pesquisa:}

Pesquisar a aplicação clínica de um pó nanoparticulado de Biosilicato® (vitrocerâmica bioativa desenvolvida no Brasil) em dentina afetada por cárie, anteriormente ao procedimento restaurador.

\section{Avaliação dos Riscos e Benefícios:}

Riscos: Há a possibilidade de que o participante sinta sensibilidade, ou a restauração apresente

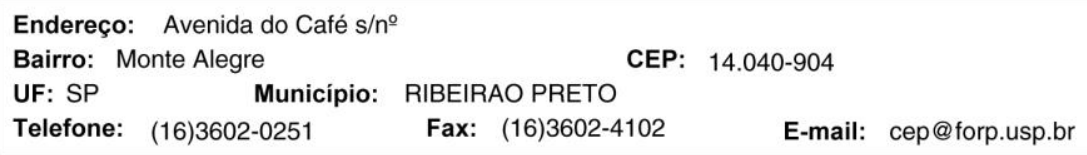




\section{FACULDADE DE ODONTOLOGIA DE RIBEIRÃO PRETO/ FORP/ USP}

Continuação do Parecer: 694.920

trincas ou manchamento marginal decorrentes do procedimento restaurador.

Benefícios: O participante receberá o tratamento restaurador no dente afetado por cárie. O material bioativo pode ser utilizado na odontologia adesiva melhorando a sucesso do tratamento restaurador.

\section{Comentários e Considerações sobre a Pesquisa:}

$\mathrm{Na}$ introdução do projeto de pesquisa são apresentados artigos científicos atuais relacionados ao assunto da proposta da pesquisa.

De acordo com o solicitado: "É necessário descrever, no arquivo do Projeto Detalhado e no arquivo do Projeto gerado pela Plataforma Brasil (a partir do preenchimento das telas), a forma de abordagem dos participantes e que eles serão selecionados na disciplina de Clínica Integrada." Pendencia foi atendida.

\section{Considerações sobre os Termos de apresentação obrigatória:}

Foi solicitado: "O TCLE deve garantir a indenização ou tratamento aos pacientes em caso de eventuais danos. Essa informação ainda não consta no TCLE e deve ser incluída para a aprovação do protocolo. É necessário excluir a informação de que não há riscos."

A pendência foi atendida.

\section{Recomendações:}

Não há.

\section{Conclusões ou Pendências e Lista de Inadequações:}

Protocolo aprovado. Os relatórios (parciais/final) deverão ser encaminhados, utilizando-se da opção "Enviar Notificação" (descrita no Manual "Submeter Notificação", disponível na Central de Suporte - canto superior direito do portal www.saude.gov.br/plataformabrasil).

\section{Situação do Parecer:}

Aprovado

\section{Necessita Apreciação da CONEP:}

Não

\section{Considerações Finais a critério do CEP:}

Conforme deliberado na $167^{a}$ R.O. do CEP.

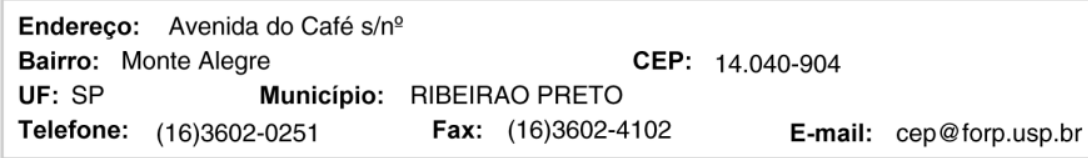




\section{FACULDADE DE ODONTOLOGIA DE RIBEIRÃO PRETO/ FORP/ USP}

Continuação do Parecer: 694.920

RIBEIRAO PRETO, 24 de Junho de 2014

Assinado por:

JOSÉ TARCÍSIO LIMA FERREIRA

(Coordenador)

Endereço: Avenida do Café $\mathrm{s} / \mathrm{n}^{\circ}$ 


\section{ANEXO B - Registro de Protocolo no ClinicalTrials.gov}

\section{ClinicalTrials.gov PRS}

Protocol Registration and Results System

ClinicalTrials.gov Protocol Registration and Results System (PRS) Receipt

Release Date: April 10, 2017

\section{ClinicalTrials.gov ID: NCT02389569}

Study Identification

Unique Protocol ID: CAAE no: 27790214.1.0000.541

Brief Title: Clinical Study of Biosilicate Under Resin Composite Restorations in Caries Affected Teeth

Official Title: A Prospective, Double-blind, Randomized, Group Controlled Clinical Study on the Use of Biosilicate Under Resin Composite Restorations in Caries Affected Teeth

Secondary IDs:

Study Status

Record Verification: April 2017

Overall Status: Completed

Study Start: []

Primary Completion: August 1, 2016 [Actual]

Study Completion:

Sponsor/Collaborators

Sponsor: University of Sao Paulo

Responsible Party: Principal Investigator

Investigator: Karen Pintado Palomino [kpalomino]

Official Title: MSc

Affiliation: University of Sao Paulo

Collaborators: Universidade Federal de Sao Carlos

\section{Oversight}

U.S. FDA-regulated Drug:

U.S. FDA-regulated Device:

IND/IDE Protocol: No

Human Subjects Review: Board Status: Approved

Approval Number: 2779021410000541

Board Name: Ethical Committee of Dental School of Ribeirão Preto 


\section{ANEXO C - Cálculo do tamanho amostral}

[3] -- Friday, August 08, 2014 -- 09:55:26

F tests - ANOVA: Repeated measures, within factors

Analysis: A priori: Compute required sample size

Input:

Effect size $f$

$=0.15$

$\alpha$ err prob

$=0.05$

Power ( $1-\beta$ err prob)

Number of groups

$=0.80$

Number of measurements

$=4$

Corr among rep measures

$=4$

Nonsphericity correction $\epsilon$

$=0.5$

$=1$

Output: Noncentrality parameter $\lambda$

$=11.5200000$

Critical F

$=2.6547918$

Numerator df

Denominator df

$=3.0000000$

Total sample size

$=180$

Actual power

$=64$

$=0.8143938$ 


\section{ANEXO D - Calibração através da ferramenta $e$-calib}

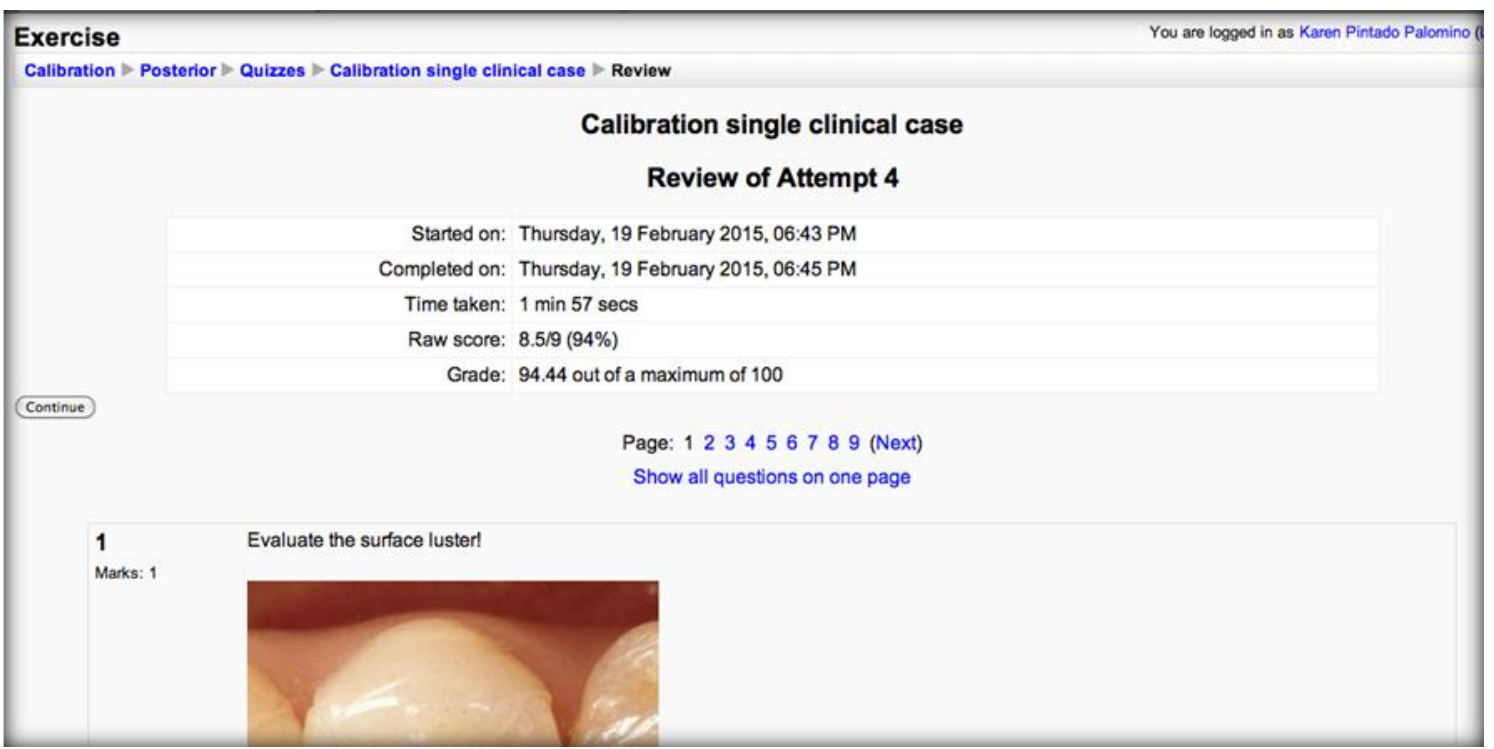


Apêndices 



\section{APÊNDICE A - Ficha de Anamnese}

Universidade de Sào Paulo

Faculdade de Odontologia de Ribeirào Preto

FICHA DE ANAMNESE DO PACIENTE

Identificaçào do paciente:

Nome:
RG: Idade:
Endereço: _ Cidade:
Bairro:
Fone Residencial: __elular:__

História da Saúde Geral:

- Você sofre/sofreu de alguma doença crônica ou sistêmica? (SIM) (NÃO) Qual?

- Está ou esteve recentemente em tratamento médico? (SIM) (NÃO) Qual?

- Você está tomando algum remédio? (SIM) (NÃO) Qual?

- Está grávida ou amamentando? (SIM) (NÃO)

- Vocế fuma? (SIM) (NÃO)

\section{História da Saúde Bucal:}

- Range os dentes?

- Mastiga dos dois lados da boca?

- Tem hábito de mascar chiclete ou bala?

- Ingere muito doce?

- Toma café ou outros liquidos escuros com muita frequência?

- Sente sua gengiva inchada ou dolorida? Sua gengiva sangra frequentemente ou quando escova os dentes?

- Quantas vezes ao dia você escova os dentes?

- Quantas vezes ao dia usa fio dental?

- Você tem dor espontânea em algum dente? Qual?

- Você sente dor em algum dente com alimento frio ou quente? Qual?

\section{Exame clinico:}

- Alterações em tecidos duros ou moles

- Uso de aparelho ortodôntico

- Doença periodontal / inflamação gengival

- Higiene bucal deficiente

- Presença de contato prematuro

- Número de dentes ausentes:

- Presença de cárie dental:

\begin{tabular}{|c|c|c|c|c|c|c|c|c|c|c|c|}
\hline & $\begin{array}{l}\text { Classe I } \\
\text { ou II }\end{array}$ & $\begin{array}{l}\text { Resposta } \\
\text { positiva a } \\
\text { vitalidade } \\
\text { pulpar }\end{array}$ & $\begin{array}{l}\text { Presença de } \\
\text { fatura ou } \\
\text { trinca }\end{array}$ & $\begin{array}{l}\text { Evidencia de } \\
\text { radiolucidez } \\
\text { periapical. }\end{array}$ & $\begin{array}{l}\text { Presença } \\
\text { de } \\
\text { antagenista }\end{array}$ & & $\begin{array}{l}\text { Classe I } \\
\text { Ou II }\end{array}$ & $\begin{array}{l}\text { Presença } \\
\text { de } \\
\text { fratura } \\
\text { ou trinca }\end{array}$ & $\begin{array}{l}\text { Resposta + } \\
\text { sitalidade } \\
\text { pulpar }\end{array}$ & $\begin{array}{l}\text { Evidencia de } \\
\text { radiolucidez } \\
\text { periapical. }\end{array}$ & $\begin{array}{l}\text { Presença } \\
\text { de } \\
\text { antagonista }\end{array}$ \\
\hline 18 & & & & & & 28 & & & & & \\
\hline 17 & & & & & & 27 & & & & & \\
\hline 16 & & & & & & 26 & & & & & \\
\hline 15 & & & & & & 25 & & & & & \\
\hline 14 & & & & & & 24 & & & & & \\
\hline 44 & & & & & & 34 & & & & & \\
\hline 45 & & & & & & 35 & & & & & \\
\hline 46 & & & & & & 36 & & & & & \\
\hline 47 & & & & & & 37 & & & & & \\
\hline 48 & & & & & & 38 & & & & & \\
\hline
\end{tabular}




\title{
APÊNDICE B - Termo de Consentimento Livre e Esclarecido
}

\author{
UNIVERSIDADE DE SÃO PAULO \\ FACULDADE DE ODONTOLOGIA DE RIBEIRÄO PRETO \\ TERMO DE CONSENTIMENTO LIVRE E ESCLARECIDO
}

Este documento é um convite para que o(a) Senhor(a)

participe do estudo: Estudo prospectivo, duplo-cego, randomizado, com grupo controle sobre o uso de Biosilicato sob restaurações em resina composta em dentes afetados por cárie. Os responsáveis por esta pesquisa e pela apresentação deste Termo de Consentimento são a Pós-graduanda (Doutoranda) Karen Pintado Palomino e a Prof ${ }^{\mathrm{a}}$. $\mathrm{Dr}^{\mathrm{a}}$. Camila Tirapelli (Orientadora) e nosso objetivo é avaliar o desempenho clínico de restaurações em resina associados a um novo material (Biosilicato). Desta maneira, se o(a) Senhor(a) pretende participar do estudo é importante saber que:

- Um exame clínico identificará se o(a) Senhor(a) está apto a participar do estudo.

- Haverão quatro tipos de procedimentos restauradores (com materiais de diferentes marcas). Cada paciente será submetido a apenas um dos quatro tipos, de acordo com a distribuição (por sorteio) feita pelos pesquisadores.

- Todos os materiais e procedimentos relacionados ao estudo serão fornecidos pelos pesquisadores (instruções, escova de dente, pasta de dente, fio dental e materiais necessários para o tratamento restaurador).

- Deverão ser necessárias até 4 consultas com intervalo mínimo de uma semana, três e seis meses a partir da primeira consulta (de aproximadamente 01 hora cada) durante o período do estudo. $O(A)$ Senhor(a) deve ter disponibilidade para esses comparecimentos. $\mathrm{O}$ agendamento para o comparecimento será sempre feito com 15 dias de antecedência. Faltas não justificadas poderão exclui-lo do estudo.

- Como beneficio prestado pelo estudo, o(a) Senhor(a) receberá o tratamento restaurador, instruções de higiene oral e materiais de higiene bucal.

- Durante todo o periodo do estudo o(a) Senhor(a) pode solicitar maiores informações ou decidir se recusar a participar sem que isto acarrete qualquer penalidade e não cause prejuizo ao seu tratamento. Portanto, não haverá interferência no tratamento caso o Senhor(a) não aceite participar da pesquisa.

- Há a possibilidade de que o(a) Senhor(a) sinta sensibilidade no dente tratado ou ocorra manchamento, trincas na restauração decorrentes do procedimento restaurador.

- Qualquer desconforto ou problema, causado pelo estudo, será de responsabilidade dos pesquisadores e consequentemente, será resolvido pelos mesmos. Dessa forma, garante-se a indenização ou tratamento ao Senhor (a) em caso de eventuais danos.

- Todas as informações coletadas serão mantidas sob absoluto sigilo.

- Reclamações e/ou insatisfações poderão ser comunicadas à Secretaria do Comitê de Ética em Pesquisa CEP/FORP/USP (Secretária: Marcela Scatolin Calache - cep@forp.usp.br / 16-3602.0493) de segunda à sextafeira no periodo das 8 às $12 \mathrm{~h}$, desde que os reclamantes se identifiquem, sendo que o seu nome será mantido em anonimato.

- Durante todo o período do estudo, o(a) Senhor(a) será acompanhada pela doutoranda Karen Pintado Palomino a quem poderá contactar para conversar sobre assuntos relacionados ao tratamento (16-36020322/ 16988227464 / karenpintado@usp.br).

- Caso haja a necessidade de ressarcimento de despesas (transporte e alimentação), os pesquisadores se responsabilizarão por tal.

- Este termo foi elaborado em 2 (duas) vias, uma ficará sob poder da equipe de pesquisa e você receberá outra via deste Termo de Consentimento Livre e Esclarecido - TCLE.

Ribeirão Preto - SP, de de 201

Karen Pintado Palomino (CPF:233.818.598-62)

Profa. Dra. Camila Tirapelli (CPF: $285.998 .278-71)$

Declaro que li e entendi os objetivos, riscos e beneficios da minha participação na pesquisa e concordo em participar.

$\frac{\text { Participante/endereço, telefone. }}{\text { AVENIDA DO CAFE S/N }}$




\section{APÊNDICE C - Ficha de Avaliação Clínica}

\section{FICHA DE AVALIAÇ̃̃O CLÍNICA (Critérios FDI)}

Estudo Clínico: "Estudo prospectivo, duplo-cego, randomizado, com grupo controle sobre o uso de Biosilicato sob restaurações em resina composta em dentes afetados por carie."

ID Paciente:

Restauração: Dente:

Classe:

Face:.

Dia $(\mathrm{d} / \mathrm{m} / \mathrm{a})$ : Baseline............ 1. Follow-up .............. 2. Follow-up

\begin{tabular}{|c|c|c|c|c|c|c|c|c|}
\hline \multirow{3}{*}{$\begin{array}{l}\text { A) PROPRIEDADES ESTÉTICAS } \\
\text { 1. Brilho Superficial }\end{array}$} & \multicolumn{8}{|c|}{ ESCORE } \\
\hline & \multicolumn{2}{|c|}{ Baseline } & \multicolumn{2}{|c|}{$1^{\circ}$ Follow-up } & \multicolumn{2}{|c|}{$2^{\circ}$ Follow-up } & \multicolumn{2}{|c|}{$3^{\circ}$ Follow-up } \\
\hline & & & & & & & & \\
\hline 2. Manchamento Marginal & & & & & & & & \\
\hline 3. Estabilidade de cor e translucidez & & & & & & & & \\
\hline 4. Forma anatômica & & & & & & & & \\
\hline Avaliador & 1 & 2 & 1 & 2 & 1 & 2 & 1 & 2 \\
\hline
\end{tabular}

\begin{tabular}{|c|c|c|c|c|c|c|c|c|}
\hline \multirow{3}{*}{$\begin{array}{l}\text { B) PROPRIEDADES FUNCIONAIS } \\
\text { 5. Fratura do material e retenção }\end{array}$} & \multicolumn{8}{|c|}{ ESCORE } \\
\hline & \multicolumn{2}{|c|}{ Baseline } & \multicolumn{2}{|c|}{$1^{\circ}$ Follow-up } & \multicolumn{2}{|c|}{$2^{\circ}$ Follow-up } & \multicolumn{2}{|c|}{$3^{\circ}$ Follow-up } \\
\hline & & & & & & & & \\
\hline \multicolumn{9}{|l|}{ 6. Adaptação Marginal } \\
\hline \multicolumn{9}{|l|}{$\begin{array}{l}\text { 7. Contorno Oclusal e Desgaste } \\
\text { (Qualitativamente) }\end{array}$} \\
\hline \multicolumn{9}{|l|}{ 8. Forma anatômica proximal } \\
\hline \multicolumn{9}{|l|}{$\begin{array}{l}\text { 9. Avaliação Radiográfica } \\
\text { (Quando aplicável) }\end{array}$} \\
\hline \multicolumn{9}{|l|}{ 10. Opinião do paciente } \\
\hline Avaliador & 1 & 2 & 1 & 2 & 1 & 2 & 1 & 2 \\
\hline
\end{tabular}

\begin{tabular}{|c|c|c|c|c|c|c|c|c|}
\hline \multirow{3}{*}{$\begin{array}{l}\text { C) PROPRIEDADES BIOLÓGICAS } \\
\text { 11. Hipersensibilidade pós-operatória }\end{array}$} & \multicolumn{8}{|c|}{ ESCORE } \\
\hline & \multicolumn{2}{|c|}{ Baseline } & \multicolumn{2}{|c|}{$1^{\circ}$ Follow-up } & \multicolumn{2}{|c|}{$2^{\circ}$ Follow-up } & \multicolumn{2}{|c|}{$3^{\circ}$ Follow-up } \\
\hline & & & & & & & & \\
\hline \multicolumn{9}{|l|}{ 12. Recorrência de cárie } \\
\hline \multicolumn{9}{|l|}{ 13. Integridade dental } \\
\hline \multicolumn{9}{|l|}{$\begin{array}{l}\text { 14. Resposta periodontal (sempre } \\
\text { comparado a um dente referencial) }\end{array}$} \\
\hline \multicolumn{9}{|l|}{ 15. Mucosa adjacente } \\
\hline \multicolumn{9}{|l|}{ 16. Saúde oral e geral } \\
\hline Avaliador & 1 & 2 & 1 & 2 & 1 & 2 & 1 & 2 \\
\hline
\end{tabular}

